IZA DP No. 10271

On the Quantity and Quality of Girls:

New Evidence on Abortion, Fertility, and

Parental Investments

S Anukriti

Sonia Bhalotra

Hiu Tam

October 2016 


\title{
On the Quantity and Quality of Girls: New Evidence on Abortion, Fertility, and Parental Investments
}

\author{
S Anukriti \\ Boston College \\ and IZA \\ Sonia Bhalotra \\ University of Essex \\ and IZA \\ Hiu Tam \\ London School of Economics
}

\section{Discussion Paper No. 10271 \\ October 2016}

\author{
IZA \\ P.O. Box 7240 \\ 53072 Bonn \\ Germany \\ Phone: +49-228-3894-0 \\ Fax: +49-228-3894-180 \\ E-mail: iza@iza.org
}

\begin{abstract}
Any opinions expressed here are those of the author(s) and not those of IZA. Research published in this series may include views on policy, but the institute itself takes no institutional policy positions. The IZA research network is committed to the IZA Guiding Principles of Research Integrity.

The Institute for the Study of Labor (IZA) in Bonn is a local and virtual international research center and a place of communication between science, politics and business. IZA is an independent nonprofit organization supported by Deutsche Post Foundation. The center is associated with the University of Bonn and offers a stimulating research environment through its international network, workshops and conferences, data service, project support, research visits and doctoral program. IZA engages in (i) original and internationally competitive research in all fields of labor economics, (ii) development of policy concepts, and (iii) dissemination of research results and concepts to the interested public.
\end{abstract}

IZA Discussion Papers often represent preliminary work and are circulated to encourage discussion. Citation of such a paper should account for its provisional character. A revised version may be available directly from the author. 


\begin{abstract} On the Quantity and Quality of Girls:
New Evidence on Abortion, Fertility, and Parental Investments*

The introduction of prenatal sex-detection technologies in India has led to a phenomenal increase in abortion of female fetuses. We investigate their impact on son-biased fertility stopping behavior, parental investments in girls relative to boys, and the relative chances of girls surviving after birth. We find a moderation of son-biased fertility, erosion of gender gaps in breastfeeding and immunization, and complete convergence in the post-neonatal mortality rates of boys and girls. For every five aborted girls, we estimate that roughly one additional girl survives to age five. The results are not driven by endogenous compositional shifts, being robust to the inclusion of mother fixed effects. Our findings have implications not only for counts of missing girls but also for the later life outcomes of girls, conditioned by greater early life investments in them.
\end{abstract}

JEL Classification: I15, J13, J16

Keywords: abortion, child mortality, fertility, gender, health, India, missing girls, parental investments, prenatal sex detection, sex-selection, ultrasound

Corresponding author:

S Anukriti
Department of Economics
Boston College
329 Maloney Hall
Chestnut Hill, MA 02467
USA
E-mail: anukriti@bc.edu

\footnotetext{
* We thank Prashant Bharadwaj, Abhishek Chakravarty, Ritam Chaurey, Diana Greene Foster, Liberated Gonzalez, Rachel Heath, Mahesh Karra, Melanie Khamis, Adriana Kugler, Annemie Maertens, Claudia Olivetti, Laura Schechter, Alessandro Tarozzi, Ushma Upadhyay, and Shing-Yi Wang, and participants at various seminars and conferences for their helpful comments and suggestions. We are grateful to Luojia Hu and Analia Schlosser for discussion of our related papers.
} 


\section{Introduction}

Innovations in birth control technology have had substantial socioeconomic impacts. The contraceptive pill, for instance, gave women unprecedented control over fertility, preventing unwanted births and allowing women to determine the timing of births, with dramatic consequences for their marriage and labor market choices (Goldin and Katz (2002), Bailey (2006)). The legislation of abortion has similarly empowered women by enabling them to eliminate unwanted births (Gruber et al. (1999)). In fact, birth control technology has had far-reaching implications not only for women but also for children to the extent that parental investments tend to be greater in children that are more "wanted" when they are born (Grossman and Joyce (1990), Gruber et al. (1999), Donohue and Levitt (2001), Charles and Stephens Jr. (2006), Donohue et al. (2009)).

This paper investigates the impacts on child quantity and quality of another new technology that has altered the demographic landscape in countries where sons are valued more than daughters, namely, prenatal sex detection technology (henceforth, ultrasound; see Section 2). An ultrasound scan can reveal fetal sex quite reliably at as early as 12 weeks of gestation, enabling selective abortion of unwanted girls without, in principle, risking the mother's health (Epner et al. (1998)). We focus on India, where ultrasound was introduced in the mid-1980s, before which abortion had been legalized. The low cost and the non-invasive nature of ultrasound scans has led to their widespread use for fetal sex determination, resulting in a staggering rise in sex-selective abortion, equivalent to 6 percent of potential female births during 1995-2005 (Bhalotra and Cochrane (2010)). ${ }^{1}$ The demand for abortion technology is high even in the absence of son preference. For instance, despite access to contraceptive methods, 21 percent of all pregnancies in 2011 in the United States ended in abortion (Guttmacher Institute). ${ }^{2}$

When fetal sex determination is impossible, parents can adjust the gender composition of their children in two ways. First, by continuing childbearing till they achieve, for instance, the desired number of sons. Several studies document son-biased fertility stopping behavior, which results in girls having more siblings that boys ((Clark (2000), Bhalotra and van Soest (2008), Jensen (2012), Rosenblum (2013)). The quantity-quality trade-off, driven by the budget constraint, implies that, even if parents do not actively discriminate against daughters, a gender gap in outcomes will emerge simply because girls, on average, grow up in families with fewer per capita resources. The second option is to subject girls to deliberate neglect, culminating as excess girl mortality in early childhood (Das Gupta (1987), Pitt and Rosenzweig (1990), Sen (1990), Rose (2000), Oster (2009), Bhalotra (2010), Jayachandran and Kuziemko (2011)). In this paper, we test the hypothesis that the facility to detect and, subsequently, terminate unwanted female fetuses in the post-ultrasound era weakened both of these channels. In other words, we expect a weakening of son-biased fertility stopping behavior and a reduction in postnatal discrimination against girls, measured by child

\footnotetext{
${ }^{1}$ Bhalotra and Cochrane (2010) estimate that 480,000 girls - greater than the number of girls born in the United Kingdom each year - were aborted per year in India during 1995-2005.

${ }^{2}$ https://www.guttmacher.org/fact-sheet/induced-abortion-united-states
} 
investments and mortality rates.

However, it is challenging to identify the behavioral effects of prenatal sex detection technology when there is selection into conception or abortion. Moreover, the direction of selection into conception and abortion is a priori ambiguous (Gruber et al. (1999), Pop-Eleches (2006), Ananat et al. (2009)). ${ }^{3}$ A second issue is that revelation of the sex of the child may lead parents to deliberately lower fetal investments in girls (Almond et al. (2010), Bharadwaj and Lakdawala (2013)). Any resulting gender-biased miscarriage, by creating selection into birth, can make it harder to interpret changes in post-birth investments as causal effects of availability of prenatal sex detection (through it facilitating sex-selective abortion). We attempt to address these challenges.

Our strategy combines supply-driven changes in ultrasound availability with plausibly exogenous family-level variation in the incentive to sex-select. We construct an indicator for cohorts born preversus post-ultrasound exploiting information on the first imports of ultrasound scanners after tariff reductions in the mid-1980s. We construct a second indicator for cohorts born after a major expansion in availability associated with initiation of local production from the mid-1990s, driven by relaxation of industrial licensing regulations. Previous work shows that these supply-side changes resulted in a phenomenal rise in sex-selective abortion (Bhalotra and Cochrane (2010)). Familylevel variation in the incentive to conduct sex-selection is captured in an indicator for the sex of the firstborn child. Previous research shows that (a) the sex of the firstborn child is quasirandom and (b) that sex-selective abortion among second- and higher-order births is concentrated in families with a firstborn daughter (Almond and Edlund (2008), Abrevaya (2009), Bhalotra and Cochrane (2010)). The identifying assumption, which we verify, is that, in the absence of ultrasound technology, trends in the outcomes would have been identical across first-son and first-daughter families. We distinguish neonatal and post-neonatal child survival rates because changes in prenatal investments are more likely to exhibit in neonatal rates, while post-neonatal survival is more clearly a function of postnatal investments. ${ }^{4}$

We use data containing the complete fertility histories of women to construct indicators of births and deaths, as a result of which we can link biological siblings. This allows us to use mother fixed effects to account for selection. In contrast to earlier studies of abortion (Gruber et al. (1999), Pop-Eleches (2006), Ananat et al. (2009)), we analyze parental investments in and survival of girls relative to boys. Differencing by gender allows us to control for unobservable trends that equally affect both boys and girls. Another useful feature of the data, that we exploit, is that they contain the mother's stated preferences, including desired fertility and the desired number of sons versus daughters. We investigate the robustness of our estimates to conditioning upon changes in these

\footnotetext{
${ }^{3}$ Pop-Eleches (2006) discusses studies of abortion in developed countries, highlighting that many preceding his study do not adjust for selection. Selection into conception is a persistent issue in analyses of birth outcomes; see, for instance, Dehejia and Lleras-Muney (2004), Bhalotra (2010), Ananat and Hungerman (2012), and Brown (2016).

${ }^{4}$ Neonatal mortality refers to death within one month of birth and post-neonatal child mortality means death after the first month of birth but before age five.
} 
preferences is a flexible manner. This allows us to more confidently attribute any changes in the outcomes to changes in (ultrasound) technology rather than to other factors such as modernization, which may have contemporaneously changed (stated) preferences.

We estimate reduced form equations for three sets of outcomes. First, we estimate changes in the relative survival of girls. Since we know from previous research that the introduction of ultrasound led to a sharp increase in female feticide, our expectation is that this substituted for postnatal discrimination against girls, leading to a reduction in girl relative to boy mortality after birth. We examine results by birth order and the socioeconomic status (SES) of parents so as to identify where in these distributions the relevant changes occur. Second, we estimate changes in parental investments in girls relative to boys, so as to tie any changes in survival to parental behavioral choices. Third, we investigate impacts on fertility defined, as is usual, as live births. In general, increased opportunities for abortion may lead to lower or higher fertility (e.g., Ananat et al. (2009), Ananat and Hungerman (2012)). Abortion mechanically reduces the number of live births conditional upon the number of pregnancies; but the knowledge that a pregnancy can be aborted may stimulate more pregnancies and the net effect on fertility is ambiguous a priori. However, since ultrasound led to sex-selective abortion and not abortion per se, we can test an unambiguous prediction, which is that there is less son-biased fertility stopping post-ultrasound.

Our main findings are as follows. We find that the pre-ultrasound gender gap in post-neonatal child mortality for second- and higher-order births in firstborn-girl families relative to firstborn-boy families (equal to 2.17 percentage points (p.p.)) is completely eliminated by ultrasound technology. Similarly, there is complete closure of the gender gap in sibling size between firstborn-girl and firstborn-boy families (which, pre-ultrasound, was 0.14). Consonant with these results, we find a significant narrowing of gender gaps in parental investments. A simple accounting exercise suggests that increases in vaccination and breastfeeding in favor of girls explain 34 to 38 percent of the observed decline in post-neonatal excess female mortality (EFM). ${ }^{5}$ We also document a narrowing of the gender gap in neonatal mortality - 33 percent closure post-ultrasound - which we argue undermines the empirical relevance of any purposive under-investment in female fetuses.

Nevertheless, the decline in postnatal death of girls only partially offsets the rise in female feticide. Our estimates imply that 60,879 excess postnatal female child deaths were averted each year (via ultrasound-driven declines in male-biased fertility and substitution of postnatal discrimination with prenatal discrimination), but that the rise in the number of aborted girls was much higher. For every five girls that "went missing" before birth, only one girl survived after birth who otherwise would have died.

If sex-selective abortion is concentrated among families with stronger son preference then girls born in the post-ultrasound era will be more likely to be born into families with weaker son prefer-

\footnotetext{
${ }^{5}$ Note that vaccination and breastfeeding are only two of the many markers of parental investments. It is possible that parents also increased other investments in girls and that can further explain the observed EFM decline; however, we do not have data on the same.
} 
ence, and this would then be a reason that they do better. We investigate this and find no evidence of such sorting. We show that this is because stated son preference is not correlated with the tendency to sex-select. Instead, there are marked SES patterns in sex-selection, with wealthy and educated women being more likely to abort girls (Bhalotra and Cochrane (2010)). So the average girl born post-ultrasound (relative to pre-ultrasound) is more likely to be born into a low SES family. However, stated son preference is systematically lower in wealthy and educated, i.e., high-SES families. ${ }^{6}$

The relative fertility decline in firstborn-girl families is driven by a shift from having four or more children toward having three or fewer children. The relative decline in female mortality is concentrated in first, second, and third children in firstborn-girl families. In general, the absolute decline in excess girl mortality is larger among women of low SES, while the decline in fertility among women with firstborn daughters is broadly similar across socioeconomic groups. Previous work shows that sex-selective abortion in India is more prevalent among educated and wealthy women (Bhalotra and Cochrane (2010)). So, responses to ultrasound technology in terms of sexselective abortion, fertility, and postnatal investments in girls versus boys occur on different SES margins. Importantly, these results suggest that ultrasound availability generated a shift in the distribution of girls in favor of low-SES families since more girls were aborted in high-SES families and more girls survived to age five in low-SES families. This implies that the average long-run outcomes for girls (driven by improved early-life investments) are unlikely to converge toward those for boys as much as within-SES-group and within-household differences.

While a number of studies have sought to identify how changes in abortion law in different countries have modified fertility and investment in children, the evidence on how prenatal sex detection technology (which made sex-selective abortion feasible) modifies fertility and investment in girls is more limited. Lin et al. (2014) show that abortion legalization in Taiwan decreased neonatal female mortality for higher-parity births conditional on SES and had no impact on postneonatal mortality. They also find a reduction in fertility at third and higher parity, and a shift in the composition of births towards low-SES families. They do not examine health investments. Almond et al. (2010) find, in contrast to us, that ultrasound access in China increased neonatal EFM, which suggests that parents consciously reduced prenatal inputs in girls. They find no impact on gender gaps in post-neonatal mortality, and they do not examine fertility. Our finding of a post-ultrasound decline in excess post-neonatal girl mortality is empirically relevant, given that the gender gap in post-neonatal child mortality in India is quite large -1.5 p.p. overall and 3 p.p. among children preceded by a firstborn girl (Table A.1). ${ }^{7}$

\footnotetext{
${ }^{6}$ This may mean that high-SES families under-report son preference more than low-SES families. However, it may instead be the case that wealth and education facilitate access to and acceptance of prenatal sex detection and abortion, and are associated with lower desired fertility. We discuss these findings further in Section 5.

${ }^{7}$ In comparison, before the 1985 abortion legalization that Lin et al. (2014) examine, the average postneonatal infant EFM in Taiwan in 1981 was -0.11 p.p., i.e., not biased against girls (Yang et al. (1996)).
} 
The paper most closely related to ours is Hu and Schlosser (2015), that seeks to answer a similar question, but using a different empirical approach. They model gender gaps in malnutrition and mortality of children as a function of state-year variation in the sex ratio at birth. However, the state level sex ratio at birth is jointly determined with the outcomes. Once fetal sex detection is feasible, parents will simultaneously decide whether to conceive, whether to use prenatal sex diagnosis, whether to abort if the fetus is a girl, and how much to invest in male versus female births that are taken to term. The joint outcomes, thus, are fertility, the sex ratio at birth (which is more male if there is more girl abortion), post-birth investments in girls relative to boys, and girl relative to boy survival. The identifying assumption in $\mathrm{Hu}$ and Schlosser (2015) is that changes in the average male to female ratio at birth within a state over time are uncorrelated with unobserved factors that could differentially affect male and female outcomes. Since we model EFM by firstborn sex (which varies at the household level), we difference out all such omitted variables.

$\mathrm{Hu}$ and Schlosser (2015) find a narrowing of gender gaps in malnutrition but, despite this, find no change in excess girl mortality. ${ }^{8}$ They state: "Particularly puzzling is why we find a differential improvement in female nutritional status but do not see any significant increase in female survival probabilities ( $p p$. 1257)." Using a different statistical approach, we find large post-ultrasound changes in mortality rates that result in a complete closure of the boy-girl mortality gap, specifically in households with first-born girls for whom this gap is most marked in the pre-ultrasound period. In this way, we resolve the puzzle. ${ }^{9}$

More generally, we take this research agenda forward. The large changes in girl relative to boy

Moreover, India and China differ in the age distribution of missing girls. In China, the imbalance in the sex ratio for under-5 children in primarily at birth (83 percent), while there is a more even spread across early childhood in India (Table A.2). In particular, the contribution of post-neonatal EFM to the number of missing girls is 33 percent in India but only 3 percent in China.

${ }^{8}$ They find the same result for malnutrition in a companion paper that distinguishes the North-Western states (where abortion was higher) from the rest of India, but do not examine mortality (Hu and Schlosser (2012)).

${ }^{9}$ This difference in findings appears to be for the following reasons. First, they pool firstborn-girl and firstborn-boy families. However, previous research shows that the introduction of ultrasound in India led to sex-selection primarily in firstborn-girl families ((Bhalotra and Cochrane (2010)) and sex selection in China exhibits a similar pattern (Almond et al. (2013)). The summary statistics we present for EFM in the preultrasound period similarly show that it was concentrated in firstborn-girl families. For instance, the girl-boy differential in post-neonatal child mortality was 3 p.p. for births preceded by a firstborn girl in contrast to 0.9 p.p. for births preceded by a firstborn boy. This is an enormous difference, so a specification that forces equal coefficients for the two groups may veil relevant changes. Second, their sample includes few(er) pre-ultrasound cohorts. If we select a shorter sample like in Hu and Schlosser (2015) and do not distinguish firstborn-girl and firstborn-boy families, then we are able to replicate their result that there is no postultrasound change in EFM. But our estimates and the raw data confirm large reductions. Third, as discussed above, their approach may not sufficiently account for simultaneity and selection. We use information on the first imports of ultrasound scanners and the initiation of local production to generate variation in nationwide availability of prenatal sex-detection techniques. In particular, our strategy employs differences between preand post- ultrasound cohorts (interacted with family differences in terms of the firstborn child gender). We also employ a mother fixed effects estimator to account for selection-given the longer span of our data, many mothers have fertility histories that are interrupted by the arrival of ultrasound technology. 
survival that we document contribute new evidence to current debates on biased population sex ratios in India. We also investigate SES gradients in the gender-differentiated survival and fertility responses to the introduction of ultrasound technology. These findings are of interest because the dynamic implications of recent changes in the quantity and quality of girls (relative to boys) in India depend on where in the SES distribution these changes occur, for instance, because of marital hypergamy (Edlund (1999)).

Additionally, our study is of considerable significance for the following reasons. First, we find that there is increased post-neonatal and neonatal survival of girls relative to boys post-ultrasound but that this is more than offset by increased prenatal loss of girls due to feticide. So the number of missing women continues to increase, and this has implications for violence against women, prostitution, sexually-transmitted diseases, marriage market imbalances, and elderly care (Edlund (1999), Drèze and Khera (2000), Kaur (2004), Edlund et al. (2007), Ahlawat (2009), Ebenstein and Sharygin (2009), Bhaskar (2011), Amaral and Bhalotra (2016)). Second, we find that girls born in the post-ultrasound era are receiving greater early-life investments, with pre-existing boy-girl gaps in immunization and breastfeeding narrowing considerably. This not only contributes to their survival but is predictive of improvements in cognitive attainment, income, and longevity for girls (Bhalotra and Venkataramani (2013), Currie and Rossin-Slater (2015), Bhalotra et al. (2016b)), and indeed the outcomes of their offspring (Currie and Moretti (2007), Almond and Currie (2011), Bhalotra and Rawlings (2011)). Narrowing of gender differences in human capital also tends to be associated with higher growth rates and social change (Klasen (2002), Lagerlöf (2003)).

Third, our result that girls are more likely to be found in low-SES households post-ultrasound aligns with the predictions of Edlund (1999) and, as she discusses, has implications for marriage and violence. Fourth, the fertility decline (concentrated in firstborn-girl families) we observe not only benefits girls through increased resources per capita, it is also potentially beneficial for the health of mothers, which is depleted by the high levels of fertility motivated by the desire to bear sons (Milazzo (2014)). More generally, fertility decline in developing countries has been shown to be associated with economic growth, human capital accumulation, and women's empowerment (Joshi and Schultz (2007), Rosenzweig and Zhang (2009), Miller (2010), Ashraf et al. (2013)).

The rest of the paper is organized as follows. Section 2 describes the Indian context. Sections 3 and 4 discuss the empirical strategy and the data. Section 5 presents results and Section 6 presents estimates of the implied magnitude of substitution between postnatal discrimination and sex-selective abortions due to ultrasound access. Section 7 concludes.

\section{Context}

While son preference has characterized parts of Indian society for centuries, the availability of affordable prenatal sex-diagnostic techniques combined with legal access to abortion is more recent. Abortion was legalized in India with the passage of the Medical Termination of Pregnancy (MTP) Act in 1971, effective in most states in 1972. The Act specifies the reasons for which an abortion can be legally performed and requires that it be performed by a registered medical practitioner in 
certified abortion facilities. ${ }^{10}$ Abortion is legal if the pregnancy that it terminates endangers the woman's life, causes grave injury to her physical or mental health, is a result of rape or contraceptive failure (the latter applies only to married women), or is likely to result in the birth of a child suffering from serious physical or mental abnormalities. Consent is not required from the woman's husband or from other family members; however, a guardian's consent is required if the woman seeking an abortion is either less than 18 years old or is mentally ill. The Act allows an unintended pregnancy to be terminated up to 20 weeks' gestation; however, if the pregnancy is beyond 12 weeks, approval is required from two medical practitioners (Arnold et al. (2002)). The stated purpose of the Act was to regulate and ensure access to safe abortion, although it has been argued that the political motivation was population control (Phadke (1997)).

Fetal sex determination first became possible in India with the advent of amniocentesis in the 1970s. This technology was introduced to detect genetic abnormalities but was soon being used to detect fetal sex. As early as 1976, the government banned the use of these tests for sex determination in government facilities (Arnold et al. (2002)). The private sector remained unregulated but widespread use was limited by the high direct cost and the invasiveness of amniocentesis. Fetal sex-selection only really became feasible after 1980-becoming evident at the population level after 1985 and widespread by 1995 - with the arrival of ultrasound scanners. Ultrasound availability during the early diffusion period was driven by the liberalization of India's import sector. The first ultrasound scanner was imported in 1987 (Mahal et al. (2006)). Thereafter, the quantity of imports rapidly increased (Figure 1) as import duties on medical equipment were gradually lowered. The import tariff on medical devices declined from 40 to 60 percent in the 1980s to 25 percent in the late 1990s to 12.5 percent in 2003-04, and then to the currently uniform rate of 5 percent. Domestic production of ultrasound machines grew 15-fold between 1988 and 2003 (George (2006), Grover and Vijayvergia (2006)), following relaxation of industrial licensing regulations. The bottom graph in Figure 1 shows that, once domestic production began, it was orders of magnitude larger than imports.

Demand for ultrasound scans proliferated as a result of the technology being non-invasive and its wide affordability at about $\$ 10-\$ 20$ for a scan or an abortion (Arnold et al. (2002)). ${ }^{11}$ The trend in ultrasound use (also in Figure 1) closely tracks the supply of ultrasound machines. Additionally, Figure 2 shows that the officially reported number of abortions (that includes both sex-selective and other abortions) follows a similar trend and is positively correlated with self-reported ultrasound use during pregnancy. Clinics and portable facilities have mushroomed, advertising availability of ultrasound with slogans conveying that the cost of a scan is much lower than the future costs of dowry. ${ }^{12}$ Additional amendments to the MTP Act in 2002 and 2003 increased public sector provision

\footnotetext{
${ }^{10}$ More information on the certification criteria is available in Stillman et al. (2014).

${ }^{11}$ These may be significant costs in a country where many live under the $\$ 1.25$-a-day line. The costs cumulate if repeated scans and abortions are needed before a boy is conceived and vary with distance of the household from the clinic and with the safety of the procedures.

${ }^{12}$ Dowry is a ubiquitous feature of the Indian marriage market and payments from the bride's family to
} 
and made abortion safer (Stillman et al. (2014)). Other things equal, this could have contributed to a further increase in feticide since 2002.

Since the late 1980s, sex-selection has become the dominant concern amongst women's and human rights organizations. ${ }^{13}$ Their campaigns led to the central government passing the Prenatal Sex Diagnostic Techniques (Regulation and Prevention of Misuse) (PNDT) Act in 1994. This act was effective from January 1, 1996. The PNDT Act made it illegal to use prenatal sex-diagnostic techniques (like ultrasound) to reveal the sex of a fetus. Following the revelation in the 2001 Census of a continuing deterioration in the sex ratio, the PNDT Act was strengthened by a 2002 Amendment (effective 2003) incorporating a ban on advertising prenatal sex determination and increased penalties for violations. ${ }^{14}$ It is widely believed that these regulations have made little difference (Visaria (2005)), although Nandi and Deolalikar (2013) find that they did have some impact. These bans are difficult to enforce because ultrasound (or alternatives like amniocentesis) are also used for medical purposes and in routine prenatal care, making it easy to cover up sex determination as a motive.

In general, the fetal environment has improved in India. The growth in income and the decline in poverty since the early 1980s has been widely documented; fertility decline set in from 1981 (Bhalotra and van Soest (2008)); and neonatal mortality rates have been decreasing. Maternal mortality is estimated to have declined (Bhat (2002)) and maternal age at birth has risen. Improvements in fetal health tend to favor boys, whereas our hypothesis is that the trend, driven by the availability of ultrasound scanners, has been in favor of girls.

\section{Empirical Methodology}

The hypothesis we test in this paper is that the availability of prenatal sex-detection technology (and, in particular, ultrasound) simultaneously modified the decisions to conceive, to use prenatal sex detection and abort if the fetus is female, and to invest, possibly differently, in surviving girls and boys. Observable outcomes of these decisions are live birth, the probability that a birth is female (or, the sex ratio at birth), gender-differentiated investments (like breastfeeding and vaccination) and girl relative to boy mortality rates.

As mentioned in Section 1, we exploit exogenous variation in the supply of ultrasound scanners, interacted with quasi-random variation in the family-level proclivity to commit sex-selection (con-

the groom's family at the time of marriage can amount to several multiples of annual household income (Anukriti et al. (2016)), and can motivate parents to eliminate female births (Bhalotra et al. (2016a)).

${ }^{13}$ Feminist and socialist groups in the United States and other richer countries have hotly defended a prochoice stance against a pro-life stance on abortion. The focus of public discussion is on benefits for women rather than on benefits for children. For instance, http://www.theguardian.com/commentisfree/2014/ oct/14/abortion-right-to-privacy-women-right-to-equality and https://socialistworker.org/ 2013/11/01/abortion-every-womans-right. Indian feminists, on the other hand, have been divided by the seeming contradiction of supporting a woman's right to abortion while opposing sex-selective abortion (Kumar (1983), Gangoli (1998)).

${ }^{14}$ More details on the PNDT Act are available in Retherford and Roy (2003) and Visaria (2005). 
ditional on underlying preferences) to estimate the impacts of ultrasound availability. Since we are interested in gender gaps in parental investments, survival, and sibship size, we use the sex of the child as a third interaction in a triple differences-in-differences (DDD) regression specification.

Since the first imports of ultrasound scanners and the initiation of local production constitute structural breaks in supply at the national level, a simple pre-post comparison of outcomes that relies upon differential exposure to ultrasound technology is at risk of reflecting correlated macroevents. ${ }^{15}$ The wave of economic liberalization in India that lowered import tariffs and relaxed licensing of domestic production was, for instance, also associated with greater exposure of women to Western media and with rising incomes for large sections of the population. We address this problem by interacting cohort variation in exposure to the new technology with the sex of the firstborn child of the mother, which is a quasi-random variable indicating the mother's "willingness" to conduct sex-selective abortion.

The assumption that the sex of the first child is randomly determined is supported by the data. See the top left graph in Figure 3 which shows that the sex ratio at first birth in India lies within the normal range during our sample period, and shows no tendency to increase over time. ${ }^{16}$ Additionally, there are no significant socioeconomic differences between families with a firstborn son and a firstborn daughter (to be presented shortly in Table A.4). Exogeneity of first-born sex has also been previously defended (Das Gupta and Bhat (1997), Visaria (2005), Bhalotra and Cochrane (2010)) and lines up with recent survey data that suggest that parents do not always prefer having a son over a daughter. Jayachandran (2016) finds that although the vast majority of families want to have a son if they can only have one child, at a family size of two they prefer having one daughter and one son over having two sons. As desired and actual fertility in India are well above one (Table A.3), it is reasonable to assume that parents are not averse to having one daughter, despite a strong desire for at least one son.

Previous studies have established that parents randomly exposed to a "firstborn girl treatment" are more likely to practice sex-selection at higher-parity births (Bhalotra and Cochrane (2010), Rosenblum (2013)) consistent with a documented desire for at least one son. Figure 3 clearly depicts this pattern: after ultrasound technology became available, second, third, and fourth births became increasingly more male but only for families without a son. So, the interaction with first child's sex captures the differential incentives to sex-select among otherwise similar families.

If sex of the firstborn is random, excess female mortality (EFM) among families with a firstborn girl and a firstborn boy should follow a similar trend before the availability of prenatal sex-selection technology. We show that this is the case. See Figure 4 where Panel A plots the 5-year moving average of EFM for firstborn-boy and firstborn-girl families for our sample period and Panel B

\footnotetext{
${ }^{15}$ We do not use measures of state-specific adoption since it is endogenous; see Jayachandran et al. (2010) for a similar argument pertaining to the introduction of antibiotics in the United States. Bhalotra and Cochrane (2010) document that access to ultrasound in India was widespread and that the costs of ultrasound and abortion were not prohibitive even for relatively poor households.

${ }^{16}$ Figure 3 reproduces Figures 1-4 from Bhalotra and Cochrane (2010).
} 
plots the differential trend for these two groups. Although EFM is significantly higher for births preceded by a firstborn girl during the pre-ultrasound period, the gap remained constant until 1985, providing support for the identifying assumption of parallel pre-reform trends.

Even if our specification addresses potential concerns about omitted trends, one might still worry that we identify compositional rather than causal effects. For example, if higher SES women were more likely to change their behavior in response to ultrasound availability, then the postultrasound composition of births will be lower-risk than pre-ultrasound. If, in addition, the gender gap in outcomes among high SES births is narrower (we discuss the evidence later), any causal effects of ultrasound availability on post-birth gender gaps will be conflated with this compositional effect. More generally, if there was selection into conception, sex-selection, and abortion after prenatal sex detection became feasible, then our estimates of child mortality are subject to bias. We believe that this is not a first-order problem since we effectively difference between first-daughter and firstson families conditional upon SES. We nevertheless address this concern by introducing mother fixed-effects, comparing outcomes for children born to the same mother but differentially exposed to ultrasound technology. ${ }^{17}$ We also investigate sensitivity of our estimates to conditioning upon stated preferences including desired fertility and the desired number of sons versus daughters, and we directly investigate endogenous heterogeneity in fertility.

\subsection{Regression Specifications}

To capture the time variation in ultrasound availability, we split our sample into three broad timeperiods, defining 1973-1984 as the pre-ultrasound period, 1985-1994 as the early diffusion period, and 1995-2005 as the late diffusion period when ultrasound supply and use became widespread. Bhalotra and Cochrane (2010) identify 1985 as a break-point in the trend of the average sex ratio at birth using non-parametric plots and flexible parametric specifications. As an imbalanced sex ratio at birth captures sex-selective abortions, the break-point also serves as a proxy for the trend-break in ultrasound availability. They identify 1995 as a second break-point based on the sharp increase in supply of ultrasound scanners following the acceleration of trade liberalization in the early and mid-1990s; this trend-break is clearly visible in Figure 1. Our results are similar if we vary the precise thresholds used to define the three time periods.

For child $i$ of birth order $b$ born to mother $j$ in year $t$ and state $s$, we estimate the following

\footnotetext{
${ }^{17}$ This involves selecting a sample of families with at least two children of opposite sex. We therefore present estimates with and without fixed effects to assess coefficient stability.
} 
specification: ${ }^{18}$

$$
\begin{aligned}
Y_{i j t}= & \alpha+\beta_{1} G_{j} * F_{i} * \operatorname{Post}_{t}^{1}+\beta_{2} G_{j} * F_{i} * \text { Post }_{t}^{2} \\
& +\gamma G_{j} * F_{i}+\omega_{t} G_{j}+\sigma_{t} F_{i} \\
& +\mathbf{X}_{\mathbf{i j t}}^{\prime} \tau+\delta_{s} F_{i}+\nu_{s} G_{j}+\psi_{b} F_{i}+\xi_{b} G_{j} \\
& +\rho_{b t}+\eta_{b s}+\phi_{s t}+\epsilon_{i j t}
\end{aligned}
$$

The dependent variable, $Y_{i j t}$, is either a mortality indicator for child $i$ or a measure of parental investments in children, including breastfeeding and immunization. ${ }^{19}$ The indicator variable $G_{j}$ equals one if the first child of mother $j$ is a girl. The variable $F_{i}$ equals one if child $i$ is female. Post $_{t}^{1}$ indicates that $t$ belongs to the early diffusion period (1985-1994) and Post $t_{t}^{2}$ indicates that $t$ belongs to the late diffusion period (1995-2005). Attached to the two triple interaction terms are the coefficients of interest.

A vector of socioeconomic and demographic characteristics, $\mathbf{X}_{\mathbf{i j t}}^{\prime}$, comprises indicators for household wealth quintiles, educational attainment of child's parents, mother's birth cohort, mother's age at birth, caste, religion, and residence in a rural area. We also control for the main effects of $G_{j}$ and $F_{i}$ and fixed effects for state, birth year (or cohort, of the child), and birth order. We allow birth cohort fixed effects to vary by firstborn sex $\left(\omega_{t} G_{j}\right)$, by child gender $\left(\sigma_{t} F_{i}\right)$, and by birth order $\left(\rho_{b t}\right)$, which is a very flexible way of controlling for possibly omitted trends. We also allow state and birth order fixed effects to vary by firstborn sex and by child gender $\left(\delta_{s} F_{i}, \nu_{s} G_{j}, \psi_{b} F_{i}, \xi_{b} G_{j}\right)$. In addition, we include state fixed effects specific to birth order $\left(\eta_{b s}\right)$ and to birth year $\left(\phi_{s t}\right)$.

Child gender-specific cohort fixed effects $\left(\sigma_{t} F_{i}\right)$ account for any nationwide changes that may influence gender gaps in the outcomes, including improvements in maternal health or prenatal care which we expect benefit male fetuses more than female fetuses given the evidence on greater sensitivity of males to prenatal inputs (Low (2000)). They also account for any trends in son preference associated with modernization. Cohort fixed effects varying by sex of the firstborn child in the family $\left(\omega_{t} G_{j}\right)$ control for nationwide trends that may have differentially affected mortality of children in firstborn-girl versus firstborn-boy families. For instance, the "Trivers-Willards hypothesis" implies that firstborn-boy families are more often of higher SES than firstborn-girl families, and it is plausible that trends in the outcomes differ by SES and that the SES-observables we control for do not capture every relevant expression of SES.

Allowing the state fixed effects to vary with both child gender $\left(\delta_{s} F_{i}\right)$ and sex of the firstborn child $\left(\nu_{s} G_{j}\right)$ allows state-level time-invariant factors, such as soil quality (Carranza (2015)), to have gender-specific effects and ensures that we absorb any cross-sectional heterogeneity that may be correlated with firstborn sex. We interact indicators for child gender and sex of the firstborn with

\footnotetext{
${ }^{18}$ The variable state refers to the mother's state of residence at the time of survey and may differ from the child's state of birth. Restricting the sample to women who have not migrated between their first birth and the survey date does not substantively change the estimates.

${ }^{19}$ More details on the variables used in the regression analysis are available in Appendix 1.
} 
birth order $\left(\psi_{b} F_{i}, \xi_{b} G_{j}\right)$ given previous evidence that son preference varies with birth order and that sex of the firstborn child influences the exercise of son preference.

Lastly, $\phi_{s t}, \eta_{b s}$, and $\rho_{b t}$ control non-parametrically for, respectively, state-specific time effects (e.g., differential growth rates of state GDP or availability of abortion and other health services), state-specific birth order effects, and birth order specific time effects. This rich set of fixed effects enables us to rule out a wide range of confounding variables and trends that can interfere with a causal interpretation of our findings, and we thereby provide better identification than earlier related research.

We include first births in our sample and set $G_{j}$ equal to zero for them. ${ }^{20}$ The "control" group comprises pre-ultrasound births, second- and higher-order births to mothers whose firstborn is a boy, and first births. The coefficient $\gamma$ measures the difference in excess female mortality (EFM) or the gender gap in health investments between the treatment and control groups during the preultrasound period. The coefficients $\beta_{1}$ and $\beta_{2}$ capture how these gaps evolved over the early and late diffusion periods relative to the pre-ultrasound period. Standard errors are clustered by state.

Since our data comprise multiple births per woman, we also estimate specification (1) including mother fixed effects, exploiting the differential exposure of siblings to ultrasound technology. As discussed, this strategy addresses concerns pertaining to selection on underlying preferences or socioeconomic characteristics correlated with both access to or uptake of ultrasound technology and investments in girls versus boys. This approach also addresses any potential bias arising from a preponderance of male births in higher SES families ("Trivers-Willards hypothesis") even in the absence of sex-selection. Since we do not observe large differences in the socioeconomic characteristics of firstborn-boy and firstborn-girl families (in Table A.4), we expect that selection is of limited concern, but we nevertheless allow for it.

We examine the impact of availability of prenatal sex detection on gender gaps in fertility in two ways. First, we test if ultrasound altered the male-bias in the hazard of birth in a given year for firstborn-girl versus firstborn-boy mothers. ${ }^{21}$ For this specification, we utilize a retrospective mother-year panel in which a woman enters the panel in her year of marriage and exits in the year of survey. For mother $i$ from state $s$ of age $a$ in year $t$, who has given birth to $b-1$ children by $t$ and whose last birth took place $r$ years ago, we estimate the following logistic regression:

$$
\begin{aligned}
\text { Birth }_{i t}= & \alpha+\beta_{1} G_{i} * \text { Post }_{t}^{1}+\beta_{2} G_{i} * \text { Post }_{t}^{2}+\gamma G_{i}+\omega_{t} \\
& +\mathbf{X}_{\mathbf{i}}^{\prime} \tau+\phi_{a}+\psi_{b}+\sigma_{r}+\delta_{s}+\nu_{s} G_{i}+\theta_{s t}+\epsilon_{i t}
\end{aligned}
$$

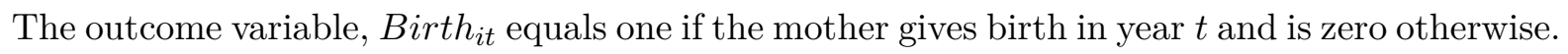
Post $_{t}^{1}$, Post $_{t}^{2}$, and $G_{j}$ are defined as earlier. The vector $\mathbf{X}_{\mathbf{i}}^{\prime}$ comprises indicators for household wealth quintiles, educational attainment of the mother and her husband, caste, religion, residence in a

\footnotetext{
${ }^{20}$ For higher-order births, $G_{j}$ equals one if the first child of mother $j$ is a girl and zero otherwise.

${ }^{21}$ Since our empirical strategy relies on the sex of the first birth, the sample excludes the 11 percent of women in the data who had never given birth by the time of the survey.
} 
rural area, and mother's year of birth. We include fixed effects for year $\left(\omega_{t}\right)$, state $\left(\delta_{s}\right)$, mother's age $\left(\phi_{a}\right)$, parity $\left(\psi_{b}\right)$, and years since last birth $\left(\sigma_{r}\right)$, state-specific firstborn-girl fixed effects $\left(\nu_{s} G_{j}\right)$, and state-specific year fixed effects $\left(\theta_{s t}\right) .^{22}$

Additionally, we attempt to estimate the effect on the "stock" of children a woman has at the time of survey. ${ }^{23}$ Specifically, we estimate the following specification for woman $j$ in state $s$ who has $N_{j t}$ children in the year of survey, $t$ :

$$
\begin{aligned}
N_{j t}= & \alpha+\beta_{1} G_{j} * \text { Post }_{t}^{1}+\beta_{2} G_{j} * \text { Post }_{t}^{2}+\gamma G_{j}+\sigma \text { Post }_{t}^{1}+\psi \text { Post }_{t}^{2} \\
& +\mathbf{X}_{\mathbf{j}}^{\prime} \tau+\delta_{s}+\nu_{s} G_{j}+\theta_{s} \text { Post }_{t}^{1}+\omega_{s} \text { Post }_{t}^{2}+\epsilon_{j t}
\end{aligned}
$$

We restrict the sample to mothers who either were always exposed or never exposed to ultrasound for the year-span of their births. In other words, we retain women who had all their births strictly within one of the three time-periods - pre-ultrasound, early diffusion, or late diffusion. Post $t_{t}^{1}$ and Post $_{t}^{2}$ indicate that a woman began and completed childbearing respectively during 1985-1995 and after 1995. The variable $G_{j}$ is, as before, an indicator for the firstborn being a girl. The vector $\mathbf{X}_{\mathbf{j}}^{\prime}$ comprises indicators for household wealth quintiles, educational attainment of the woman and her husband, caste, religion, residence in a rural area, woman's birth year, and woman's age at the time of survey. We include fixed effects for the woman's birth year as fertility is right-censored for some women. Moreover, we include state fixed effects $\left(\delta_{s}\right)$, state-specific firstborn-girl fixed effects $\left(\nu_{s} G_{j}\right)$, and allow the effects of the post-ultrasound indicators to vary by state $\left(\theta_{s}\right.$ Post $_{t}^{1}$ and $\omega_{s}$ Post $_{t}^{2}$ ). The coefficient $\gamma$ provides an indication of the extent to which the pre-ultrasound period was characterized by son-biased fertility stopping. The coefficients $\beta_{1}$ and $\beta_{2}$ test our hypothesis that after fetal sex determination became feasible, there was less son-bias in fertility decisions, i.e., the fertility difference between families with a firstborn girl and families with a firstborn boy narrowed. ${ }^{24}$

\section{Data and Descriptive Statistics}

The mortality and fertility equations are estimated using three pooled rounds of the National Family Health Survey (NFHS) conducted in 1992-93, 1998-99, and 2005-06. These nationwide, repeated,

\footnotetext{
${ }^{22}$ We also modify this specification by including mother fixed effects to test if ultrasound availability delays time to the next birth for a given mother, conditional upon the time since last birth, in the post-ultrasound (relative to the pre-ultrasound) period and whether this delay is on average greater in firstborn-girl (relative to firstborn-boy) families. The results from this specification are available upon request.

${ }^{23}$ Like specification (2), here too we exclude women who had never given birth by the time of the survey.

${ }^{24}$ In principle, the excluded mothers, whose fertility spans more than one period should be similar to the included mothers. We checked for balance and found that in fact the excluded mothers are, on average, of lower SES and are older. However, we always control for SES (education, wealth, urban) and flexibly control for age, and, within the sample, our estimates identify differences by firstborn sex. In any case, we also present fertility results separately for each SES group (within our sample) and, as we show later, for most SES indicators, differences in the coefficients of interest are small. Lastly, our results are robust to the inclusion of fixed effects for the years of first and last birth of every women and fixed effects for their interactions with each other, with state fixed effects, and with the firstborn sex indicator.
} 
cross-sectional surveys are representative at the state level and report complete birth histories for all interviewed women, including children's month, year, and order of birth, mother's age at birth, and age at death of deceased children. ${ }^{25}$ The sample comprises 503,316 births of 232,259 mothers that occurred in 1973-2005.

For our mortality and postnatal health specifications, we pool all births of the surveyed women to create a child-level dataset. The hazard of birth specification, on the other hand, is a retrospective mother-year panel that is created from women's retrospective birth histories. Our third specification, that examines the fertility stock, simply pools all surveyed women to form a woman-level dataset.

In the pre-ultrasound era, there were large gender gaps in post-neonatal child mortality. Trends in EFM by the sex of the first child are depicted in Figure 4 and Table 1. During 1973-1984, girls preceded by a firstborn girl were 3 p.p. more likely than boys to suffer post-neonatal child mortality. After 1985, following introduction of ultrasound, there is a clear decline in the gender gap in mortality in this group, to 1.78 p.p. during 1985-1994 and to 1.18 p.p. during 1995-2005. There was also a marked decline in the gender gap in mortality in families with a firstborn son, but from a smaller initial level. Among pre-ultrasound cohorts, the gap was 0.88 p.p. and this declined to 0.50 p.p. in the early diffusion period and 0.15 p.p. during the late diffusion period.

Table A.4 reports summary statistics for the main variables used in the analysis, by the sex of the firstborn child for pre- and post-ultrasound periods. The fraction of female births, a marker of sex-selective abortion, declined from 0.48 in the pre-ultrasound period to 0.47 in the late diffusion period for births preceded by a firstborn girl, but not for births preceded by a firstborn boy. Fertility is consistently higher for mothers with a firstborn daughter than for mothers with a firstborn son, illustrating son-biased fertility stopping. This difference narrows in the post-ultrasound period, consistent with our prediction that sex-selective abortion substituted son-biased fertility behavior as a way of achieving the desired sex composition of births. Mother's age at birth has increased over time, and more so for mothers with a firstborn girl, consistent with reduced fertility.

Firstborn-boy and firstborn-girl families appear well-matched in each period on most relevant characteristics including rural residence, religion, caste, wealth, and father's education. More than 70 percent of the births occur in Hindu families and close to 70 percent in rural areas. However, over time, births preceded by a firstborn girl are increasingly born to less educated mothers relative to births preceded by a firstborn boy. We investigate this more formally in exploring heterogeneity in fertility responses to ultrasound by education of the mother and, as we shall see, our results confirm that literate women exhibit greater reductions in son-biased fertility stopping than illiterate women, consistent with the summary statistics. In the main regressions, we consistently control for various markers of SES and, importantly, specifications with mother fixed effects are free from any potential bias introduced by differences in SES between firstborn-boy and firstborn-girl families.

Although the NFHS contain fairly rich data on investments in children, these questions are asked only for children born in a few years preceding each survey and there is no pre-ultrasound data on

\footnotetext{
${ }^{25}$ Since the state of Sikkim changed its border during the period of analysis, we exclude it from our sample.
} 
investments. ${ }^{26}$ For this reason, we utilize the 1999 round of the Rural Economic and Demographic Survey (REDS). REDS is restricted to rural women from 16 major states and reports age at death for deceased children but does not record the year of birth for children who did not survive to the date of survey. To the extent that deceased children are likely to have received lower health investments than surviving children and (as we show) excess girl mortality was higher during the pre-ultrasound period than in the post-ultrasound years, the exclusion of deceased children will tend to bias the estimated effects downward. In this sense, the estimates we present are conservative. We nevertheless also present estimates using the NFHS data - which is not biased by the exclusion of deceased children - by exploiting increasing penetration of ultrasound during post-ultrasound years.

Table A.5 reports summary statistics for the REDS sample. The definition of pre-ultrasound and early diffusion period is the same as in Table A.4 but the late diffusion period is shorter (19951999). Vaccination rates have increased over time for all children from about 70 percent probability of receiving at least one vaccine in the pre-ultrasound period to above 90 percent likelihood in the late diffusion period. In the pre-ultrasound period, children preceded by a firstborn boy were 3 p.p. more likely to be immunized than children preceded by a firstborn girl and this gap was closed post-ultrasound. Breastfeeding is nearly universal for girls and boys in India. The mean duration of breastfeeding was about 19 months in the pre-ultrasound period and nearly 90 percent of boys and girls (who survived to the survey date) were breastfed for at least 12 months. The gender gaps manifest in terms of breastfeeding duration, after age one, though they are not apparent in the sample means in Table A.5, possibly because the mean breastfeeding duration is mechanically lower in the 1995-1999 period because some of the children in that group were of breastfeeding age at the time of survey. This is another weakness of the REDS that we redress by showing results estimated from the NFHS data as well.

\section{Results}

\subsection{Excess Female Mortality}

In Table 2, we present estimates of the impacts of the introduction and diffusion of ultrasound technology on neonatal and post-neonatal child mortality. ${ }^{27}$ We add controls as we move across columns, with column (4) being the richest specification. The coefficient of Firstborn girl * Female confirms that, during the pre-ultrasound period, girls were significantly more likely to die neonatally (by 0.9 p.p.) and during early childhood (by 1.5 p.p.) among children preceded by a firstborn sister relative to a firstborn brother. ${ }^{28}$ The triple-interaction coefficients, Firstborn girl * Female * Post, indicate a 33 percent decline in the neonatal EFM gap between firstborn-girl and firstborn-

\footnotetext{
${ }^{26}$ NFHS-1, 2, and 3 collected health investments for, respectively, the last three children born after January 1988, the last two children born after January 1995, and all children born after January 2001.

${ }^{27}$ Table A.6 reports estimates for infant and child mortality.

${ }^{28}$ The probability of post-neonatal child mortality for boys in the pre-ultrasound period was 6.2 percent in firstborn-boy families and 5.7 percent in firstborn-girl families.
} 
boy families, relative to the 1.765 p.p. baseline gap. For post-neonatal child mortality, all of the baseline EFM gap between firstborn-girl and firstborn-boy families (i.e., 2.167 p.p.) was eliminated once ultrasound technology became available. These results are robust to the inclusion of mother fixed effects.

We can decisively reject an increase in relative girl neonatal mortality, which could arise if, having detected child sex, parents made smaller fetal investments in girls. In fact, the decline in neonatal EFM biases us against finding a decline in post-neonatal EFM because, in the postultrasound cohorts, the marginal survivors of the neonatal period are negatively selected (i.e., in the pre-ultrasound period they would have succumbed to neonatal mortality, but now they "just survive").

Larger reductions in post-neonatal than in neonatal mortality are consistent with the increases in postnatal investments that we document below, given that neonatal survival is less dependent upon postnatal investments and more closely linked to maternal health and delivery conditions. Our findings are also congruous with previous work; for instance, Almond et al. (2006) show that hospital de-segregation after the Civil Rights Act led to a narrowing of the racial gap in postneonatal but not neonatal mortality. ${ }^{29}$ The significance of our results is enhanced by the fact that reductions in post-neonatal mortality also improve later life circumstances, predicting adult height, a marker of health (Bozzoli et al. (2009)) and cognitive performance (Chay et al. (2009)).

Estimates by birth order are in Table A.7. The coefficients indicate reductions in post-neonatal mortality among girls across birth order, but the largest and only statistically significant coefficients are among second births. This may reflect the common finding that parents are particularly averse to having more than two girls (which applies at order three and above), ${ }^{30}$ so there remains a girl-boy differential in post-neonatal mortality at higher orders.

We also estimate specification (1) for a sample of first births, re-defining Post $t_{t}^{1}$ and Post ${ }_{t}^{2}$ as indicators for the second child being born during the early and late ultrasound diffusion periods, respectively (see Table A.8). If, in violation of our assumption, ultrasound access also led to sexselection for first births, we would also expect to see a decline in EFM for first births. The results confirm no pre-ultrasound difference in the risk of death by gender, and no post-ultrasound change. This validates our assumption that parents do not manipulate the sex of first births.

\subsubsection{Changes in Preferences versus Technology}

We utilize women's self-reported preferences for fertility (i.e., ideal number of children) and sons (i.e., ideal sex ratio of children) to test if trends in other factors, such as women's education, led to changes in preferences, which in turn influenced sex differences in child investments and mortality.

\footnotetext{
${ }^{29}$ Similarly, The Million Deaths Study (2010) in India shows that only 3.2 percent of neonatal deaths were caused by diarrhea - a function of clean water and nutrition - in contrast to 22.2 percent of post-neonatal deaths.

${ }^{30}$ Almond and Edlund (2008) show that Indian, Chinese, and Korean families with no previous sons exhibit male-biased sex ratios at third parity but not before in the 2000 US Census and Bhalotra and Cochrane (2010)) show that the male-bias in the sex ratio at birth in India is increasing in birth order.
} 
Our main specification is, in principle, robust to this source of bias as our identification strategy teases out structural breaks in the outcomes that coincide with sharp changes in the availability of ultrasound technology. We nevertheless assess the potential role of changes in preferences as follows. First, we include them as controls in specification (1) and, to strengthen this test, we interact the preference variables with the Female dummy and the Firstborn girl dummy. The coefficients of interest are not changed by these additions (Table A.9). We then control for another measure of gender biased preferences - the state-year gender enrollment ratio at ages 6-11 and 11-14 and, again, the results are stable. The coefficients of these additional terms are interesting in their own right, and are consistent with our expectations. The coefficients of Ideal Sex Ratio * Female and Enrollment Gender Gap * Female are positive, implying that EFM is higher in families with a stronger preference of sons. The coefficient on Ideal Fertility * Female is negative, implying that, conditional on son preference, a declining trend in fertility leads to higher EFM, a finding that is consistent with Jayachandran (2016).

Second, we check if, post-ultrasound, girls are more likely to be born into families with weaker son preference, as this would then be a reason that they do better. This pattern would arise if families that commit female feticide have stronger son preference than families that take their girl conceptions to term. We focus on the behavior of firstborn-girl families because the data show that these are the families that abort girls (Figure 3). We test for this channel by estimating specification (1) with mother's self-reported ideal fertility and ideal proportion of sons as dependent variables (Table A.10). The triple-interaction coefficients indicate that female children born post-ultrasound in a firstborn-girl family relative to a firstborn-boy family are no more likely post-ultrasound than pre-ultrasound to be born to mothers with lower son preference. This suggests that feticide depends more upon characteristics like wealth and education (this is demonstrated in Bhalotra and Cochrane (2010), who also show that these characteristics are negatively correlated with desired fertility) than on stated son preference. Indeed, stated son preference is lower in wealthy and educated families even though they commit more female feticide; a vivid portrayal of this is in Figures A.1 and A.2. ${ }^{31}$

\subsubsection{Exploiting Variation in Self-reported Ultrasound Use}

Thus far, we have chosen not to use the available individual data on ultrasound use because uptake is potentially endogenous and the data, being self-reported, may be inaccurate. However, we now use these data to corroborate the previous results which are based on changes in the availability

\footnotetext{
${ }^{31}$ The finding that girls in India are increasingly being born in (Bhalotra and Cochrane (2010)) and surviving in (our results, discussed in detail shortly) low-SES families aligns with the predictions of Edlund (1999). However, if the Trivers-Willards mechanism, which accounts for parents caring not only about the sex of their offspring but also about the chances that their offspring reproduce, were a key driver for this pattern, then we may expect this to express in stated son preference. Our finding that high-SES parents report lower son preference even though they engage in stronger son-preferring behaviors can be explained either by (i) high-SES parents being more socialized into under-stating their true son preference or (ii) sex-selective behaviors being driven by economic and social factors (lower desired fertility or greater affordability of safe ultrasound and abortion facilities among high-SES women) rather than by the Trivers-Willards mechanism, even if the latter is present.
} 
of ultrasound driven by different import and licensing regimes. ${ }^{32}$ We average individual-level data to obtain the percentage of births in a state and a year for which the mother reports having a prenatal ultrasound scan at some point during pregnancy $\left(\right.$ Ultr $\left._{s t}\right) .{ }^{33}$ The earliest year for which this variable can be defined is 1996 so now, instead of comparing pre- and post-ultrasound births, we compare births in states with varying intensity of ultrasound use. The results in Table A.11 confirm those in Table 2.

\subsubsection{Other Robustness Checks}

In the main analysis, we incorporate pre-ultrasound cohorts in the sample and control for underlying trends in the outcomes. We nevertheless confirm that our findings are not being driven by any pretrends by restricting the sample to the pre-ultrasound period and then re-estimating specification (1) with a single Post indicator, one each for "placebo" (or fake) treatment years 1977 through 1982 (Table A.12). We find no evidence of an underlying convergence in mortality outcomes for boys and girls that is unrelated to ultrasound availability.

Earlier we referenced previous research which verifies that the sex of the firstborn child was not manipulated upon the introduction of ultrasound (Bhalotra and Cochrane (2010)). We nevertheless investigate this differently, restricting the sample to women whose first child was born in the preultrasound period. We then re-estimate equation (1) (Table A.13) and although there are fewer observations (especially for the late diffusion period), the coefficients of interest remain negative and statistically significant.

\subsection{Postnatal Health Investments}

We posited above that declining post-neonatal mortality among girls signals increased parental investments. We directly test for this in Table 3. The outcomes are the number of months a child is breastfed, indicators for breastfeeding duration being at least 12,24 , and 36 months; ${ }^{34}$ a dummy variable indicating that the child has received at least one vaccine; and medical expenditure (in Rupees) on the child in the year prior to the survey. ${ }^{35}$ Pre-ultrasound, in families with a firstborn girl, boys were breastfed for a longer duration and were more likely to be vaccinated and to receive expenditure during illness. The estimates show that the gender gaps in breastfeeding and vaccination were virtually eliminated post-ultrasound in firstborn-girl families. ${ }^{36}$ A previous literature

\footnotetext{
${ }^{32}$ Notably, self-reported ultrasound use is larger among mothers with a firstborn girl relative to a firstborn boy, consistent with the former being more likely to practice sex-selection at higher parities.

${ }^{33}$ The denominator equals the number of births with a non-missing response on the question pertaining to ultrasound use during pregnancy.

${ }^{34}$ Here, the sample is restricted to children who are at least 12,24 , and 36 months old, respectively.

${ }^{35}$ Medical expenditure is conditional upon illness and includes doctor's fees, medicines, and costs of special diets during the illness. The specifications are similar to those for mortality except that we drop the urban indicator since REDS covers only rural households, the wealth quintiles (not reported in REDS) and, since we have a smaller sample, we drop $\rho_{b t}, \xi_{b} G_{j}$, and $\nu_{s} G_{j}$ and replace $\phi_{s t}$ with state-specific linear time trends.

${ }^{36}$ There is a significant improvement in the total duration of breastfeeding and in breastfeeding during the second year of life. Since most Indian children are breastfed through the first year of life, it makes sense that gender gaps in breastfeeding duration emerge after age one. The coefficients on breastfeeding for at least 36
} 
estimates that breastfeeding differences explain about 9 percent of the gender gap in post-neonatal child mortality in India (Jayachandran and Kuziemko (2011)) and that sex differences in vaccinations explain between 20 - 30 percent (Oster (2009)). We estimate that the contributions of breastfeeding and vaccination to the ultrasound-led decline in EFM are, respectively, 25 percent and 9 to 13 percent (details in Appendix 2).

For reasons discussed in Section 4, we also present results using the NFHS data in Table A.14. The NFHS contains information not only on immunization and breastfeeding, but also reports the number of antenatal checks during pregnancy. The results are broadly similar. ${ }^{37}$ Estimates by birth order (available upon request) are also congruous with the birth order specific results for survival.

Consistent with there being no pre-ultrasound EFM for first births and no post-ultrasound change, we find no significant pre-ultrasound gender gaps in breastfeeding and immunization rates among first births and no differences in these outcomes for first births whose younger siblings were born before versus after ultrasound access. To the extent that the bulk of immunization and breastfeeding investments in the first child are made before the second birth, these findings are not surprising. ${ }^{38}$ However, we find that pre-ultrasound, firstborn girls received lower medical and educational expenditure than firstborn boys and that these gaps narrowed after ultrasound became available (see Table A.15). ${ }^{39}$ We also find that ultrasound access decreased the gender gaps in children's school enrollment albeit the effects are insignificant. ${ }^{40}$ Overall, these result are consistent with sex-selection driven fertility decline in firstborn-girl families raising per capita resources that benefit all children.

Our strictest specifications identify gender gaps. The estimates do not directly deliver an estimate of the absolute gains or losses for boys in firstborn-girl families (which would require examining the coefficients of $G_{j} *$ Post $_{t}^{1}$ and $G_{j} *$ Post $_{t}^{2}$ ) because we include among controls the vector $\omega_{t} G_{j}$. Replacing $\omega_{t} G_{j}$ with $G_{j} *$ Post $_{t}^{1}$ and $G_{j} *$ Post $_{t}^{2}$ in specification (1), shows that, in firstborn-girl fam-

months and for medical expenditure during sickness are positive but imprecise.

${ }^{37}$ The estimates of gender gaps during the early diffusion period inTable A.14 are similar to the corresponding numbers (i.e., sums of the coefficients in the first two rows) in Table 3. The coefficients in the second row of Table A.14 capture the differences in gender gaps during the two post-ultrasound periods, and are also similar to the corresponding estimates (i.e., differences of the coefficients in the second and third rows) in Table 3. For instance, column (2) of Table A.14 implies that the gender gap in the likelihood of receiving at least one vaccine was 2.5 p.p. lower in the late diffusion period relative to the early diffusion period, while the corresponding magnitude is 3.7 p.p. in column (6) of panel A in Table 3.

${ }^{38}$ However, breastfeeding acts as a natural contraceptive, and consequently girls relative to boys at lower birth orders are breastfed for shorter period so that parents can start trying to have a son (Jayachandran and Kuziemko (2011)); but the ability to sex-select is useful only post-conception, so this channel is unlikely to get significantly affected by ultrasound access.

${ }^{39}$ Pre-ultrasound, even among firstborns, girls were 12 p.p. less likely to be provided allopathic treatment if they were ill. Similarly, annual education and medical expenditure on firstborn girls was lower by, respectively, Rs. 562 and Rs. 69 relative to firstborn boys.

${ }^{40} \mathrm{~A}$ potential reason for insignificant effects on enrollment is that public school education for girls is free in India, and thus parents may not discriminate in terms of sending their children to school. It is more likely that gender bias manifests in the quality of schooling (private versus public schools (Azam and Kingdon (2013)) and enrollment in higher education; however, we do not have adequate data on these dimensions. 
ilies, not only girls but boys too received greater immunization post-ultrasound, while breastfeeding duration was only significantly extended for girls. ${ }^{41}$ These results are consistent with smaller sibship sizes in firstborn-girl families. The magnitude of gains is smaller for boys than for girls. We find no significant change in boy survival alongside increases in girl survival in firstborn-girl families, however.

\subsection{Fertility}

For reasons detailed earlier, in Tables 4 and 5 we investigate if son-biased fertility stopping behavior changed subsequent to the availability of sex-selection technology. The coefficient of Firstborn Girl is positive and significant in both tables confirming that, pre-ultrasound, women whose first child was a girl were 15.5 p.p. more likely to give birth in a given year and had 0.155 more births than women with a firstborn son. Our estimates show that these differentials were eliminated once ultrasound technology became available. ${ }^{42}$ Controlling for mother's fertility preference and son preference does not significantly alter these effects, which suggests that the estimated coefficients reflect changes in behavior in response to changes in technology rather than changes in preferences. ${ }^{43}$

Since sex-selective abortion allows parents to avoid unwanted children, we also test whether availability of ultrasound drove actual fertility closer to desired fertility. Our estimates in Table 5 imply a complete elimination of undesired fertility, which the first row shows was 0.117 births in first-girl relative to first-boy families. To put this in a wider perspective, the presence of HIV reduces the average number of births a woman has during her life-cycle by 0.15 (Shapira (2013)). The coefficients of interest (those on the triple-interaction terms) are similar for actual fertility (in column 2) and for actual minus desired fertility (in column 3). This again confirms that the decline in actual fertility in first-girl families that we document is not driven by a decline in desired fertility.

The coefficients of the stated preference terms reveal that actual fertility is, as we may expect, increasing in desired fertility and in the desired ratio of sons to daughters. However, excess fertility is decreasing in the ideal ratio of sons to daughters, suggesting that desired fertility rises more steeply with son preference than actual fertility. ${ }^{44}$ Again, this makes sense, given that the desire to have sons leads to the widely documented phenomenon of son-biased fertility stopping (which is evident from the baseline statistics in the first row). Since actual fertility is not fully in the control of parents, it will tend to rise less than proportionately with desired fertility.

Table A.16 shows that the relative fertility decline in firstborn-girl families is driven by a shift from having four or more children toward having two or three children.

\footnotetext{
${ }^{41}$ Results available upon request.

${ }^{42}$ Estimates conditional upon mother fixed effects are not statistically significantly different, and are available on request.

${ }^{43}$ As a robustness check, like for EFM, we also ran a specification where Firstborn girl * Post 1 and Firstborn girl * Post2 are interacted with the preference variables; the results remain the same.

${ }^{44}$ Regressions of actual fertility and ideal fertility on the ideal sex ratio variable confirm this. However, note that unobserved shocks that increase, say the (measured) desired number of boys, would drive up both the ideal sex ratio and ideal fertility creating a positive upward bias on the latter coefficient.
} 


\subsection{Heterogeneity}

Although stated son preference is weaker among urban, educated, and wealthy women (Figure A.2), they exhibit higher rates of prenatal sex selection (Figure A.1). This pattern is consistent with their reporting lower desired fertility (Figure A.3), with educated individuals being more likely to adopt a new technology (Lleras-Muney and Lichtenberg (2005)), and with their being more efficacious in achieving their targets (Rosenzweig and Schultz (1989)). Also, wealth may matter at the margin for affordability of ultrasound scans and (safe) abortion, especially if a woman engages in multiple events. So, if there were a strict substitution of prenatal for postnatal girl mortality, we may expect the reductions in mortality and fertility that we document in this paper to be concentrated among educated and wealthy mothers. However, it is possible that these responses occur at different margins.

We examine if our results differ by mother's educational attainment (illiterate versus literate), household wealth (bottom 40 versus top 20 percent), mother's employment status (paid employment versus rest), ${ }^{45}$ household caste (scheduled caste (SC) versus other), ${ }^{46}$ and rural versus urban residence. Tables 6 and 7 respectively present estimates for post-neonatal child EFM (using the mother fixed-effects specification) and gender gaps in sibling size. ${ }^{47}$ In each regression, we continue to control for all SES variables, except the one being used to examine heterogeneity.

The tables show the baseline gender gaps in firstborn-girl families (first rows) and test to what extent they narrowed during the post-ultrasound period (second and third rows). In the preultrasound era, the general pattern was that, among firstborn-girl families, excess girl post-neonatal mortality was greater in low SES groups (illiterate, poor, unemployed, rural), but not significantly different for high versus low caste families. However, baseline gender gaps in sibling size were larger among literate, rich, urban, and non-SC women. ${ }^{48}$

Post-ultrasound EFM decline was steeper in poor and rural households, and households in which women were in unpaid employment. ${ }^{49}$ This is, in principle, consistent with larger increases in investment but also with a given change in investment having larger survival impacts in low-SES households where other causes of child mortality, such as infection rates, are higher. However, the absolute decline in EFM was broadly similar among literate versus illiterate mothers (and greater in relative terms in the literate group given their lower baseline rates). The decline in son-biased

\footnotetext{
${ }^{45}$ The results are robust to using alternative comparisons, including employed (paid or unpaid) versus unemployed.

${ }^{46}$ We pool high castes and other backward classes (OBC) because the first survey round does not distinguish them. Since OBC are better-off than SC households, the categories we use preserve the caste hierarchy in India. We also pool scheduled tribes (ST) with the higher caste group based upon finding that they take similar coefficients when included as a separate category.

${ }^{47}$ Table A.17 presents the heterogeneity results for effects on the number of children.

${ }^{48}$ This is not the case for women's employment but, in India, on average, low-SES women are more likely to be employed, driven to work by poverty.

${ }^{49}$ Women's labor force participation is hockey-stick shaped in India, being most common among the poor (Das and Desai (2003).
} 
fertility stopping is greater among high-caste, literate, rich, urban women and women in unpaid employment. Neither baseline differences nor post-ultrasound changes in mortality and fertility line up exactly, consistent with direct effects of ultrasound availability on each outcome (rather than either outcome being nothing but a pathway for the other).

We also split each SES-subsample by caste. ${ }^{50}$ Unlike other dimensions of SES, caste is exogenous in that an individual is born into a caste and remains in it. The caste hierarchy has been preserved by the low prevalence of inter-caste marriages. ${ }^{51}$ The upper-castes have historically laid greater emphasis on ritual purity and adherence to religious texts, which often compromises the position of women (Das Gupta et al. (2003), Das Gupta (2010)). In accordance with this, pre-ultrasound excesses in mortality and family size in girl-led families and post-ultrasound declines were, on average, larger in higher caste households. Interacting caste with other indicators of SES shows that at the low-end of the SES distribution, low castes are more gender-equal but at the highend, low caste behavior is similar to that of high-castes. This is consistent with the process of Sanskritization, wherein lower castes emulate the upper castes in seeking upward mobility (Srinivas (1962)).

\section{Estimates of Substitution}

To assess the extent of substitution between postnatal and prenatal discrimination due to ultrasound technology, we use our estimates to compute the number of female child deaths that have been averted and compare them with the number of girls who are missing, both due to prenatal sexdetection. These calculations are described in Appendix 3. We find that for every girl that survived due to ultrasound technology, five girls were aborted before birth. ${ }^{52}$

We calculate the proportion of discriminated births for which parents substituted postnatal discrimination with prenatal discrimination as the decline in the number of girls missing due to EFM $(=-60,879)$ divided by the total number of missing girls in the pre-ultrasound period $(=196,667)$. This calculation implies that, for nearly 31 percent of the births, parents who were practicing postnatal discrimination in the pre-ultrasound period switched to prenatal discrimination after ultrasound became available. The percentage of switchers is much larger than the estimates in Lin et al. (2014) who find that 4 percent of parents of second-parity births and 8 percent of parents of third- and higher-parity births made the switch in Taiwan.

\footnotetext{
${ }^{50}$ We include households of all religions and use the self-reported caste of the household for our analysis while using religion as a control variable. These results are available upon request.

${ }^{51}$ According to the 2005 India Human Development Survey, only 4.4 percent of women were married to a spouse from a different caste.

${ }^{52}$ These estimates take into account the endogenous changes in fertility, ignoring which the substitution is 5.5 rather than 5 . Lower average fertility implies that the share of all births that are lower parity is increasing and since sex ratios are closer to the biological norm at lower parities (and consistent with the norm for first births), this will contribute (through a compositional effect) to the average sex ratio being less male-biased than otherwise.
} 


\section{Conclusion}

As ultrasound technology became increasingly available, the global annual number of sex-selective abortions increased from nearly zero in the late 1970s to 1.6 million per year in 2005-2010 (Bongaarts and Guilmoto (2015)), with India and China being the biggest contributors. The stark growth in female feticide has garnered a lot of attention from academics, policymakers, and popular media. While most public attention has focused upon the increasing deficit of girl children, it has also been noted that a large share of sex-selective abortions in India are conducted in unsafe environments. Complications due to unsafe abortion account for an estimated 9 percent of all maternal deaths in India (Stillman et al. (2014)). ${ }^{53}$ Moral arguments can be made both in favor of parents' right to choose the sex of their offspring as well as against selective abortion of girls (Kumar (1983)). Abstracting from these ethical dilemmas, there are several reasons why a significantly male-biased sex ratio at birth is undesirable. The resulting scarcity of women on the marriage market can substantially increase the number of unmarried and childless men, ${ }^{54}$ who may face destitution in old age since children through marriage are the most important source of support for the elderly in countries like India that lack institutional social security (Das Gupta et al. (2010)). Rising sex ratios can lead to increased trafficking of women, ${ }^{55}$ higher prevalence of sexually-transmitted diseases (Ebenstein and Sharygin (2009)), and more crime (Edlund et al. (2007), Drèze and Khera (2000)). Sex-selection may also result in girls being consistently born to lower-status parents, thereby relegating women to lower social strata (Edlund (1999), Bhalotra and Cochrane (2010)). On the other hand, a shortage of women on the marriage market may increase their bargaining power and welfare. ${ }^{56}$ It has also been argued that sex-selective abortions might be preferable to infanticide or postnatal discrimination (Goodkind (1996)).

Our analysis shows that the increase in sex-selective abortions fueled by ultrasound technology substantially decreased postnatal gender discrimination against girl children in India. Relative to available studies, we contribute new evidence and present a more comprehensive analysis. We find that sex-selection eliminated gender gaps in post-neonatal child mortality, postnatal health investments, and sibling size among second- and higher-parity births in households with a firstborn daughter relative to households with a firstborn son. So, although fewer girls were born, those that survived to birth were treated more equally, were more likely to survive to age five, and on account of higher investments in, for instance breastfeeding and immunization, we can project that they

\footnotetext{
${ }^{53}$ The maternal mortality ratio in India was 178 maternal deaths per 100,000 live births in 2010-12.

${ }^{54}$ Bhaskar (2011) estimates that one in five boys born in recent cohorts in China will be unable to find female partners.

${ }^{55}$ Recent evidence shows that a shortage of women in north Indian states has led to the import of brides from other poorer states in India (Kaur (2004), Ahlawat (2009)).

${ }^{56}$ See Chiappori et al. (2002) and related papers for the large literature on household bargaining in developed countries. Stopnitzky (2012) shows that a relative scarcity of women in Haryana has increased their bargaining power on the marriage market and they are able to secure improved sanitation facilities at home as a result.
} 
are more likely to do well as adults. However, our evidence suggests that surviving girls in the post-ultrasound regime are more likely to be in low-SES households, and for every additional girl that survived after birth, five girls were aborted.

\section{References}

AbrevayA, J. (2009): "Are There Missing Girls in the United States? Evidence from Birth Data," American Economic Journal: Applied Economics, 1, 1-34.

Ahlawat, N. (2009): "Missing Brides in Rural Haryana: A Study of Adverse Sex Ratio, Poverty and Addiction," Social Change, 39, 46-63.

Almond, D., K. Y. Chay, and M. Greenstone (2006): "Civil Rights, the War on Poverty, and Black-White Convergence in Infant Mortality in the Rural South and Mississippi," MIT Department of Economics Working Paper No. 07-04.

Almond, D. And J. Currie (2011): "Killing Me Softly: The Fetal Origins Hypothesis," Journal of Economic Perspectives, 25, 153-72.

Almond, D. And L. Edlund (2008): "Son Biased Sex Ratios in the US 2000 Census," Proceedings of the National Academy of Sciences of the United States of America, 105, 5681-5682.

Almond, D., H. Li, And L. Meng (2010): "Son Preference and Early Childhood Investments in China," Working Paper.

Almond, D., H. Li, and S. Zhang (2013): "Land Reform and Sex-Selection in China," NBER Working Paper 19153.

Amaral, S. and S. Bhalotra (2016): "Unmarried men and crime against women: Long run effects of sex selection in India," Mimeo, University of Essex.

Ananat, E. O., J. Gruber, P. B. Levine, and D. Staiger (2009): "Abortion and Selection," Review of Economics and Statistics, 91, 124-136.

Ananat, E. O. And D. M. Hungerman (2012): "The Power of the Pill for the Next Generation: Oral Contraception's Effects on Fertility, Abortion, and Maternal and Child Characteristics," Review of Economics and Statistics, 94, 37-51.

Anderson, S. And D. Ray (2010): "Missing Women: Age and Disease," Review of Economic Studies, 77, 1262-1300.

Anukriti, S., S. Kwon, And N. Prakash (2016): "Dowry: Household Responses to Expected Marriage Payments," mimeo.

Arnold, F., S. Kishor, And T. Roy (2002): "Sex-selective Abortions in India," Population and Development Review, 28, 759-785.

Ashraf, Q. H., D. N. Weil, And J. Wilde (2013): "The Effect of Fertility Reduction on Economic Growth," Population and development review, 39, 97-130.

Azam, M. And G. G. Kingdon (2013): "Are girls the fairer sex in India? Revisiting intrahousehold allocation of education expenditure," World Development, 42, 143-164.

Bailey, M. (2006): "More Power to the Pill: The Impact of Contraceptive Freedom on Women's Life Cycle Labor Supply," Quarterly Journal of Economics, 121, 289-320.

Bhalotra, S. (2010): "Fatal Fluctuations: Cyclicality in Infant Mortality in India," Journal of Development Economics, 93, 7-19.

Bhalotra, S., A. Chakravarty, and S. Gulesci (2016a): "The Price of Gold: Dowry and Death in India," IZA Discussion Paper 9679. 
Bhalotra, S. And T. Cochrane (2010): "Where Have All the Young Girls Gone? Identification of Sex Selection in India," IZA Discussion Paper No. 5381.

Bhalotra, S., M. Karlsson, and T. Nilsson (2016b): "Infant Health and Longevity: Evidence from a Historical Intervention in Sweden," Journal of European Economic Association, Forthcoming.

Bhalotra, S. And S. Rawlings (2011): "Intergenerational Persistence in Health in Developing Countries: the Penalty of Gender Inequality?" Journal of Public Economics, 95, 286-299.

Bhalotra, S. And A. VAn Soest (2008): "Birth-Spacing, Fertility and Neonatal Mortality in India: Dynamics, Frailty, and Fecundity," Journal of Econometrics, 143, 274-290.

Bhalotra, S. and A. Venkataramani (2013): "Cognitive Development and Infectious Disease: Gender Differences in Investments and Outcomes," IZA Discussion Paper 7833.

Bharadwaj, P. and L. K. Lakdawala (2013): "Discrimination Begins in the Womb: Evidence of Sex-Selective Prenatal Investments," Journal of Human Resources, 48, 71-113.

Bhaskar, V. (2011): "Sex Selection and Gender Balance," American Economic Journal: Microeconomics, 3, 214-244.

Bhat, P. (2002): "Maternal Mortality in India: An Update," Studies in Family Planning, 33, $227-236$.

Bongants, J. and C. Guilmoto (2015): "How Many More Missing Women? Excess Female Mortality and Prenatal Sex Selection, 1970-2050," Population and Development Review, 41, 241269.

Bozzoli, C., A. Deaton, and C. Quintana-Domeque (2009): "Adult Height and Childhood Disease," Demography, 46, 647-669.

Brown, R. (2016): "The Mexican Drug War and Early-Life Health: The Impact of Violent Crime on Birth Outcomes," Unpublish manuscript.

Carranza, E. (2015): "Soil Endowments, Female Labor Force Participation, and the Demographic Deficit of Women in India," American Economic Journal: Applied Economics, 6, 1997-225.

Charles, K. K. And M. Stephens JR. (2006): “Abortion Legalization and Adolescent Substance Abuse," Journal of Law and Economics, 49, 481-505.

Chay, K. Y., J. Guryan, and B. Mazumder (2009): "Birth Cohort and the Black-White Achievement Gap: The Roles of Access and Health Soon After Birth," NBER Working Paper 15078 .

Chiappori, P.-A., B. Fortin, And G. Lacroix (2002): "Household Labor Supply, Sharing Rule and the Marriage Market," Journal of Political Economy, 110, 37-72.

Clark, S. (2000): "Son Preference and Sex Composition of Children: Evidence from India," Demography, 37, 95-108.

Currie, J. And E. Moretti (2007): "Biology as Destiny? Short and Long-Run Determinants of Intergenerational Transmission of Birth Weight," Journal of Labor Economics, 25, 231-264.

Currie, J. And M. Rossin-Slater (2015): "Early-life Origins of Lifecycle Well-being: Research and Policy Implications," Journal of Policy Analysis and Management, 34, 208-242.

Das, M. B. And S. Desai (2003): "Why are Educated Women Less Likely to be Employed in India? Testing Competing Hypotheses," Social Protection Discussion Paper Series 0313, World Bank.

Das Gupta, M. (1987): "Selective Discrimination Against Female Children in Rural Punjab, India," Population and Development Review, 13, 77-100. 
(2010): "Family Systems, Political Systems, and Asia's 'Missing Girls': The Construction of Son Preference and Its Unraveling," Asian Population Studies, 6, 123-152.

Das Gupta, M. And P. Bhat (1997): "Fertility Decline and Increased Manifestation of Sex Bias in India," Population Studies, 51, 307-315.

Das Gupta, M., A. Ebenstein, and E. J. Sharygin (2010): "China's Marriage Market and Upcoming Challenges for Elderly Men," World Bank Policy Research Working Paper 5351.

Das Gupta, M., J. Zhenghua, L. Bohua, X. Zhenming, W. Chung, and B. Hwa-Ok (2003): "Why is Son Preference So Persistent in East and South Asia? A Cross-country Study of China, India and the Republic of Korea," Journal of Development Studies, 40, 153-187.

Dehejia, R. And A. Lleras-Muney (2004): "Booms, Busts, and Babies' Health," The Quarterly Journal of Economics, 119, 1091-1130.

Donohue, J. J. I., J. Grogger, And S. D. Levitt (2009): "The Impact of Legalized Abortion on Teen Childbearing," American Law and Economics Review, 11, $24-46$.

Donohue, J. J. I. And S. D. Levitt (2001): "The Impact of Legalized Abortion on Crime," Quarterly Journal of Economics, 141, 379-420.

Drèze, J. AND R. Khera (2000): "Crime, Gender, and Society in India: Insights from Homicide Data," Population and Development Review, 26, 335-352.

Ebenstein, A. Y. And E. J. Sharygin (2009): "The Consequences of the Missing Girls of China," The World Bank Economic Review, 23, 399-425.

Edlund, L. (1999): "Son Preference, Sex Ratios and Marriage Patterns," Journal of Political Economy, 107, 1275-1304.

Edlund, L., H. Li, J. Yi, And J. Zhang (2007): "Sex Ratios and Crime: Evidence from China's One Child Policy," IZA Discussion Paper 3214.

Epner, J. E. G., H. S. Jonas, And D. L. Seckinger (1998): "Late-term Abortion," Journal of American Medical Association, 280, 724-729.

Gangoli, G. (1998): "Reproduction, Abortion and Women's Health," Social Scientist, 26, 83-105.

George, S. (2006): "Sex Ratio in India, Response to Jha, Prabhat, Rajesh Kumar, Neeraj Dhingra," The Lancet, 367, 1725.

Goldin, C. And L. Katz (2002): "The Power of the Pill: Oral Contraceptives and Women's Career and Marriage Decisions," Journal of Political Economy, 110, 730-770.

Goodkind, D. (1996): "On Substituting Sex Preference Strategies in East Asia: Does Prenatal Sex Selection Reduce Postnatal Discrimination?" Population and Development Review, 22, 111-125.

Grossman, M. and J. Joyce, Theodore (1990): "Unobservables, Pregnancy Resolutions, and Birth Weight Production Functions in New York City," Journal of Political Economy, 98, 9831007.

Grover, A. And R. Vijayvergia (2006): "Sex Ratio in India, Response to Jha, Prabhat, Rajesh Kumar, Neeraj Dhingra," The Lancet, 367, 1726.

Gruber, J., P. B. Levine, And D. Staiger (1999): "Abortion Legalization and Child Living Circumstances: Who is the Marginal Child?" Quarterly Journal of Economics, 114, 263-292.

Hu, L. And A. Schlosser (2012): "Trends in Prenatal Sex Selection and Girls' Nutritional Status in India," CESifo Economic Studies, 58, 348-372. 
(2015): "Prenatal Sex Determination and Girls' Well-Being: Evidence from India," Economic Journal, 125, 1227-1261.

Jayachandran, S. (2016): "Fertility Decline and Missing Women," American Economic Journal: Applied Economics (forthcoming).

JAYACHANDRAn, S. AND I. KuZIEMko (2011): "Why Do Mothers Breastfeed Girls Less Than Boys: Evidence and Implications for Child Health in India," Quarterly Journal of Economics, $126,1485-1538$.

Jayachandran, S., A. Lleras-Muney, And K. Smith (2010): "Modern Medicine and the 20thCentury Decline in Mortality: Evidence on the Impact of Sulfa Drugs," American Economic Journal: Applied Economics, 2, 118-146.

Jensen, R. (2012): "Another Mouth to Feed? The Effects of Fertility on Girls' Malnutrition," CESifo Economic Studies, 58, 322-47.

Joshi, S. And T. P. Schultz (2007): "Family Planning as an Investment in Development: Evaluation of a Program's Consequences in Matlab, Bangladesh," Yale University Economic Growth Center Discussion Paper.

Kaur, R. (2004): "Across-Region Marriages: Poverty, Female Migration and the Sex Ratio," Economic and Political Weekly, 39, 2595-2603.

Klasen, S. (2002): "Low Schooling for Girls, Slower Growth for All? Cross-Country Evidence on the Effect of Gender Inequality in Education on Economic Development," World Bank Economic Review, 16, 345-373.

Kumar, D. (1983): "Male Utopias or Nightmares?" Economic and Political Weekly, 18, 61-64.

LagerlöF, Nils-Petterf, N.-P. (2003): "Gender Equality and Long-Run Growth," Journal of Economic Growth, 8, 403-426.

Lin, M.-J., J.-T. Liu, AND N. Qian (2014): "More Missing Women, Fewer Dying Girls: The Impact of Abortion on Sex Ratios at Birth and Excess Female Mortality in Taiwan," Journal of European Economic Association, 12.

Lleras-Muney, A. And F. Lichtenberg (2005): "The Effect Of Education On Medical Technology Adoption: Are The More Educated More Likely To Use New Drugs?" Annales d'Economie et Statistique.

Low, B. S. (2000): Why Sex Matters: A Darwinian Look at Human Behavior, Princeton, NJ: Princeton University Press.

Mahal, A., A. Varshney, And S. Taman (2006): "Diffusion of Diagnostic Medical Devices and Policy Implications for India," International Journal of Technology Assessment in Health Care, $22,184-190$.

Milazzo, A. (2014): "Why Are Adult Women Missing? Son Preference and Maternal Survival in India," World Bank Policy Research Working Paper 6802.

Miller, G. (2010): "Contraception as Development? New Evidence from Family Planning in Colombia," The Economic Journal, 120, 709-736.

Nandi, A. And A. B. Deolalikar (2013): "Does a legal ban on sex-selective abortions improve child sex ratios? Evidence from a policy change in India," Journal of Development Economics, $103,216-228$.

Oster, E. (2009): "Proximate Sources of Population Sex Imbalances in India," Demography, 46.

Phadke, S. (1997): "Pro Choice or Population Control: A Study of the Medical Termination of Pregnancy Act, Government of India 1971," Re/Productions. 
Pitt, M. And M. R. Rosenzweig (1990): "Estimating the Intrahousehold Incidence of Illness: Child Health and Gender-inequality in the Allocation of Time," International Economic Review, 31, 969-989.

Pop-Eleches, C. (2006): "The Impact of a Change in Abortion Regime on Socio-Economic Outcomes of Children: Evidence from Romania," Journal of Political Economy, 114, 744-773.

Retherford, R. D. AND V. Mishra (2001): "An Evaluation of Recent Estimates of fertility Trends in India," National Family Heath Survey Subject Reports.

Retherford, R. D. And T. Roy (2003): "Factors Affecting Sex-Selective Abortion In India," National Family Heath Survey Bulletin, 17.

Rose, E. (2000): "Gender Bias, Credit Constraints and Time Allocation in Rural India," Economic Journal, 110, 738-758.

Rosenblum, D. (2013): "The effect of fertility decisions on excess female mortality in India," Journal of Population Economics, 26, 147-180.

Rosenzweig, M. And T. P. Schultz (1989): "Schooling, Information and Nonmarket Productivity: Contraceptive Use and Its Effectiveness," International Economic Review, 30, 457-477.

Rosenzweig, M. R. And J. Zhang (2009): "Do Population Control Policies Induce More Human Capital Investment? Twins, Birth Weight and China's "One-Child" policy," The Review of Economic Studies, 76, 1149-1174.

SEn, A. (1990): "More Than 100 Million Women Are Missing," New York Review of Books, 61-66.

SHAPIRA, G. (2013): "How subjective beliefs about HIV infection affect life-cycle fertility : Evidence from rural Malawi," Journal of Human Resources (forthcoming).

SRInivas, M. (1962): Caste in Modern India: And Other Essays, Asia Publishing House, Bombay.

Stillman, M., J. J. Frost, S. Singh, A. M. Moore, and S. Kalyanwala (2014): "Abortion in India: A Literature Review," New York: Guttmacher Institute.

Stopnitzky, Y. (2012): "The Bargaining Power of Missing Women: Evidence from a Sanitation Campaign in India," Unpublished manuscript, University of San Francisco.

Visaria, L. (2005): "Female Deficit in India: Role of Prevention of Sex Selective Abortion Act," mimeo.

Yang, W.-S., H. H. Knöbel, And C.-J. C. Chen (1996): "Gender differences in postneonatal infant mortality in Taiwan," Social Science and Medicine, 43, 1461-1465.

\section{Appendix 1: Variable Descriptions}

- Excess Female Mortality: Female mortality - Male mortality

- Neonatal mortality: Death within one month of birth

- Post-neonatal child mortality: Death after the first month of birth but before age five

- Post $_{t}^{1}$ : indicator variable for $t \in 1985-1994$

- Post $_{t}^{2}$ : indicator variable for $t \in 1995-2005$

- $F_{i}$ : child $i$ is female 
- $G_{j}$ : first child of mother $j$ is female

- Ultra $a_{s t}$ : percentage of births in state $s$ and year $t$ for which the mother reports getting an ultrasound test at some point during the pregnancy

- Allopathic treatment: an indicator variable that equals 1 if a sick child received medical help from an allopathic doctor during the past year, and 0 otherwise

- Exp on education: amount (in Rupees) spent on fees, books, uniform, hostel pocket money, transportation, and private coaching during last year

- Doctors' fees: amount (in Rupees) spent on doctors' fees last year

- Medicine and special food: amount (in Rupees) spent on medicine and special food last year

- Medical exp: amount (in Rupees) spent on doctors' fees, medicine, and special food last year

- Ideal sex ratio: Ideal number of sons/ Ideal number of daughters (as reported by the mother)

- Ideal number of children: Mother's self-reported ideal number of children of any sex

- Education categories: no education, incomplete secondary education, and secondary or higher education

- Categories for mother's birth cohort: 1942-1960, 1961-1970, and 1971-1987

- Categories for Mother's age at birth: 12-15 years, 16-18 years, 19-24 years, 25-30 years, and 31-49 years

- Caste categories: Scheduled Castes (SC), Scheduled Tribes (ST), and Others

- Religion categories: Hindus, Muslims, and Others

\section{Appendix 2: Contributions of Breastfeeding and Vaccination}

Our estimates suggest that ultrasound access reduced post-neonatal child mortality by 1.490 p.p. (column (4) in panel B of Table 2) and increased the likelihood of being breastfed for at least 24 months by 27.5 p.p. (triple-interaction coefficient in column (5) of Panel B in Table 3). Since there was no significant effect on breastfeeding during the first year of birth, we assume that the 27.5 p.p. increase took place between 12 and 24 months from birth. According to the World Health Organization (2000), breastfeeding between the ages one and two decreases mortality by 50 percent relative to no breastfeeding. Applying this factor to the share of children who are being breastfed and the mortality rate during $12-24$ months, ${ }^{57}$ the implied mortality rate for breastfed children is

\footnotetext{
${ }^{57}$ We assume that the share of children who are being breastfed and the mortality rate during $12-24$ months are the same as those for 12-36 months used in Jayachandran and Kuziemko (2011).
} 
1.35 percent $^{58}$ and is 2.7 percent $(1.35 * 2=2.7)$ for non-breastfed children in the $12-24$ months range. This implies that not being breastfed during the 12-24 months age range increases the risk of mortality by 1.35 p.p. $(2.7-1.35=1.35)$. If breastfeeding disparities (during $12-24$ months) were the only cause of post-neonatal child mortality differences by gender, the EFM decline due to improvements in the breastfeeding gender gap would be 0.16 p.p. $(0.275 * 1.35=0.371)$. Thus breastfeeding explains about 25 percent $(0.371 / 1.490=0.249)$ of the estimated EFM decline.

Moreover, we find that ultrasound availability increased the probability of a child receiving at least one vaccination by 0.075 to 0.112 (triple-interaction coefficient in column (6) of Panel A in Table 3). The average number of vaccinations (conditional on receiving at least one vaccination) for girls preceded by a firstborn girl during the early diffusion period is 6.64 in NFHS data. Thus the estimated effects for at least one vaccination translate into an average increase in the number of vaccinations of $0.498(6.64 * 0.075=0.498)$ to $0.744(6.64 * 0.112=0.744)$. Oster $(2009)$ suggests that each vaccination reduces mortality during ages 1 to 4 by 0.26 p.p.. Thus the implied effect on EFM through vaccination is 0.129 p.p. $(0.26 * 0.498=0.129)$ to 0.193 p.p. $(0.26 * 0.744=0.193)$, which translates into 8.7 percent $(0.129 / 1.490=0.087)$ to 13 percent $(0.193 / 1.490=0.130)$ of the decline in EFM.

Note that the mortality measure is 12-36 months in Jayachandran and Kuziemko (2011) and is 1-4 years in Oster (2009). However, any exogenous change in these mortality measures would generate an almost one-to-one change in the mortality measure we use, i.e., death during 1 month to 5 years of birth.

\section{Appendix 3: Substitution of Prenatal for Postnatal Girl Mortality}

Here we use our regression estimates to calculate the magnitude of substitution from postnatal EFM to prenatal sex-selection as the ratio of the number of girls selectively aborted and the number of girls who survived due to ultrasound (and would have otherwise died postnatally). Let:

- $N$ : annual number of births in India

- $N_{F G}$ : annual number of births in India that are preceded by a firstborn girl

- $M_{F G}$ : fraction of births that are male among $N_{F G}$

- $F_{F G}$ : fraction of births that are female among $N_{F G}$

- $\Delta$ : the pre-post (counterfactual) difference

Then, the number of "missing girls" each year, i.e., the difference between the expected number of female births (given the observed number of male births and the natural sex ratio at birth) and

\footnotetext{
${ }^{58}$ Solving $0.481 x+2(1-0.481) x=2.05$ yields $x=1.35$, where 0.481 is the fraction of children aged 12 to 36 months that are being breastfed in the sample analyzed by Jayachandran and Kuziemko (2011).
} 
the observed number of female births is given by:

$$
\underbrace{\frac{0.49}{0.51}\left(N_{F G} * M_{F G}\right)}_{\text {Expected \#female births given the observed \#male births }}-\underbrace{N_{F G} * F_{F G}}_{\text {Observed \#female births }}=N_{F G}\left(\frac{0.49}{0.51}-\frac{F_{F G}}{0.51}\right)
$$

The change in the annual number of missing girls due to ultrasound access is then calculated as the difference between the number of missing girls during the pre- and the post-ultrasound periods:

$$
\begin{aligned}
& N_{F G, \text { post }}\left(\frac{0.49}{0.51}-\frac{F_{F G, \text { post }}}{0.51}\right)-N_{F G, \text { pre }}\left(\frac{0.49}{0.51}-\frac{F_{F G, \text { pre }}}{0.51}\right) \\
= & N_{F G, \text { post }} * \frac{0.49}{0.51}-N_{F G, \text { post }} * \frac{F_{F G, \text { post }}}{0.51}-N_{F G, \text { pre }} * \frac{0.49}{0.51}+N_{F G, \text { pre }} * \frac{F_{F G, \text { pre }}}{0.51} \\
= & \Delta N_{F G} * \frac{0.49}{0.51}-N_{F G, \text { post }} * \frac{F_{F G, \text { post }}}{0.51}+N_{F G, \text { pre }} * \frac{F_{F G, \text { pre }}}{0.51}
\end{aligned}
$$

(Adding and subtracting $N_{F G, p o s t} * \frac{F_{F G, p r e}}{0.51}$ )

$$
\begin{aligned}
& =\Delta N_{F G} * \frac{0.49}{0.51}-N_{F G, \text { post }} * \frac{F_{F G, \text { post }}}{0.51}+N_{F G, \text { post }} * \frac{F_{F G, p r e}}{0.51}-N_{F G, \text { post }} * \frac{F_{F G, \text { pre }}}{0.51}+N_{F G, \text { pre }} * \frac{F_{F G, p r e}}{0.51} \\
& =\Delta N_{F G} * \frac{0.49}{0.51}+N_{F G, \text { post }} * \Delta F_{F G} * \frac{-1}{0.51}-\Delta N_{F G} * \frac{F_{F G, p r e}}{0.51} \\
& =\underbrace{\Delta N_{F G} *\left(\frac{0.49}{0.51}-\frac{F_{F G, p r e}}{0.51}\right)}_{\text {(conception effect) }}+\underbrace{N_{F G, \text { post }} * \Delta F_{F G} * \frac{-1}{0.51}}_{\text {(sex-selective abortions effect) }}
\end{aligned}
$$

The change in the number of missing girls due to ultrasound can be decomposed into a "conception effect" and a "sex-selective abortion effect," as defined above. The sex-selective abortion effect refers to the fact that a smaller fraction of post-ultrasound births preceded by a firstborn girl are now female, where as the conception effect is driven by the change in the number of births that are preceded by a firstborn girl.

The number of excess postnatal female deaths in a year equals:

$$
N_{F G} * F_{F G} * E F M_{F G}
$$

where $E F M_{F G}$ refers to the difference between the probability of death by age 5 among children preceded by a firstborn girl and a firstborn boy.

The change in the number of excess postnatal female deaths can thus be written as:

$$
\begin{aligned}
& N_{F G, \text { post }} * F_{F G, \text { post }} * E F M_{F G, \text { post }}-N_{F G, \text { pre }} * F_{F G, \text { pre }} * E F M_{F G, \text { pre }} \\
= & \underbrace{N_{F G, \text { post }} * F_{F G, \text { post }} *\left(\Delta E F M_{F G}\right)}_{\text {(behavioral effect) }}+\underbrace{N_{F G, \text { post }} *\left(\Delta F_{F G}\right) * E F M_{F G, \text { pre }}}_{\text {(mechanical sex-selection effect) }}+\underbrace{\left(\Delta N_{F G}\right) * F_{F G, p r e} * E F M_{F G, p r e}}_{\text {(conception effect) }}
\end{aligned}
$$

The change in the number of excess postnatal female deaths can also be decomposed into three 
components: the "behavioral effect" refers to the EFM decline due to, say, better postnatal health investments in girls in the post-ultrasound period; the "mechanical sex-selection effect" is driven by the decrease in the fraction of post-ultrasound births that are preceded by a firstborn girl; and the "conception effect" that reflects the change in the number of births that are preceded by a firstborn girl itself.

The table below uses the aforementioned formulae to calculate the number of births preceded by a firstborn girl during the pre-ultrasound (in column (1)), during the late diffusion period (in column $(2)$ ), and the change in the number of missing girls as the difference between columns (1) and (2) in column (3). EF $M_{F G}$ in column (1) is the coefficient of Firstborn girl * Female and in column (2) is the coefficient of Firstborn girl * Female * Post2 from column (4) in panel B of Table 2. During the pre-ultrasound period, the fraction of females in births preceded by a firstborn girl was 47.9 percent. Ultrasound access decreased this fraction by 1.8 p.p. ${ }^{59}$ We calculate $\frac{N_{F G}}{N}$ from the entire sample since the pre-ultrasound sample of births is likely to be underreported due to recall bias. The number of births in column (1), $N$, is the 1995 figure from UN Statistics Division. The number of mothers, $m$, is obtained as $\frac{N}{\text { General Fertility Rate }}$ using the general fertility rate estimated from NFHS-2 by Retherford and Mishra (2001) as 131.53 per 1000 women. $\Delta N_{F G}$ is estimated to be equal to -0.0063 as is obtained from the fertility equation using the conversion method described below.

Thus, the number of "missing girls" increased by 305,496 per year due to ultrasound access. The estimated decline in EFM, on the other hand, implies that the annual number of postnatal female deaths by age 5 fell by 60,879 . The ratio of increase in sex-selective abortions and the decrease in EFM is 5.02, i.e., for every 5.02 girls aborted, one girl survived due to access to ultrasound technology.

\section{- Conversion of treatment effect from the fertility specification (2) to expected number of children born in a year.}

Let $\mathrm{N}$ to be the number of total children born in a single year. Then

$$
N=N_{1}+N_{F G}+N_{F B}
$$

where $N_{1}$ is the number of firstborn children and $N_{F B}$ and $N_{F G}$ are the number of second or higher order births respectively preceded by a firstborn girl and a firstborn boy.

- $m_{F G}$ : number of women in the 15-49 age-group with a firstborn girl

- $S_{a, F G}$ and $S_{a, F B}$ : share of women aged $a$ who have a firstborn girl and firstborn boy, respectively

\footnotetext{
${ }^{59}$ This number is derived from a regression specification similar to the one estimated by Bhalotra and Cochrane (2010). These results are reported in Table A.18.
} 
Table: Decomposition and Simulation

\begin{tabular}{|c|c|c|c|}
\hline & $\begin{array}{c}\text { Pre } \\
\text { (Pre-ultrasound) } \\
(1)\end{array}$ & $\begin{array}{c}\text { Post } \\
\text { (Late diffusion) } \\
(2)\end{array}$ & $\begin{array}{c}\Delta \\
(\text { Post - Pre }) \\
(3)\end{array}$ \\
\hline \multicolumn{4}{|l|}{ A. Regression Estimates } \\
\hline $\begin{array}{l}E F M_{F G} \\
F_{F G} \\
\frac{N_{F G}}{N}\end{array}$ & $\begin{array}{l}0.0176 \\
0.4790 \\
0.3340 \\
\end{array}$ & $\begin{array}{l}0.0040 \\
0.4605\end{array}$ & $\begin{array}{l}-0.0136 \\
-0.0185\end{array}$ \\
\hline \multicolumn{4}{|l|}{ B. Decomposition } \\
\hline $\begin{array}{l}N \\
m(\# \text { mothers }) \\
m_{F G}(\# \text { mothers with a firstborn girl }) \\
N_{F G}\end{array}$ & $\begin{aligned} & 27,300,000 \\
\approx & 207,557,211 \\
\approx & 0.3340^{*} m \\
& 0.3340^{*}(N) \\
= & 9,118,200\end{aligned}$ & $\begin{array}{c}0.3340 *(N)-0.0063^{*} m_{F G} \\
=8,681,458\end{array}$ & $\begin{array}{l}-0.0063^{*} m_{F G} \\
=-436,742\end{array}$ \\
\hline $\begin{array}{l}\Delta \text { number of excess postnatal fem } \\
\text { (1) } N_{F G, \text { post }} * F_{F G, \text { post }} *\left(\Delta E F M_{F G}\right) \\
\text { (2) } N_{F G, \text { post }} *\left(\Delta F_{F G}\right) * E F M_{F G, \text { pre }} \\
\text { (3) }\left(\Delta N_{F G}\right) * F_{F G, \text { pre }} * E F M_{F G, \text { pre }} \\
\text { (4) }=(1)+(2)+(3)\end{array}$ & le deaths: & $\begin{array}{l}\approx-54,370 \\
\approx-2,827 \\
\approx-3,682 \\
=-60,879\end{array}$ & \\
\hline $\begin{array}{l}\Delta \text { number of missing girls: } \\
\text { (5) } \Delta N_{F G} *\left(\frac{0.49}{0.51}-\frac{F_{F G, p r e}}{0.51}\right) \\
\text { (6) } N_{F G, \text { post }} * \Delta F_{F G} * \frac{-1}{0.51} \\
\text { (7) }=(5)+(6)\end{array}$ & & $\begin{array}{l}\approx-9,420 \\
\approx 314,916 \\
=305,496\end{array}$ & \\
\hline $\begin{array}{l}\Delta \text { number of missing girls / } \Delta \text { EF } \\
(8)=(7) /(4)\end{array}$ & & $=-5.02$ & \\
\hline
\end{tabular}

- $P_{a, F G}$ and $P_{a, F B}$ : probability that a women who has a firstborn girl (firstborn boy) and who is of age $a$ in a given year gives birth in that year

$$
\begin{gathered}
\Longrightarrow N_{F G}=\left(\sum_{a=15}^{a=49} P_{a, F G} S_{a, F G}\right) * m_{F G} \\
\Delta N_{F G}=N_{F G, \text { post }}-N_{F G, \text { pre }} \\
=\left(\sum_{a=15}^{a=49} P_{a, F G, \text { post }} S_{a, F G, \text { post }}-\sum_{a=15}^{a=49} P_{a, F G, \text { pre }} S_{a, F G, \text { pre }}\right) * m_{F G} \\
=\left(\sum_{a=15}^{a=49}\left(P_{a, F G, \text { post }}-P_{a, F G, \text { pre }}\right) S_{a, F G}\right) * m_{F G}
\end{gathered}
$$

assuming that $S_{a, F G, p r e}=S_{a, F G, p o s t}=S_{a, F G}$. This assumption is reasonable since ultrasound access had no effect on the decision to have a first birth or its sex ratio. 
The treatment-on-the-treated effect we estimated in equation (2) equals

$$
\begin{aligned}
& E[N \mid \text { post }, F G]-E[N \mid \text { pre }, F G] \\
= & \sum_{a=15}^{a=49}\left(P_{a, F G, \text { post }}-P_{a, F G, \text { pre }}\right) * S_{49, F G} \\
+ & \sum_{a=15}^{a=48}\left(P_{a, F G, \text { post }}-P_{a, F G, p r e}\right) * S_{48, F G} \\
+ & \sum_{a=15}^{a=47}\left(P_{a, F G, \text { post }}-P_{a, F G, p r e}\right) * S_{47, F G} \\
+ & \ldots
\end{aligned}
$$

If we assume uniform impact of ultrasound access on the probability of birth across age-groups, i.e., $P_{a, F G, p o s t}-P_{a, F G, p r e}=P_{F G, p o s t}-P_{F G, p r e}$ and assuming $S_{a, F G}=S_{F G}$ :

$$
\begin{aligned}
E[N \mid \text { post }, F G]- & E[N \mid \text { pre }, F G]=S_{F G} *\left(P_{F G, \text { post }}-P_{F G, \text { pre }}\right) *(1+2+3+\ldots+35) \\
& \sum_{a=15}^{a=49}\left(P_{a, F G, \text { post }}-P_{a, F G, \text { pre }}\right) S_{a, F G} \\
= & S_{F G} *\left(P_{F G, \text { post }}-P_{F G, \text { pre }}\right) * 35 \\
= & \frac{35}{(1+\ldots+35)} *(E[N \mid \text { post }, F G]-E[N \mid \text { pre }, F G]) \\
= & \frac{35}{630} *(E[N \mid \text { post }, F G]-E[N \mid \text { pre }, F G]) \\
& \approx 0.056 *(E[N \mid \text { post }, F G]-E[N \mid \text { pre }, F G]) \\
& \approx 0.056 *(-0.112)=-0.0063
\end{aligned}
$$




\section{Figures}

Figure 1: Ultrasound use by mothers and supply of ultrasound scanners in India
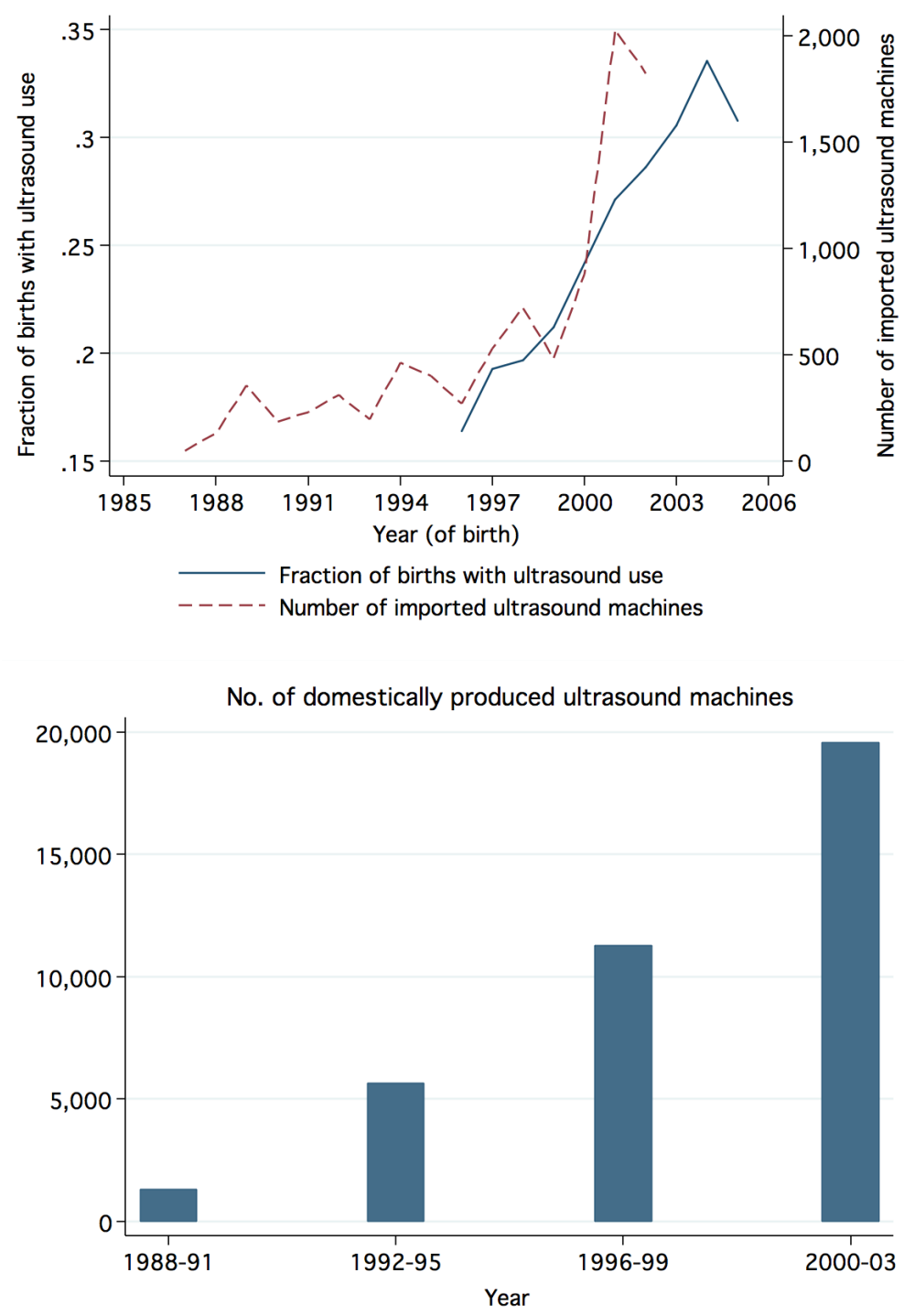

NOTES: (1) The solid line in the top graph plots the fraction of births in a year for which the mother reports getting an ultrasound test at some point during the pregnancy (the denominator equals the number of births with a non-missing response on ultrasound use). The relevant question was not asked in NFHS-1 but in NFHS-2 and NFHS-3, data on ultrasound use was collected for births since January 1995 and January 2001, respectively. The years 1995 and 2000 have been dropped due to extremely small sample sizes. (2) The dashed line in the top graph plots the number of ultrasound scanners imported at the national level, the first records of which appear in the import data in 1987; indeed, there was no category coding these scanners before then (Source: Mahal et al. (2006)). (3) The bars in the bottom graph plot the number of ultrasound machines produced domestically in India. Data source: George (2006). 
Figure 2: Number of abortions and ultrasound use by mothers in India
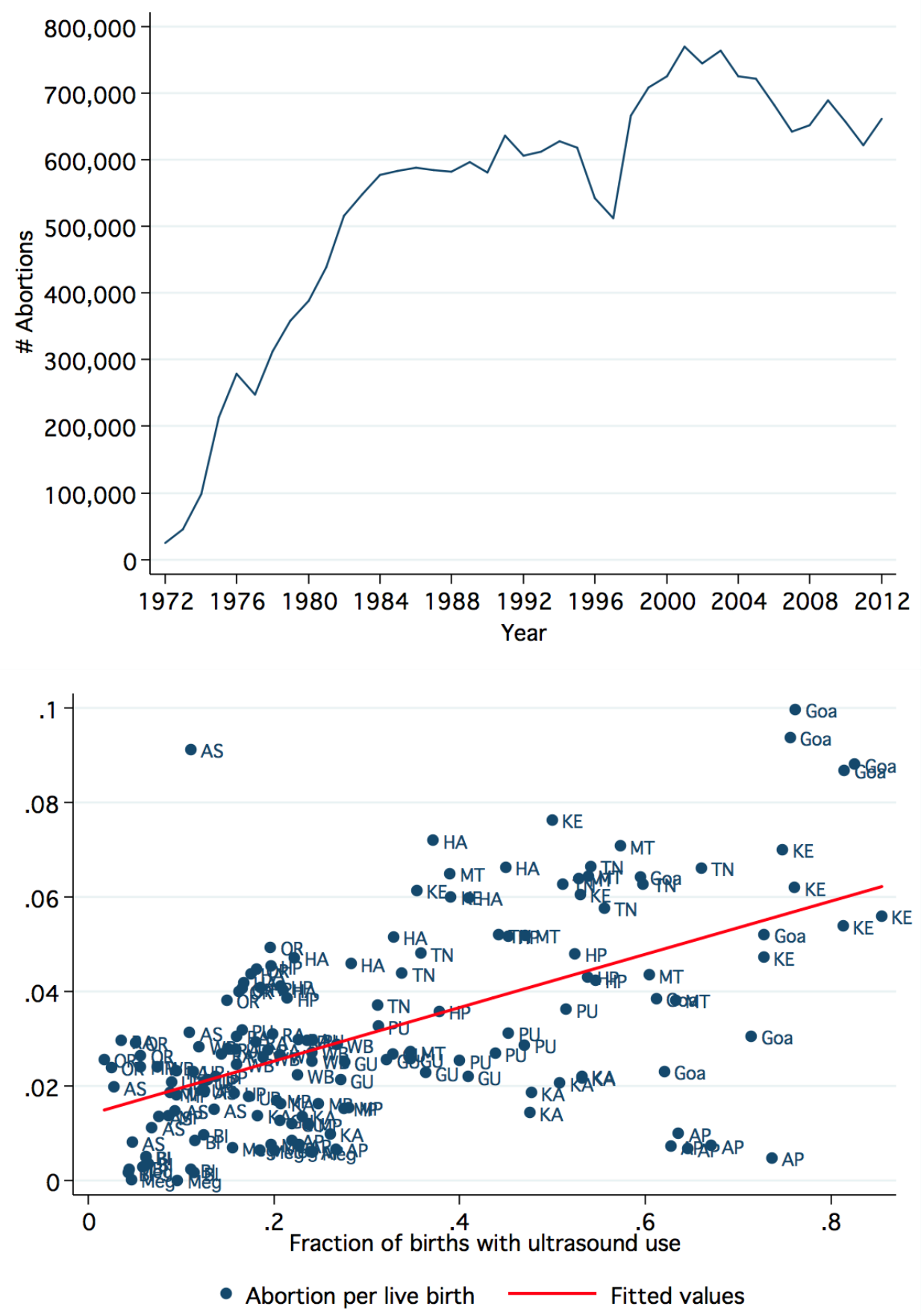

NOTES: The top graph plots the officially reported number of abortions (both sex-selective and other abortions) by state and year using data from http://www.johnstonsarchive.net/policy/ abortion/india/ab-indias.html. The bottom graph plots the state-year variation in the officially reported number of abortions and the fraction of births in a state-year for which the mother reports getting an ultrasound test at some point during the pregnancy (other details in Figure 1 notes). 
Figure 3: Trends in proportion of females at birth by birth order and sex composition of older siblings

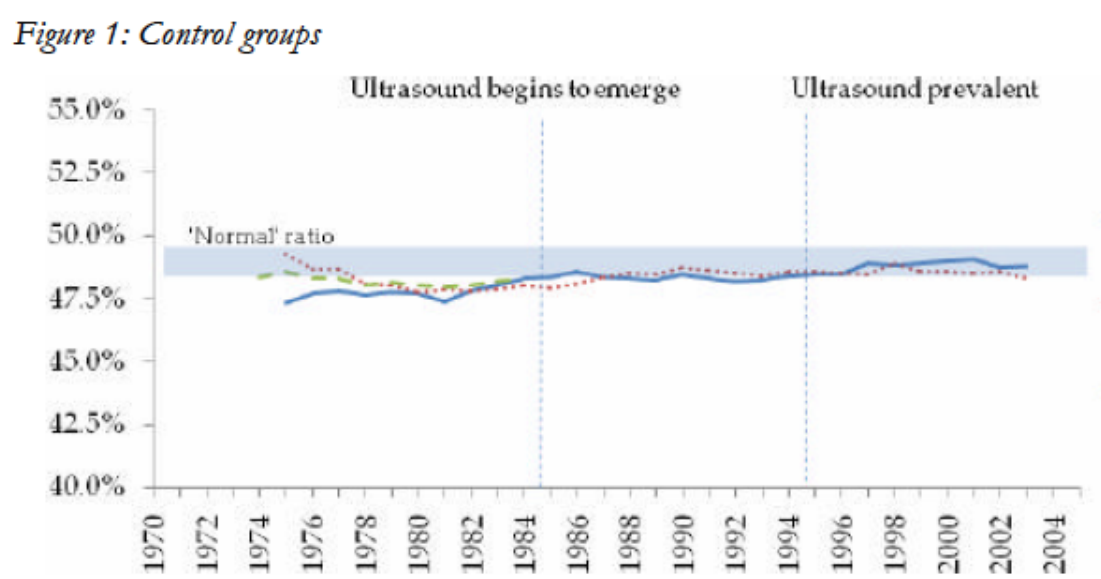

Figure 2: Second births (5-year moving average)

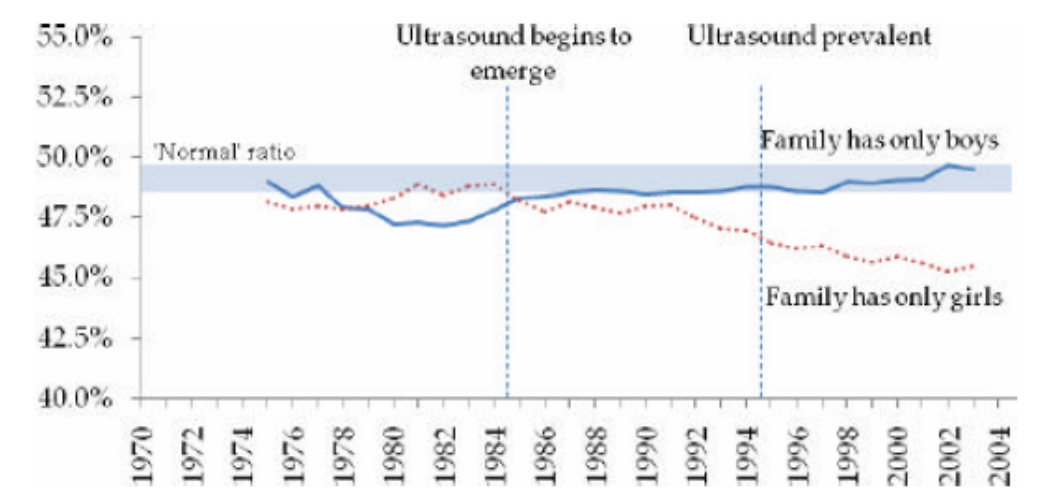

Figure 3: Third births (5-year moving average)

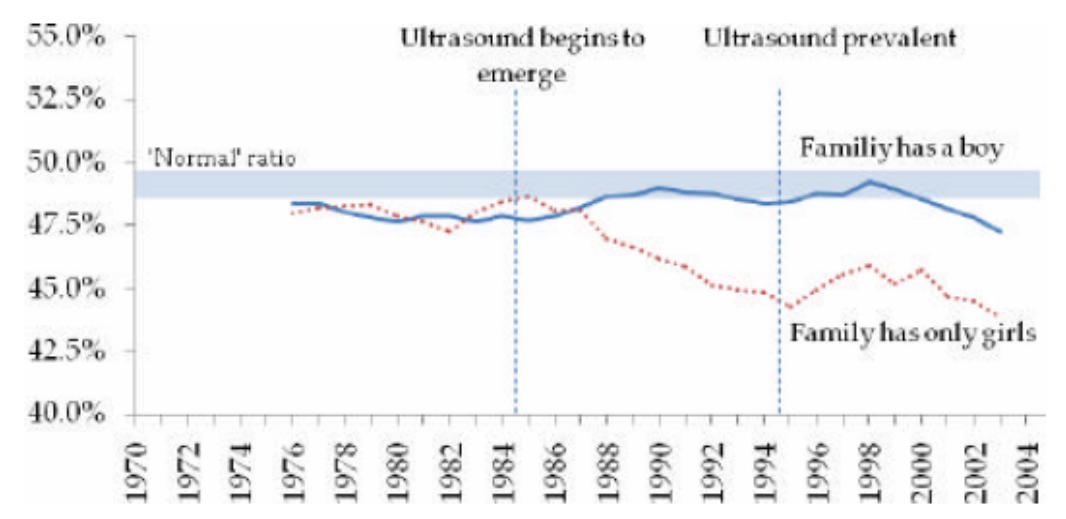

Figure 4: Fourth births (5-year moving average)
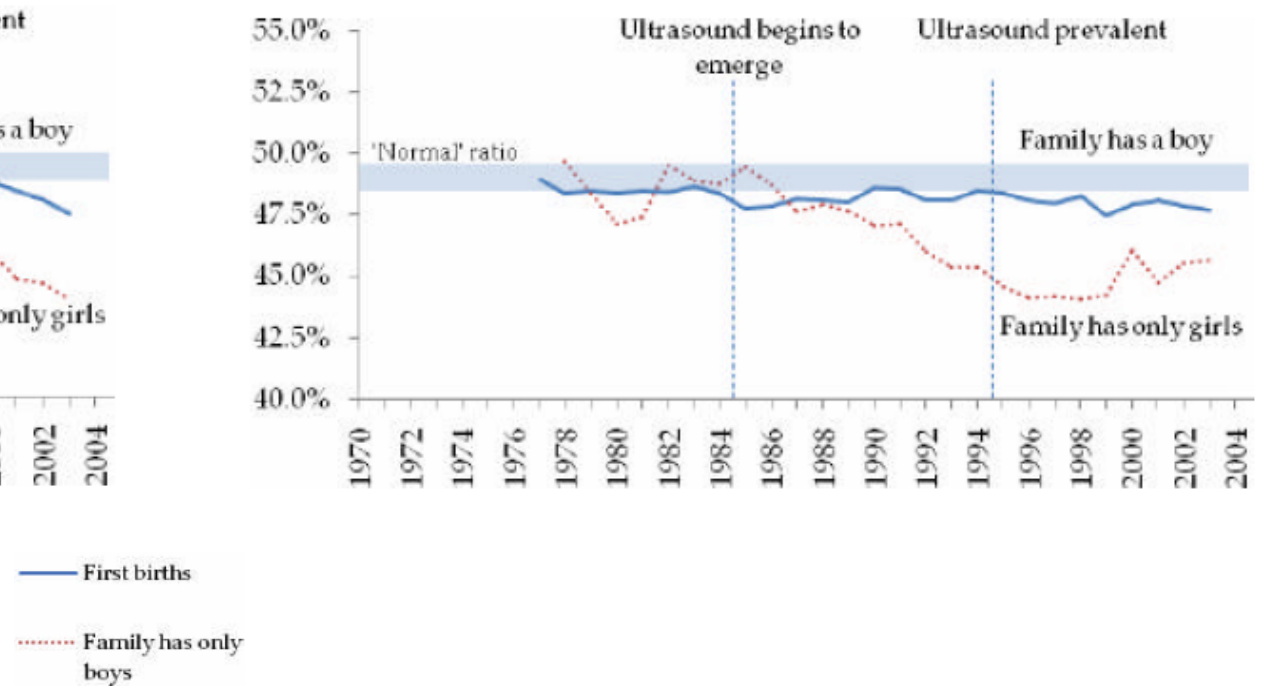

NOTES: This figure reproduces Figures 1-4 from Bhalotra and Cochrane (2010). Figure 1 shows the evolution of fraction of female births over time for first births and families that have only boys. In figures 2, 3, and 4 the trend in fraction of female births is plotted respectively for second, third, and fourth births separately for families that have one boy and families with no boys. In all cases, the y-axis shows the 5-year moving average of the fraction of female births. The figures show that the sex ratio at birth in families without sons diverges from the sex ratio in families with sons after the introduction of ultrasound. It also shows that families with sons have sex ratios in the biologically normal range. 
Figure 4: Post-neonatal excess female child mortality, by firstborn's sex
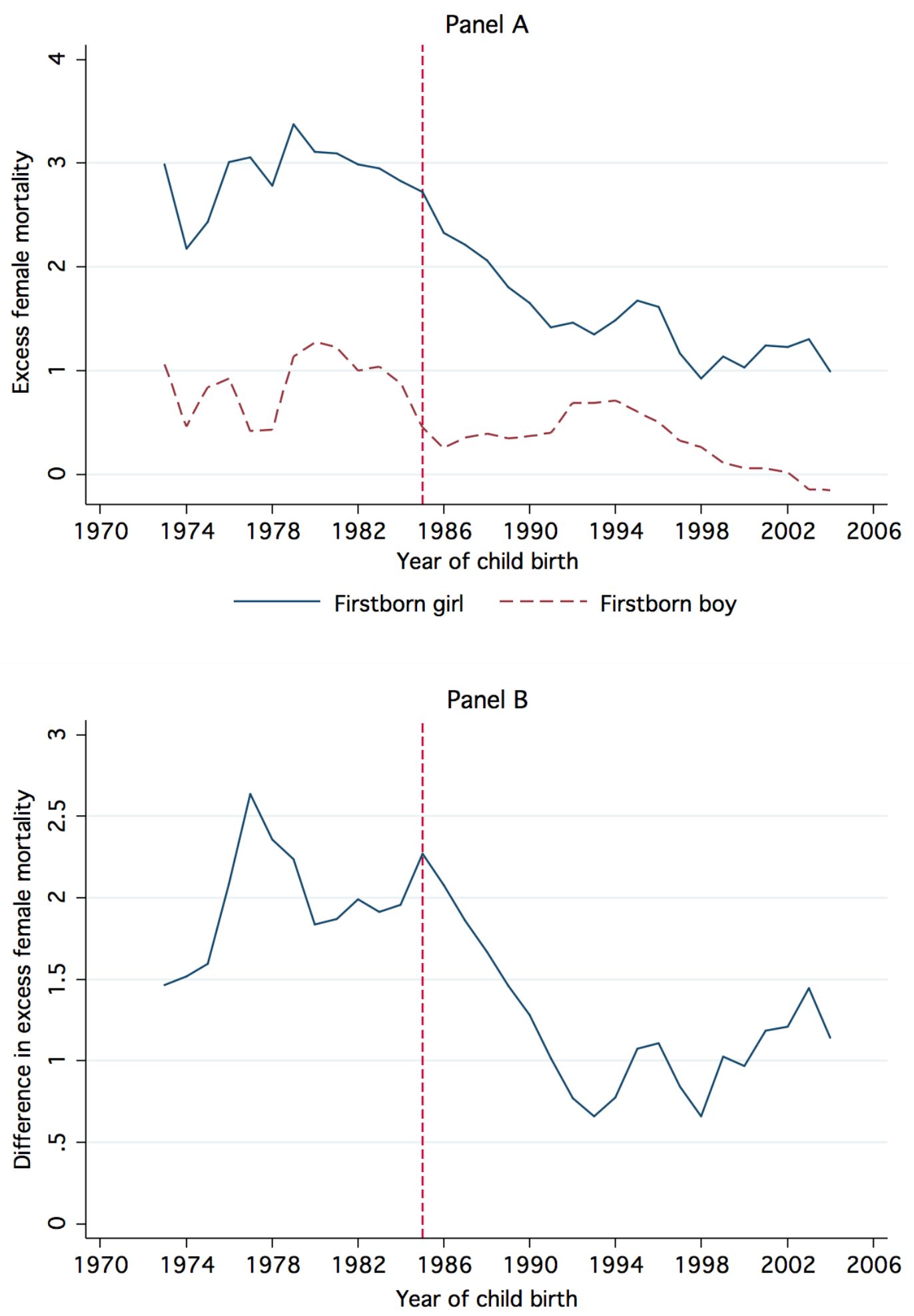

NOTES: Post-neonatal excess female child mortality equals the percentage of female births that die minus the percentage of male births that die after the first month of birth but before age five. The graph in Panel A plots the 5-year moving average of EFM among families with a firstborn girl and families with a firstborn boy; Panel B plots the EFM for births in firstborn girl families minus the EFM for births in firstborn boy families. The vertical line splits the years into pre- ayd post-ultrasound periods. 


\section{Tables}

Table 1: Unadjusted mortality rates for treatment and control groups (\%)

\begin{tabular}{|c|c|c|c|c|c|c|}
\hline & \multicolumn{3}{|c|}{ Firstborn boy families } & \multicolumn{3}{|c|}{ Firsborn girl families } \\
\hline & (1) & $(2)$ & $(3)$ & $(4)$ & $(5)$ & $(6)$ \\
\hline & Male & Female & $\begin{array}{c}\text { EFM } \\
(2)-(1)\end{array}$ & Male & Female & $\begin{array}{c}\text { EFM } \\
(5)-(4)\end{array}$ \\
\hline \multicolumn{7}{|c|}{ 1. Pre-ultrasound: 1973-1984 } \\
\hline Neonatal & 7.326 & 5.536 & -1.79 & 5.060 & 5.035 & -0.025 \\
\hline Post-neonatal Child & 6.169 & 7.052 & 0.883 & 5.721 & 8.771 & 3.050 \\
\hline $\mathrm{N}$ & 43,833 & 40,425 & & 17,252 & 15,908 & \\
\hline \multicolumn{7}{|c|}{ 2. Early diffusion period: $1985-1994$} \\
\hline Neonatal & 5.692 & 4.528 & -1.164 & 4.439 & 4.352 & -0.087 \\
\hline Post-neonatal Child & 4.380 & 4.880 & 0.500 & 4.246 & 6.021 & 1.775 \\
\hline $\mathrm{N}$ & 82,579 & 77,699 & & 43,547 & 39,519 & \\
\hline \multicolumn{7}{|c|}{ 3. Late diffusion period: $1995-2005$} \\
\hline Neonatal & 4.434 & 3.627 & -0.807 & 3.450 & 3.554 & 0.104 \\
\hline Post-neonatal Child & 2.507 & 2.658 & 0.151 & 2.523 & 3.702 & 1.179 \\
\hline $\mathrm{N}$ & 46,504 & 44,196 & & 27,713 & 24,141 & \\
\hline
\end{tabular}

NOTES: This table reports the percentage of second- and higher-order children, by firstborn sex and child gender, who suffered neonatal or post-neonatal child mortality over the three time-periods in the sample. Columns (3) and (4) report the difference between the mortality numbers in columns (1) - (2) and (4) - (5), respectively. 
Table 2: Excess female mortality

\begin{tabular}{|c|c|c|c|c|}
\hline A. Neonatal Mortality & (1) & $(2)$ & (3) & (4) \\
\hline Firstborn girl * Female & $\begin{array}{c}1.754^{* * *} \\
(0.379)\end{array}$ & $\begin{array}{c}1.705^{* * *} \\
(0.373)\end{array}$ & $\begin{array}{c}1.350^{* * *} \\
(0.382)\end{array}$ & $\begin{array}{c}0.862^{* *} \\
(0.417)\end{array}$ \\
\hline Firstborn girl $*$ Female $*$ Post 1 & $\begin{array}{l}-0.698 \\
(0.426)\end{array}$ & $\begin{array}{l}-0.665 \\
(0.422)\end{array}$ & $\begin{array}{l}-0.681 \\
(0.422)\end{array}$ & $\begin{array}{l}-0.213 \\
(0.460)\end{array}$ \\
\hline Firstborn girl $*$ Female $^{*}$ Post2 & $\begin{array}{c}-0.872^{* *} \\
(0.353)\end{array}$ & $\begin{array}{c}-0.875^{* *} \\
(0.348)\end{array}$ & $\begin{array}{c}-0.895^{* *} \\
(0.357)\end{array}$ & $\begin{array}{l}-0.369 \\
(0.429)\end{array}$ \\
\hline $\mathrm{N}$ & \multicolumn{4}{|c|}{503,316} \\
\hline Baseline mean & \multicolumn{4}{|c|}{1.765} \\
\hline B. Post-Neonatal Child Mortality & (1) & $(2)$ & (3) & $(4)$ \\
\hline Firstborn girl * Female & $\begin{array}{c}2.171^{* * * *} \\
(0.333)\end{array}$ & $\begin{array}{c}2.123^{* * *} \\
(0.332)\end{array}$ & $\begin{array}{c}1.758^{* * *} \\
(0.313)\end{array}$ & $\begin{array}{c}1.476^{* * *} \\
(0.383)\end{array}$ \\
\hline Firstborn girl $*$ Female $*$ Post 1 & $\begin{array}{c}-0.919^{* *} \\
(0.402)\end{array}$ & $\begin{array}{c}-0.872^{* *} \\
(0.401)\end{array}$ & $\begin{array}{c}-0.954^{* *} \\
(0.404)\end{array}$ & $\begin{array}{c}-0.773 \\
(0.474)\end{array}$ \\
\hline Firstborn girl ${ }^{*}$ Female $*$ Post2 & $\begin{array}{c}-1.191^{* * *} \\
(0.397)\end{array}$ & $\begin{array}{c}-1.229^{* * *} \\
(0.380)\end{array}$ & $\begin{array}{c}-1.355^{* * *} \\
(0.362)\end{array}$ & $\begin{array}{c}-1.490^{* *} \\
(0.598)\end{array}$ \\
\hline $\mathrm{N}$ & \multicolumn{4}{|c|}{478,843} \\
\hline Baseline mean & \multicolumn{4}{|c|}{2.167} \\
\hline Female ${ }^{*}$ Post1 and Female * Post2 & $\mathrm{x}$ & $\mathrm{x}$ & & \\
\hline Firstborn Girl * Post1 and Firstborn Girl * Post2 & $\mathrm{x}$ & $\mathrm{x}$ & & \\
\hline$X_{i j t}$ & & $\mathrm{x}$ & $\mathrm{x}$ & $\mathrm{x}$ \\
\hline Firstborn Girl x Birth year FE & & & $\mathrm{x}$ & $\mathrm{x}$ \\
\hline Female $\mathrm{x}$ Birth year FE & & & $\mathrm{x}$ & $\mathrm{x}$ \\
\hline Female $\mathrm{x}$ State FE & & & $\mathrm{x}$ & $\mathrm{x}$ \\
\hline Female $\mathrm{x}$ Birth order FE & & & $\mathrm{x}$ & $\mathrm{x}$ \\
\hline Birth order x Birth year FE & & & $\mathrm{x}$ & $\mathrm{x}$ \\
\hline Birth order x State FE & & & $\mathrm{x}$ & $\mathrm{x}$ \\
\hline State $\mathrm{x}$ Birth year FE & & & $\mathrm{x}$ & $\mathrm{x}$ \\
\hline Firstborn girl x State FE & & & $x$ & $x$ \\
\hline Firstborn girl x Birth order FE & & & $\mathrm{x}$ & $\mathrm{x}$ \\
\hline Mother FE & & & & $\mathrm{x}$ \\
\hline
\end{tabular}

NOTES: This table reports estimates of specification (1). Each column within a panel is a separate regression. The outcomes are mortality rates, as \% of births that do not survive. We always control for Female and fixed effects (FE) for birth year and birth order and for Firstborn girl and state FE in columns (1)-(3). The vector $X_{i j t}$ comprises mother's age at birth and, except in column (4), household wealth quintiles, caste, religion, residence in a rural area, educational attainment of child's parents, and mother's birth cohort. Standard errors in parentheses are clustered by state. Baseline mean refers to the pre-ultrasound difference between EFM in firstborn-girl and firstborn-boy families. ${ }^{* * *} 1 \%, * * 5 \%, * 10 \%$. 
Table 3: Postnatal health investments

\begin{tabular}{|c|c|c|c|c|c|c|c|c|c|}
\hline & (1) & $(2)$ & $(3)$ & $(4)$ & $(5)$ & $(6)$ & $(7)$ & $(8)$ & $(9)$ \\
\hline Panel A: & \multicolumn{3}{|c|}{ Months breastfed } & \multicolumn{3}{|c|}{ Received $\geq$ one vaccine } & \multicolumn{3}{|c|}{ Rupees spent on illness last year } \\
\hline First girl* Female & $\begin{array}{c}-5.124^{* *} \\
(1.879)\end{array}$ & $\begin{array}{c}-4.451^{* *} \\
(1.846)\end{array}$ & $\begin{array}{c}-3.851^{* *} \\
(1.747)\end{array}$ & $\begin{array}{c}-0.130^{* *} \\
(0.051)\end{array}$ & $\begin{array}{c}-0.091^{* *} \\
(0.038)\end{array}$ & $\begin{array}{l}-0.067 \\
(0.048)\end{array}$ & $\begin{array}{l}-27.150 \\
(50.961)\end{array}$ & $\begin{array}{l}-15.583 \\
(50.910)\end{array}$ & $\begin{array}{l}-87.599 \\
(56.788)\end{array}$ \\
\hline First girl ${ }^{*}$ Female ${ }^{*}$ Post 1 & $\begin{array}{l}4.739 * * \\
(2.012)\end{array}$ & $\begin{array}{l}4.040^{*} \\
(2.042)\end{array}$ & $\begin{array}{c}2.396 \\
(2.068)\end{array}$ & $\begin{array}{c}0.112^{* *} \\
(0.049)\end{array}$ & $\begin{array}{l}0.096^{*} \\
(0.048)\end{array}$ & $\begin{array}{l}0.075^{*} \\
(0.043)\end{array}$ & $\begin{array}{c}17.108 \\
(68.645)\end{array}$ & $\begin{array}{c}6.186 \\
(65.100)\end{array}$ & $\begin{array}{c}70.589 \\
(80.108)\end{array}$ \\
\hline First girl ${ }^{*}$ Female $^{*}$ Post2 & $\begin{array}{c}4.162 \\
(3.140)\end{array}$ & $\begin{array}{c}3.735 \\
(2.594)\end{array}$ & $\begin{array}{c}1.536 \\
(2.499)\end{array}$ & $\begin{array}{l}0.094^{*} \\
(0.051)\end{array}$ & $\begin{array}{l}0.068^{*} \\
(0.033)\end{array}$ & $\begin{array}{l}0.112^{* *} \\
(0.041)\end{array}$ & $\begin{array}{c}44.955 \\
(50.283)\end{array}$ & $\begin{array}{c}31.177 \\
(51.044)\end{array}$ & $\begin{array}{l}106.444 \\
(64.065)\end{array}$ \\
\hline $\begin{array}{l}\mathrm{N} \\
\text { Baseline mean }\end{array}$ & \multicolumn{3}{|c|}{13,084} & \multicolumn{3}{|c|}{20,561} & \multicolumn{3}{|c|}{$\begin{array}{c}15,156 \\
-111.58\end{array}$} \\
\hline Panel B: & \multicolumn{3}{|c|}{ Breastfed $\geq 12$ months } & \multicolumn{3}{|c|}{ Breastfed $\geq 24$ months } & \multicolumn{3}{|c|}{ Breastfed $\geq 36$ months } \\
\hline First girl* Female & $\begin{array}{l}-0.096 \\
(0.071)\end{array}$ & $\begin{array}{l}-0.083 \\
(0.090)\end{array}$ & $\begin{array}{l}-0.027 \\
(0.084)\end{array}$ & $\begin{array}{c}-0.269^{* * *} \\
(0.090)\end{array}$ & $\begin{array}{c}-0.269^{* * *} \\
(0.079)\end{array}$ & $\begin{array}{c}-0.226^{* *} \\
(0.079)\end{array}$ & $\begin{array}{c}-0.103^{* *} \\
(0.044)\end{array}$ & $\begin{array}{c}-0.083^{* *} \\
(0.038)\end{array}$ & $\begin{array}{l}-0.075 \\
(0.044)\end{array}$ \\
\hline First girl ${ }^{*}$ Female ${ }^{*}$ Post 1 & $\begin{array}{c}0.085 \\
(0.110)\end{array}$ & $\begin{array}{c}0.092 \\
(0.087)\end{array}$ & $\begin{array}{l}-0.0002 \\
(0.080)\end{array}$ & $\begin{array}{c}0.321^{* * *} \\
(0.104)\end{array}$ & $\begin{array}{c}0.275^{* *} \\
(0.114)\end{array}$ & $\begin{array}{c}0.185 \\
(0.120)\end{array}$ & $\begin{array}{c}0.087 \\
(0.069)\end{array}$ & $\begin{array}{c}0.071 \\
(0.065)\end{array}$ & $\begin{array}{c}0.029 \\
(0.076)\end{array}$ \\
\hline First girl* Female ${ }^{*}$ Post2 & $\begin{array}{c}0.096 \\
(0.101)\end{array}$ & $\begin{array}{c}0.047 \\
(0.094)\end{array}$ & $\begin{array}{l}-0.046 \\
(0.099)\end{array}$ & $\begin{array}{c}0.178 \\
(0.190)\end{array}$ & $\begin{array}{c}0.222 \\
(0.161)\end{array}$ & $\begin{array}{c}0.141 \\
(0.143)\end{array}$ & $\begin{array}{c}0.053 \\
(0.082)\end{array}$ & $\begin{array}{c}0.033 \\
(0.073)\end{array}$ & $\begin{array}{c}0.042 \\
(0.068)\end{array}$ \\
\hline $\begin{array}{l}\mathrm{N} \\
\text { Baseline mean }\end{array}$ & & $\begin{array}{c}12,447 \\
0.006\end{array}$ & & & $\begin{array}{c}11,760 \\
0.003\end{array}$ & & & $\begin{array}{c}10,942 \\
0.008\end{array}$ & \\
\hline Female*Post1 \& Female* Post2 & $\mathrm{x}$ & $\mathrm{x}$ & & $\mathrm{x}$ & $\mathrm{x}$ & & $\mathrm{x}$ & $\mathrm{x}$ & \\
\hline 1st Girl*Post1 \& 1st Girl*Post2 & $\mathrm{x}$ & $\mathrm{x}$ & & $\mathrm{x}$ & $\mathrm{x}$ & & $\mathrm{x}$ & $\mathrm{x}$ & \\
\hline$X_{i j t}$ & & $\mathrm{x}$ & $\mathrm{x}$ & & $\mathrm{x}$ & $\mathrm{x}$ & & $\mathrm{x}$ & $\mathrm{x}$ \\
\hline 1st Girl x Birth year FE & & & $\mathrm{x}$ & & & $\mathrm{x}$ & & & $\mathrm{x}$ \\
\hline Female x Birth year FE & & & $\mathrm{x}$ & & & $\mathrm{x}$ & & & $\mathrm{x}$ \\
\hline Female x State FE & & & $\mathrm{x}$ & & & $\mathrm{x}$ & & & $\mathrm{x}$ \\
\hline Female $\mathrm{x}$ Birth order FE & & & $\mathrm{x}$ & & & $\mathrm{x}$ & & & $\mathrm{x}$ \\
\hline Birth order x State FE & & & $\mathrm{x}$ & & & $\mathrm{x}$ & & & $\mathrm{x}$ \\
\hline State-specific time trends & & & $\mathrm{x}$ & & & $\mathrm{x}$ & & & $\mathrm{x}$ \\
\hline Firstborn girl x State FE & & & $\mathrm{x}$ & & & $\mathrm{x}$ & & & $\mathrm{x}$ \\
\hline Firstborn girl $\mathrm{x}$ Birth order FE & & & $\mathrm{x}$ & & & $\mathrm{x}$ & & & $\mathrm{x}$ \\
\hline
\end{tabular}

NOTES: This table reports the coefficients from specification (1) estimated for investments in children using the REDS data. Each column within a panel is from a separate regression. We control for Female, Firstborn girl, and fixed effects for birth year, birth order, and state in all columns. The vector $X_{i j t}$ comprises mother's age at birth, caste, religion, educational attainment of child's parents, and mother's birth cohort. Breastfeeding results are based on the last two surviving births of a mother. Vaccination and health expenditure results are based on all surviving children of a mother. Standard errors in parentheses are clustered by state. Baseline mean refers to the pre-ultrasound difference between the gender gaps in investments in firstborn-girl and firstborn-boy families. ${ }^{* *} 1 \%,{ }^{* *} 5 \%, * 10 \%$. Further investment results using the NFHS data are in Table A.14. 
Table 4: Fertility: Hazard of Birth

\begin{tabular}{lcccc}
\hline & $(1)$ & $(2)$ & $(3)$ & $(4)$ \\
\hline Firstborn girl & $0.173^{* * *}$ & $0.185^{* * *}$ & $0.155^{* * *}$ & $0.168^{* * *}$ \\
& $(0.011)$ & $(0.012)$ & $(0.038)$ & $(0.038)$ \\
Firstborn girl * Post1 & $-0.073^{* * *}$ & $-0.084^{* * *}$ & $-0.092^{* * *}$ & $-0.102^{* * *}$ \\
& $(0.006)$ & $(0.007)$ & $(0.009)$ & $(0.010)$ \\
& & & & \\
Firstborn girl * Post2 & $-0.190^{* * *}$ & $-0.211^{* * *}$ & $-0.220^{* * *}$ & $-0.233^{* * *}$ \\
& $(0.016)$ & $(0.018)$ & $(0.017)$ & $(0.017)$ \\
Ideal sex ratio & & & & $0.076^{* * *}$ \\
& & & & $(0.022)$ \\
Ideal no. of children & & & & $0.161^{* * *}$ \\
& & & & $(0.010)$ \\
\hline N & $2,455,630$ & $2,455,553$ & $2,455,553$ & $2,276,192$ \\
Baseline mean & & & 0.285 & \\
\hline Year FE & $\mathrm{x}$ & $\mathrm{x}$ & $\mathrm{x}$ & $\mathrm{x}$ \\
State FE & $\mathrm{x}$ & $\mathrm{x}$ & $\mathrm{x}$ & $\mathrm{x}$ \\
Age FE & $\mathrm{x}$ & $\mathrm{x}$ & $\mathrm{x}$ & $\mathrm{x}$ \\
Parity FE & $\mathrm{x}$ & $\mathrm{x}$ & $\mathrm{x}$ & $\mathrm{x}$ \\
State x Year FE & $\mathrm{x}$ & $\mathrm{x}$ & $\mathrm{x}$ & $\mathrm{x}$ \\
Years since last birth FE & & $\mathrm{x}$ & $\mathrm{x}$ & $\mathrm{x}$ \\
Firstborn girl x Year FE & & & $\mathrm{x}$ & $\mathrm{x}$ \\
\hline & & & & \\
\hline
\end{tabular}

NOTES: Estimates of specification (2). The dependent variable is an indicator for birth in a given year. Sample includes all mothers who have ever given birth, for each year from their year of marriage to the year of interview. Standard errors in parentheses are clustered by state. Baseline mean is the mean probability of birth in a given year during the pre-ultrasound period. *** $1 \%, * * 5 \%, * 10 \%$. 
Table 5: Fertility: Number of Children

\begin{tabular}{lccc}
\hline & \multicolumn{2}{c}{ Number of births } & Excess Fertility \\
\hline Firstborn girl & $(1)$ & $(2)$ & $(3)$ \\
& $0.155^{* * *}$ & $0.141^{* * *}$ & $0.117^{* * *}$ \\
& $(0.012)$ & $(0.015)$ & $(0.018)$ \\
Firstborn girl * Post1 & $-0.088^{* * *}$ & $-0.079^{* * *}$ & $-0.085^{* * *}$ \\
& $(0.016)$ & $(0.019)$ & $(0.024)$ \\
Firstborn girl * Post2 & $-0.112^{* * *}$ & $-0.100^{* * *}$ & $-0.093^{* * *}$ \\
& $(0.018)$ & $(0.023)$ & $(0.025)$ \\
Ideal no. of children & & $0.315^{* * *}$ & \\
& & $(0.018)$ & \\
Ideal sex ratio & & $0.052^{* * *}$ & $-0.345^{* * *}$ \\
& & $(0.018)$ & $(0.024)$ \\
\hline N & & 88,475 & 88,475 \\
Baseline mean & 3.001 & 3.001 & 0.451 \\
\hline
\end{tabular}

NOTES: Estimates of specification (3). The dependent variable in columns (1)-(2) is the number of births at the time of interview and in column (3) is excess fertility which equals number of births minus ideal number of children. Baseline means are average of the outcome variable in each column for mothers who had both their first and last birth within 1972-1984. Standard errors in parentheses are clustered by state. ${ }^{* * *} 1 \%, * *$ $5 \%, * 10 \%$. 
Table 6: Heterogeneity by socioeconomic status in effects on post-neonatal child mortality

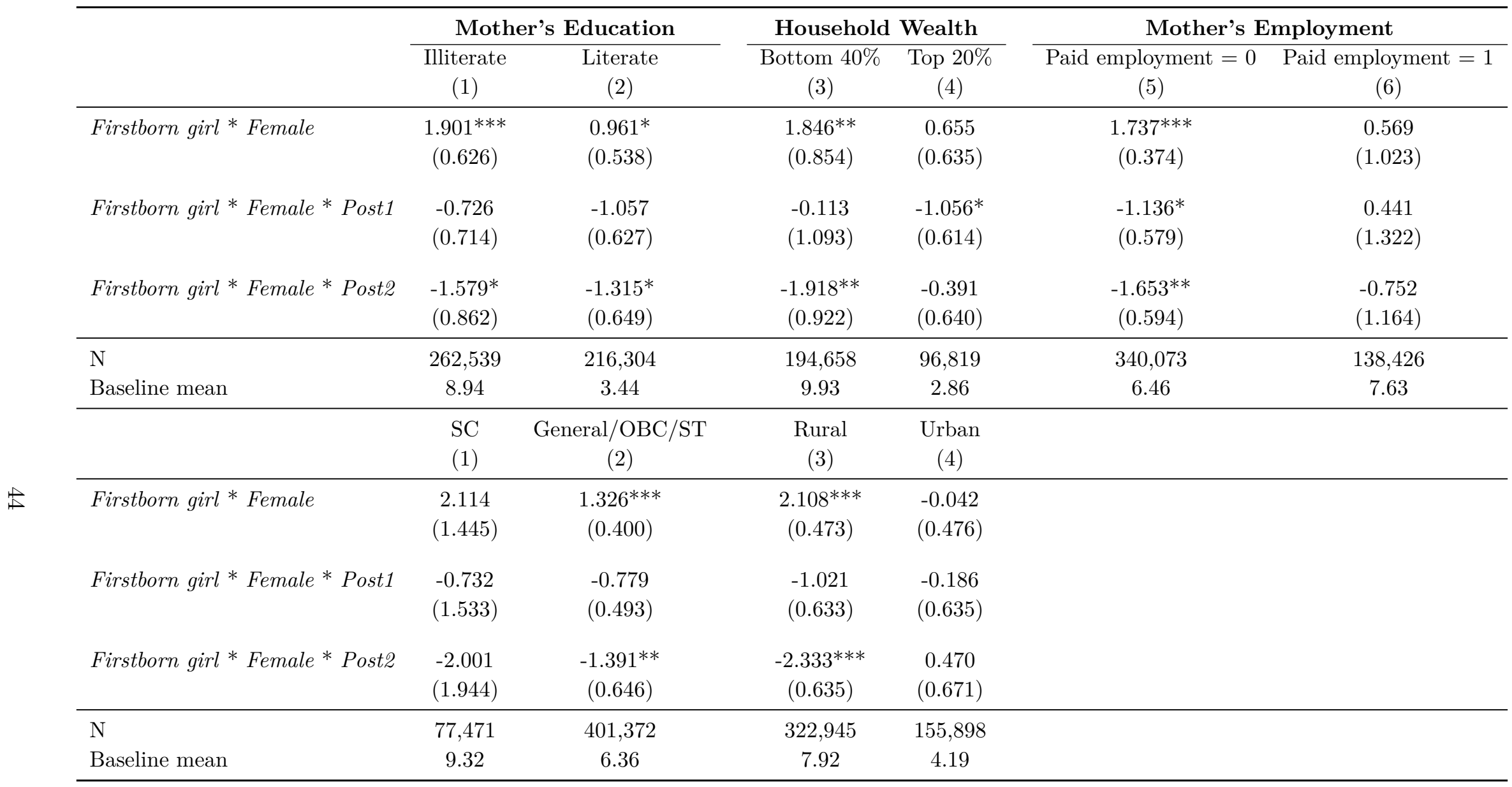

NOTES: Estimates of specification (1) with mother fixed effects for different sub-samples. Each column within a panel is a separate regression. SC, ST, OBC, and General respectively denote scheduled castes, scheduled tribes, other backward classes, and upper castes. The wealth categories are based on the national household wealth distribution. Standard errors in parentheses are clustered by state. Baseline mean refers to post-neonatal child mortality for children born in pre-ultrasound period 1972-1984, by mothers with the specific socioeconomic status. *** $1 \%,{ }^{* *} 5 \%, * 10 \%$. 
Table 7: Heterogeneity by socioeconomic status in effects on the hazard of birth

\begin{tabular}{|c|c|c|c|c|c|c|}
\hline & \multicolumn{2}{|c|}{ Mother's Education } & \multicolumn{2}{|c|}{ Wealth } & \multicolumn{2}{|c|}{ Mother's Employment } \\
\hline & $\begin{array}{l}\text { Illiterate } \\
\text { (1) }\end{array}$ & $\begin{array}{l}\text { Literate } \\
\quad(2)\end{array}$ & $\begin{array}{c}\text { Bottom } 40 \% \\
\text { (3) }\end{array}$ & $\begin{array}{c}\text { Top } 20 \% \\
\quad(4)\end{array}$ & $\begin{array}{c}\text { Paid employment }=0 \\
(5)\end{array}$ & $\begin{array}{c}\text { Paid employment }=1 \\
(6)\end{array}$ \\
\hline Firstborn girl & $\begin{array}{c}0.060^{* *} \\
(0.029)\end{array}$ & $\begin{array}{c}0.324^{* * *} \\
(0.037)\end{array}$ & $\begin{array}{c}0.091^{* *} \\
(0.043)\end{array}$ & $\begin{array}{c}0.388^{* * *} \\
(0.036)\end{array}$ & $\begin{array}{c}0.177 * * * \\
(0.046)\end{array}$ & $\begin{array}{c}0.140^{* * *} \\
(0.033)\end{array}$ \\
\hline Firstborn girl $*$ Post 1 & $\begin{array}{c}-0.059^{* * *} \\
(0.009)\end{array}$ & $\begin{array}{c}-0.133^{* * *} \\
(0.015)\end{array}$ & $\begin{array}{c}-0.093^{* * *} \\
(0.006)\end{array}$ & $\begin{array}{c}-0.114^{* * *} \\
(0.021)\end{array}$ & $\begin{array}{c}-0.114^{* * *} \\
(0.012)\end{array}$ & $\begin{array}{c}-0.062^{* * *} \\
(0.013)\end{array}$ \\
\hline Firstborn girl $*$ Post2 & $\begin{array}{c}-0.127^{* * *} \\
(0.016)\end{array}$ & $\begin{array}{c}-0.312^{* * *} \\
(0.017)\end{array}$ & $\begin{array}{c}-0.172^{* * *} \\
(0.021)\end{array}$ & $\begin{array}{c}-0.317^{* * *} \\
(0.020)\end{array}$ & $\begin{array}{c}-0.253^{* * *} \\
(0.022)\end{array}$ & $\begin{array}{c}-0.174^{* * *} \\
(0.020)\end{array}$ \\
\hline $\mathrm{N}$ & $1,351,731$ & $1,102,413$ & 971,697 & 599,531 & $1,494,545$ & 958,583 \\
\hline Baseline mean & 0.289 & 0.279 & 0.288 & 0.263 & 0.287 & 0.283 \\
\hline & \multicolumn{2}{|r|}{ Caste } & \multicolumn{2}{|c|}{ Rurality } & & \\
\hline & $\begin{array}{l}\mathrm{SC} \\
(1)\end{array}$ & $\begin{array}{c}\text { General/OBC } / \mathrm{ST} \\
(2)\end{array}$ & $\begin{array}{c}\text { Rural } \\
(3)\end{array}$ & $\begin{array}{l}\text { Urban } \\
(4)\end{array}$ & & \\
\hline Firstborn girl & $\begin{array}{c}0.078 \\
(0.048)\end{array}$ & $\begin{array}{c}0.172^{* * *} \\
(0.037)\end{array}$ & $\begin{array}{r}0.092^{* *} \\
(0.040)\end{array}$ & $\begin{array}{c}0.310^{* * *} \\
(0.038)\end{array}$ & & \\
\hline Firstborn girl * Post1 & $\begin{array}{c}-0.040^{* *} \\
(0.020)\end{array}$ & $\begin{array}{c}-0.101^{* * *} \\
(0.009)\end{array}$ & $\begin{array}{c}-0.085^{* * *} \\
(0.010)\end{array}$ & $\begin{array}{c}-0.112^{* * *} \\
(0.017)\end{array}$ & & \\
\hline Firstborn girl * Post2 & $\begin{array}{c}-0.160^{* * *} \\
(0.038)\end{array}$ & $\begin{array}{c}-0.234^{* * *} \\
(0.016)\end{array}$ & $\begin{array}{c}-0.184^{* * *} \\
(0.020)\end{array}$ & $\begin{array}{c}-0.296^{* * *} \\
(0.023)\end{array}$ & & \\
\hline $\mathrm{N}$ & 374,215 & $2,080,707$ & $1,598,030$ & 856,144 & & \\
\hline Baseline mean & 0.295 & 0.284 & 0.289 & 0.278 & & \\
\hline
\end{tabular}

NOTES: Estimates of specification (3). The dependent variable is an indicator for birth in a given year. Sample includes all mothers who have ever given birth, for each year from their year of marriage to the year of interview. Standard errors in parentheses are clustered by state. Baseline mean is the mean probability of birth in a given year during the pre-ultrasound period. ${ }^{* * *} 1 \%,{ }^{* *} 5 \%,{ }^{*} 10 \%$. 


\section{A Additional Figures and Tables}

Figure A.1: Trends in Actual Fraction of Sons
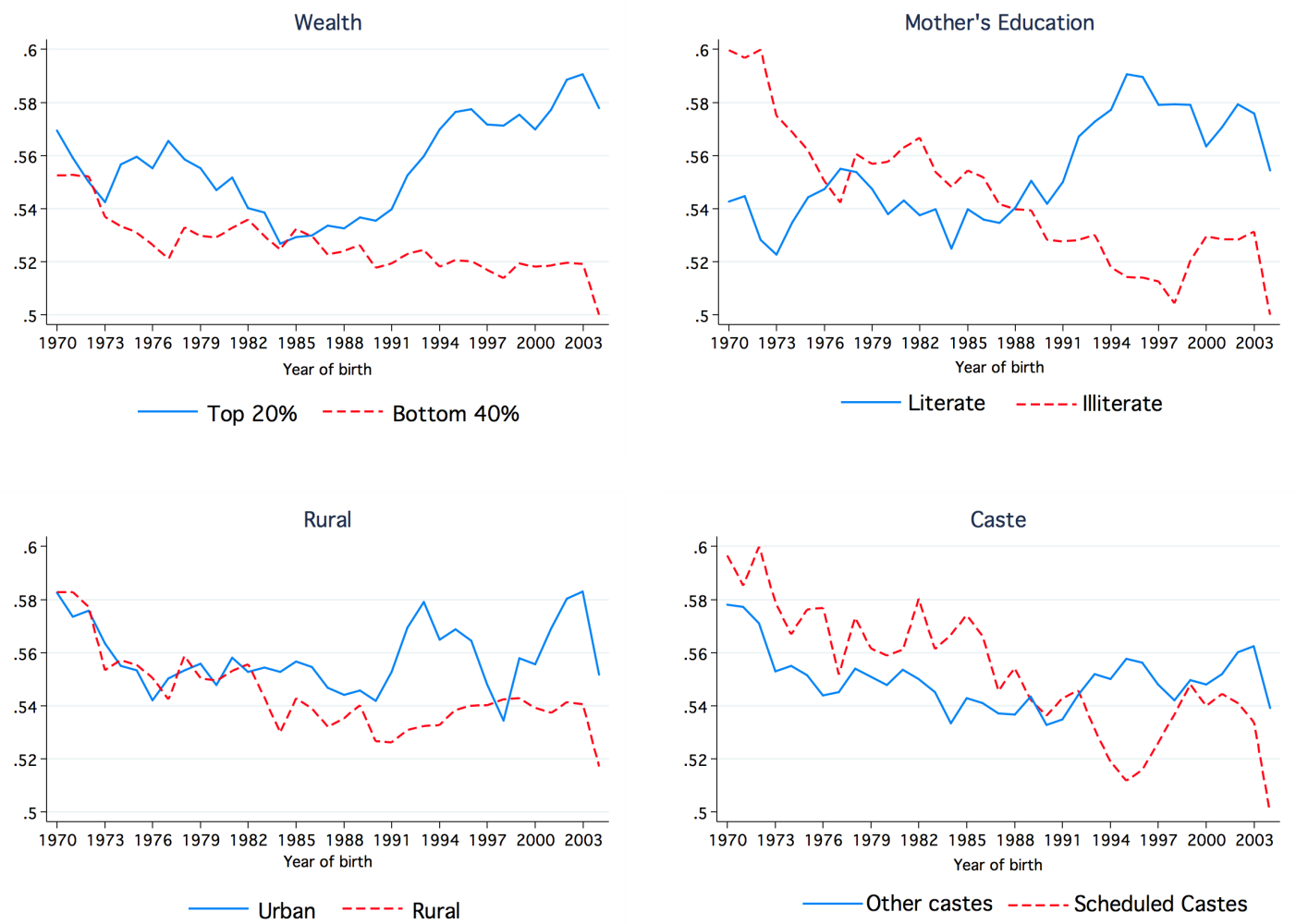

NOTES: The graph plots the trend in the 5-year moving average of actual fraction of male births among all births in a year, separately for various SES groups. 

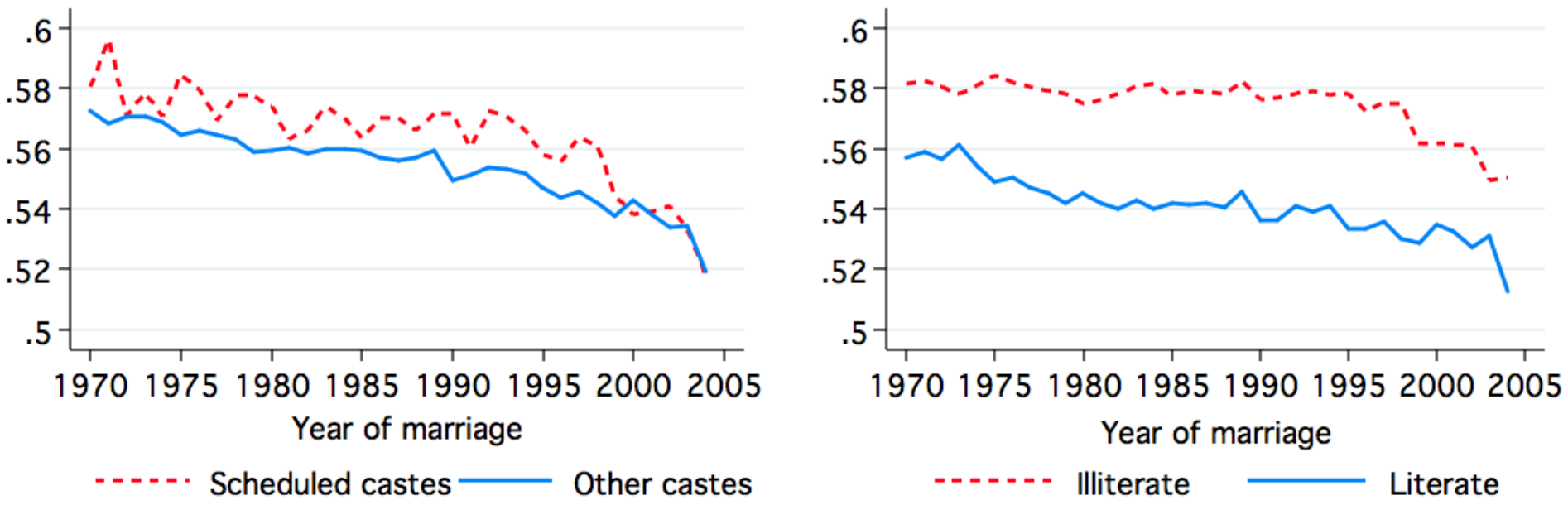

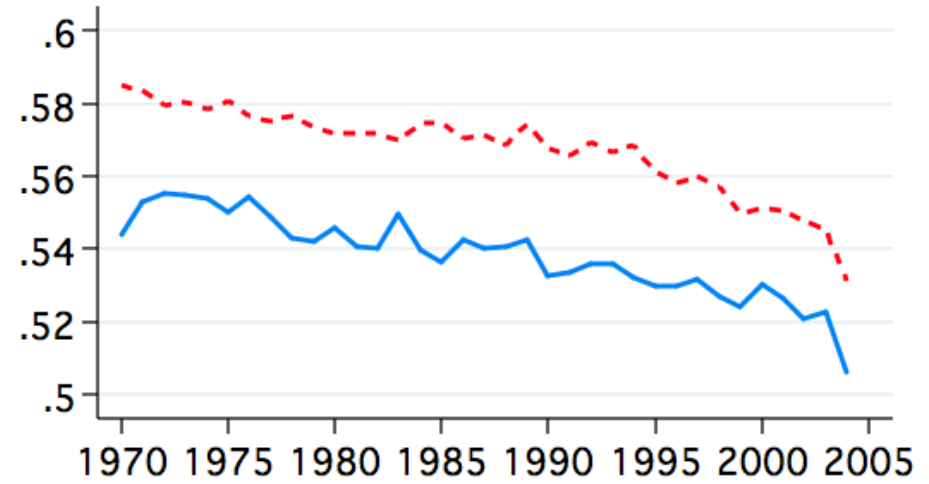

Year of marriaqe

Rural Urban

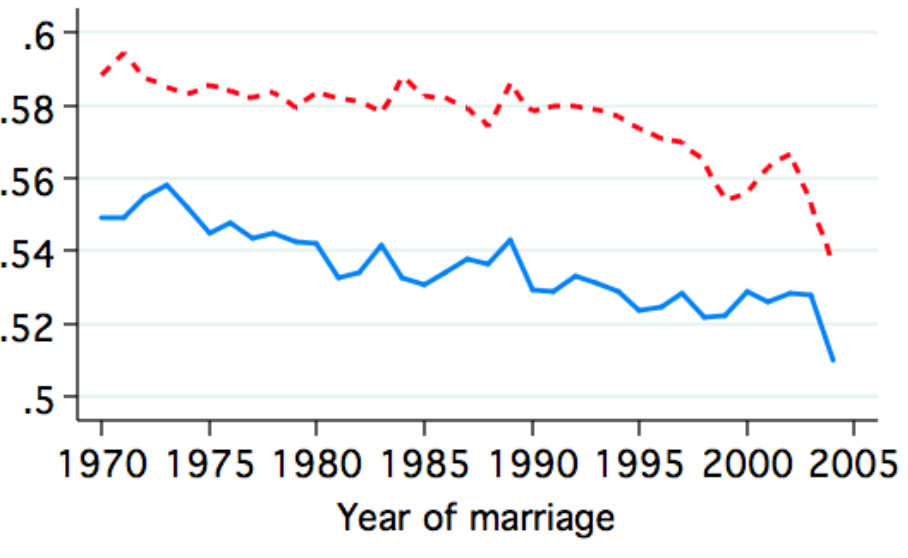

- - Bottom $40 \%$

NOTES: The above graphs plot the trend in the 5-year moving average of the reported ideal fraction of sons by year of first marriage for mothers

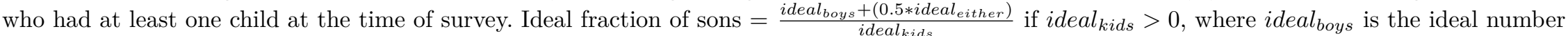
of boys, ideal $_{\text {either }}$ is the ideal number of children of either sex, and $i_{d e a l_{k i d s}}$ is the ideal number of total children, as reported by a woman. 
Figure A.3: Trends in Ideal Number of Children
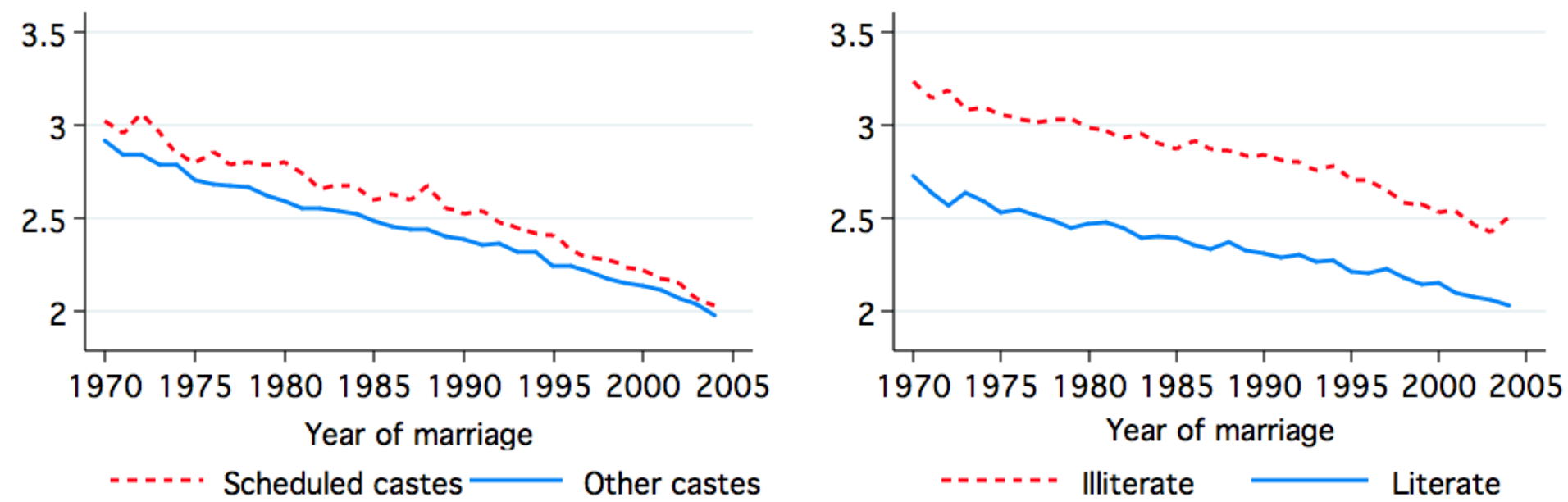

$\infty$

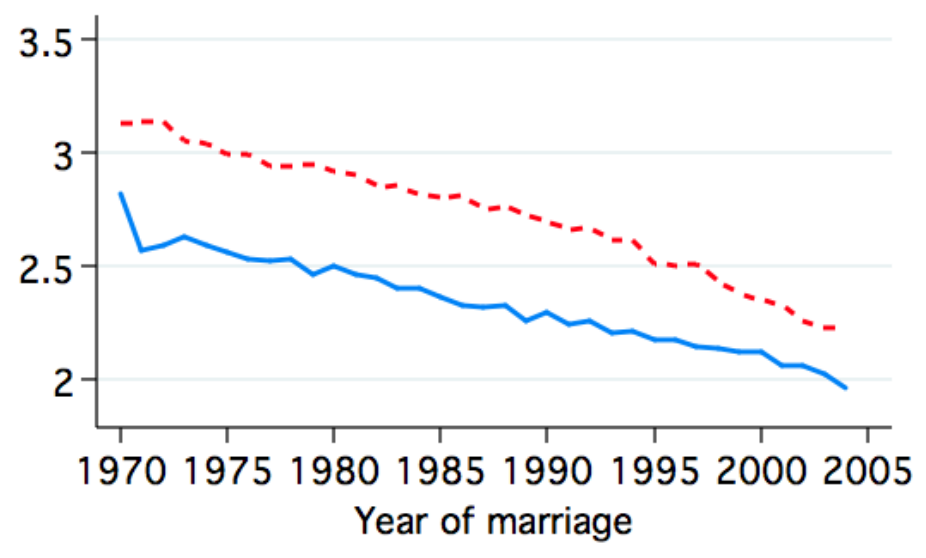

Rural

Urban

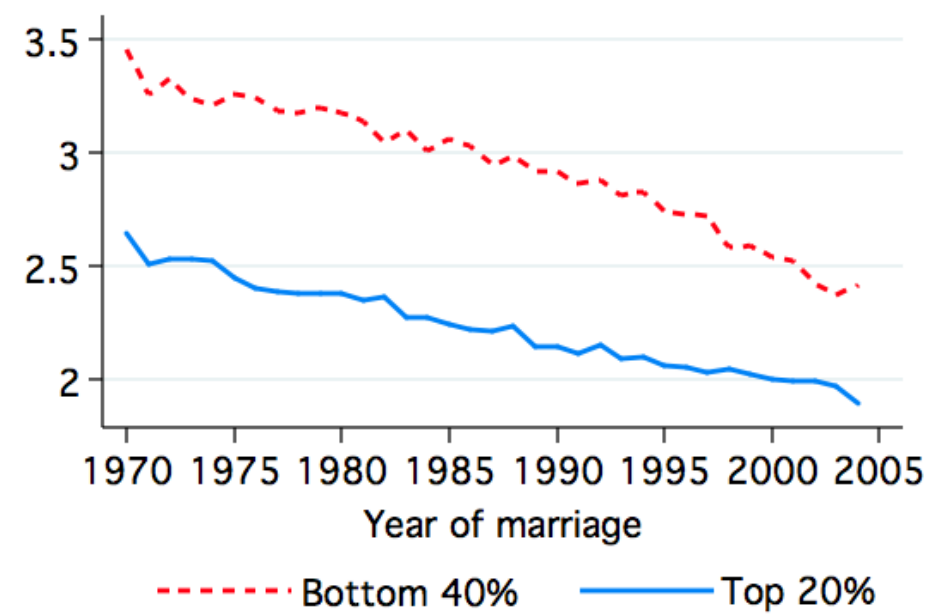

NOTES: The above graphs plot the trend in average reported ideal number of children by the year of first marriage for mothers who had at least one child at the time of survey. 
Table A.1: Sample means: Mortality rates by period

\begin{tabular}{lccc}
\hline & $\begin{array}{c}(1) \\
\text { Male }\end{array}$ & $\begin{array}{c}(2) \\
\text { Female }\end{array}$ & $\begin{array}{c}(3) \\
\text { EFM }\end{array}$ \\
\hline 1. Pre-ultrasound: 1973-1984 & & & \\
\hline Neonatal & 6.686 & 5.395 & -1.291 \\
Post-neonatal Child & 6.040 & 7.539 & 1.499 \\
\hline N & 61,085 & 56,333 & \\
\hline 2. Post-ultrasound: 1985-1994 & & & \\
\hline Neonatal & 5.259 & 4.469 & -0.790 \\
Post-neonatal Child & 4.333 & 5.265 & 0.932 \\
\hline N & 126,126 & 117,218 & \\
\hline 3. Post-ultrasound: 1995-2005 & \multicolumn{3}{c}{} \\
\hline Neonatal & 4.066 & 3.601 & -0.465 \\
Post-neonatal Child & 2.513 & 3.027 & 0.514 \\
\hline N & 74,217 & 68,337 & \\
\hline
\end{tabular}

NOTES: This table reports the percentage of second- and higher-order children, by child's gender, who suffered from neonatal, post-neonatal infant, or post-neonatal child mortality over the three time-periods in our sample. Column (3) reports the difference between the mortality numbers in columns (1) and (2). 
Table A.2: Age distribution of missing girls in 2000

\begin{tabular}{|c|c|c|c|c|c|c|c|c|}
\hline \multirow[b]{2}{*}{ Age group } & \multicolumn{2}{|c|}{ No. missing (in 000s) } & \multirow[b]{2}{*}{$(3)$} & \multicolumn{2}{|c|}{$\%$ of all missing women } & \multirow[b]{2}{*}{$(6)$} & \multicolumn{2}{|c|}{$\%$ of under- 5 missing girls } \\
\hline & $\begin{array}{c}\text { India } \\
(1)\end{array}$ & $\begin{array}{c}\text { China } \\
(2)\end{array}$ & & $\begin{array}{c}\text { India } \\
(4)\end{array}$ & $\begin{array}{c}\text { China } \\
(5)\end{array}$ & & India & China \\
\hline At birth & 184 & 644 & & $11 \%$ & $37 \%$ & & $37 \%$ & $83 \%$ \\
\hline $0-1$ & 146 & 109 & & $9 \%$ & $6 \%$ & & $30 \%$ & $14 \%$ \\
\hline $1-4$ & 164 & 23 & & $10 \%$ & $1 \%$ & & $33 \%$ & $3 \%$ \\
\hline$<5$ & 494 & 776 & & $29 \%$ & $45 \%$ & & & \\
\hline $5-14$ & 93 & 2 & & $5 \%$ & $0 \%$ & & & \\
\hline$\geq 15$ & 1125 & 947 & & $66 \%$ & $55 \%$ & & & \\
\hline Total & 1712 & 1727 & & & & & & \\
\hline
\end{tabular}

NOTES: This table is based on Anderson and Ray (2010) and reports the number of missing girls for various age groups (columns (1) and (2), missing girls as a percentage of all missing women (columns (3) and (4)), and missing girls across age groups as a percentage of all under-5 missing girls (columns (5) and (6)), separately for India and China.

Table A.3: Sample means: Gaps between actual and ideal fertility and fraction of sons

\begin{tabular}{lccc}
\hline & $(1)$ & $(2)$ & $(3)$ \\
& Actual & Ideal & Actual - Ideal \\
\hline 1. Pre-ultrasound: 1973-1984 & & & \\
\hline Fertility & 2.96 & 2.21 & 0.75 \\
Fraction of Sons & 0.58 & 0.57 & 0.01 \\
N & & & \\
\hline 2. Post-ultrasound: $\mathbf{1 9 8 5 - 1 9 9 4}$ & & & \\
\hline Fertility & 2.16 & 2.17 & -0.01 \\
Fraction of Sons & 0.55 & 0.56 & -0.01 \\
N & & & \\
\hline 3. Post-ultrasound: $\mathbf{1 9 9 5 - 2 0 0 5}$ & & & \\
\hline Fertility & 1.91 & 1.93 & -0.03 \\
Fraction of Sons & 0.53 & 0.55 & -0.02 \\
N & & & \\
\hline
\end{tabular}

NOTES: This table reports the percentage of second- and higher-order children, by child's gender, who suffered from neonatal, post-neonatal infant, or post-neonatal child mortality over the three time-periods in our sample. Column (3) reports the difference between the mortality numbers in columns (1) and (2). 
Table A.4: Sample means, all variables

\begin{tabular}{|c|c|c|c|c|c|c|}
\hline & \multicolumn{2}{|c|}{ 1973-1984 } & \multicolumn{2}{|c|}{ 1985-1994 } & \multicolumn{2}{|c|}{$1995-2005$} \\
\hline & $\begin{array}{c}\text { First boy } \\
\text { (1) }\end{array}$ & $\begin{array}{c}\text { First girl } \\
(2)\end{array}$ & $\begin{array}{c}\text { First boy } \\
(3)\end{array}$ & $\begin{array}{c}\text { First girl } \\
\text { (4) }\end{array}$ & $\begin{array}{c}\text { First boy } \\
(5)\end{array}$ & $\begin{array}{c}\text { First girl } \\
(6)\end{array}$ \\
\hline Number of children & 2.91 & 3.12 & 2.13 & 2.22 & 1.85 & 1.96 \\
\hline N (Mothers) & 14,095 & 10,690 & 25,857 & 22,169 & 23,480 & 22,372 \\
\hline N (Births) & 84,258 & 33,160 & 160,278 & 83,066 & 90,700 & 51,854 \\
\hline Female & 0.48 & 0.48 & 0.48 & 0.48 & 0.49 & 0.47 \\
\hline Rural & 0.69 & 0.70 & 0.68 & 0.71 & 0.63 & 0.67 \\
\hline Hindu & 0.77 & 0.77 & 0.75 & 0.75 & 0.71 & 0.71 \\
\hline Muslim & 0.11 & 0.12 & 0.13 & 0.14 & 0.15 & 0.16 \\
\hline $\mathrm{SC}$ & 0.14 & 0.14 & 0.16 & 0.17 & 0.18 & 0.19 \\
\hline ST & 0.12 & 0.13 & 0.14 & 0.14 & 0.16 & 0.16 \\
\hline \multicolumn{7}{|l|}{ Mother birth cohort: } \\
\hline 1942-1960 & 0.60 & 0.73 & 0.11 & 0.19 & 0.01 & 0.01 \\
\hline 1961-1970 & 0.40 & 0.27 & 0.62 & 0.67 & 0.17 & 0.28 \\
\hline 1971-1987 & 0.00 & 0.00 & 0.28 & 0.14 & 0.82 & 0.71 \\
\hline \multicolumn{7}{|l|}{ Mother's age at birth: } \\
\hline $12-15$ & 0.09 & 0.01 & 0.06 & 0.01 & 0.03 & 0.00 \\
\hline $16-18$ & 0.26 & 0.12 & 0.20 & 0.08 & 0.15 & 0.06 \\
\hline $19-24$ & 0.49 & 0.56 & 0.49 & 0.49 & 0.49 & 0.44 \\
\hline $25-30$ & 0.15 & 0.27 & 0.20 & 0.33 & 0.25 & 0.37 \\
\hline $31-49$ & 0.02 & 0.04 & 0.05 & 0.09 & 0.08 & 0.13 \\
\hline \multicolumn{7}{|l|}{ Mother's education: } \\
\hline No education & 0.61 & 0.63 & 0.56 & 0.62 & 0.43 & 0.53 \\
\hline Incomplete secondary & 0.34 & 0.34 & 0.36 & 0.33 & 0.43 & 0.38 \\
\hline Secondary or higher & 0.05 & 0.03 & 0.08 & 0.06 & 0.14 & 0.08 \\
\hline \multicolumn{7}{|l|}{ Father's education: } \\
\hline No education & 0.33 & 0.34 & 0.31 & 0.33 & 0.25 & 0.30 \\
\hline Incomplete secondary & 0.51 & 0.52 & 0.51 & 0.50 & 0.56 & 0.55 \\
\hline Secondary or higher & 0.17 & 0.14 & 0.19 & 0.16 & 0.19 & 0.15 \\
\hline \multicolumn{7}{|l|}{ Household wealth: } \\
\hline 2nd quintile & 0.15 & 0.14 & 0.17 & 0.17 & 0.18 & 0.21 \\
\hline 3rd quintile & 0.18 & 0.19 & 0.17 & 0.18 & 0.18 & 0.19 \\
\hline 4th quintile & 0.21 & 0.22 & 0.21 & 0.21 & 0.21 & 0.20 \\
\hline Richest quintile & 0.22 & 0.21 & 0.20 & 0.17 & 0.21 & 0.16 \\
\hline Child can read and write & 0.80 & 0.79 & 0.81 & 0.79 & 0.73 & 0.71 \\
\hline Child still in school & 0.52 & 0.62 & 0.77 & 0.79 & 0.70 & 0.69 \\
\hline $\mathrm{N}$ & 51,484 & 20,531 & 67,794 & 32,749 & 26,379 & 14,475 \\
\hline Full immunization & & & 0.39 & 0.35 & 0.51 & 0.45 \\
\hline $\mathrm{N}$ & & & 19,154 & 11,398 & 31,127 & 18,130 \\
\hline Number of months breastfed & & & 13.04 & 13.34 & 13.64 & 14.10 \\
\hline $\mathrm{N}$ & & & 19,871 & 12,057 & 32,324 & 19,228 \\
\hline Number of antenatal checks & & & 2.62 & 2.11 & 3.75 & 3.07 \\
\hline $\mathrm{N}$ & & & 23,571 & 13,865 & 34,197 & 20,892 \\
\hline
\end{tabular}

NOTES: SC and ST denote Scheduled Castes and Scheduled Tribes. Number of children refers to fertility at the time of survey. Data are NFHS, three rounds. 
Table A.5: Sample means, postnatal health investments

\begin{tabular}{|c|c|c|c|c|c|c|}
\hline \multirow[b]{2}{*}{ Variable } & \multicolumn{2}{|c|}{ 1973-1984 } & \multicolumn{2}{|c|}{ 1985-1994 } & \multicolumn{2}{|c|}{ 1995-1999 } \\
\hline & First boy & First girl & First boy & First girl & First boy & First girl \\
\hline Female & 0.44 & 0.47 & 0.46 & 0.47 & 0.47 & 0.45 \\
\hline $\mathrm{SC}$ & 0.13 & 0.14 & 0.14 & 0.16 & 0.15 & 0.16 \\
\hline $\mathrm{ST}$ & 0.07 & 0.06 & 0.08 & 0.07 & 0.09 & 0.08 \\
\hline $\mathrm{OBC}$ & 0.35 & 0.39 & 0.35 & 0.34 & 0.35 & 0.34 \\
\hline Hindu & 0.88 & 0.90 & 0.87 & 0.91 & 0.89 & 0.90 \\
\hline Muslim & 0.08 & 0.06 & 0.09 & 0.06 & 0.07 & 0.07 \\
\hline Sikh & 0.03 & 0.03 & 0.03 & 0.02 & 0.03 & 0.02 \\
\hline Christian & 0.01 & 0.00 & 0.01 & 0.00 & 0.01 & 0.01 \\
\hline Mother's age at birth & 24.12 & 26.31 & 23.62 & 26.03 & 23.72 & 26.21 \\
\hline Mother is literate & 1.52 & 1.49 & 1.47 & 1.47 & 1.36 & 1.43 \\
\hline Father's years of education & 5.23 & 5.54 & 5.83 & 5.71 & 6.93 & 6.15 \\
\hline At least one vaccine & 0.73 & 0.70 & 0.88 & 0.89 & 0.93 & 0.94 \\
\hline N (Births) & 5,788 & 1,962 & 6,440 & 2,744 & 2,960 & 1,268 \\
\hline Breastfed & 0.99 & 0.99 & 0.99 & 0.99 & 0.77 & 0.79 \\
\hline No. of months breastfed & 18.88 & 19.07 & 18.34 & 18.32 & 12.66 & 13.39 \\
\hline N (Births) & 2,674 & 1,021 & 3,969 & 1,846 & 2,765 & 1,209 \\
\hline Breastfed at least 12 months & 0.90 & 0.90 & 0.88 & 0.89 & 0.71 & 0.75 \\
\hline $\mathrm{N}$ (Births) & 2,674 & 1,021 & 3,969 & 1,846 & 2,332 & 976 \\
\hline Breastfed at least 24 months & 0.40 & 0.40 & 0.36 & 0.35 & 0.26 & 0.29 \\
\hline $\mathrm{N}$ (Births) & 2,674 & 1,021 & 3,969 & 1,846 & 1,820 & 780 \\
\hline Breastfed at least 36 months & 0.07 & 0.08 & 0.07 & 0.05 & 0.03 & 0.05 \\
\hline N (Births) & 2,674 & 1,021 & 3,969 & 1,846 & 1,217 & 527 \\
\hline Expense on illness (last year) & 160.78 & 227.01 & 168.16 & 152.01 & 216.64 & 184.66 \\
\hline N (Births) & 192 & 643 & 6,253 & 2,665 & 2,877 & 1,240 \\
\hline
\end{tabular}

NOTES: Sample from 1999 REDS data. SC, ST, and OBC denote Scheduled Castes, Scheduled Tribes, and Other Backward Classes. The sample is restricted to children who were alive at the time of survey. Breastfeeding information is available only for a woman's last two children who were alive at the time of survey. Sample is restricted to children at least 12, 24, and 36 months old while calculating the proportion of children who were breastfed for 12, 24, and 36 months, respectively. Expenditure on illness is in Rupees. 
Table A.6: Further Results: Different age-exposures for childhood mortality

\begin{tabular}{lcccc}
\hline & $\begin{array}{c}\text { Neonatal } \\
(1)\end{array}$ & $\begin{array}{c}\text { Infant } \\
(2)\end{array}$ & $\begin{array}{c}\text { Post-neo Child } \\
(3)\end{array}$ & $\begin{array}{c}\text { Child } \\
(4)\end{array}$ \\
\hline Firstborn girl * Female & $1.350^{* * *}$ & $2.067^{* * *}$ & $1.758^{* * *}$ & $2.893^{* * *}$ \\
& $(0.382)$ & $(0.479)$ & $(0.313)$ & $(0.481)$ \\
Firstborn girl * Female * Post1 & -0.681 & $-0.984^{*}$ & $-0.954^{* *}$ & $-1.490^{* *}$ \\
& $(0.422)$ & $(0.536)$ & $(0.404)$ & $(0.550)$ \\
Firstborn girl * Female * Post2 & $-0.895^{* *}$ & $-1.175^{* * *}$ & $-1.355^{* * *}$ & $-2.059^{* * *}$ \\
& $(0.357)$ & $(0.408)$ & $(0.362)$ & $(0.468)$ \\
\hline $\mathrm{N}$ & 503,316 & 503,316 & 478,843 & 503,316 \\
\hline
\end{tabular}

NOTES: Estimates of specification (1) for different measures of mortality. The explanatory variables are the same as those in Column (3) of Table 2. Standard errors in parentheses are clustered by state. *** $1 \%$, ** $5 \%, * 10 \%$.

Table A.7: Heterogeneity in effects on post-neonatal child mortality by birth order

\begin{tabular}{lcccccc}
\hline Birth order & $\begin{array}{c}\text { 2nd } \\
(1)\end{array}$ & $\begin{array}{c}\text { 3rd } \\
(2)\end{array}$ & $\begin{array}{c}4 \text { th } \\
(3)\end{array}$ & $\begin{array}{c}5 \text { th } \\
(4)\end{array}$ & $\begin{array}{c}6 \text { th } \\
(5)\end{array}$ & $\begin{array}{c}7 \text { th } \\
(6)\end{array}$ \\
\hline Firstborn girl * Female & $\begin{array}{c}2.198^{* * *} \\
(0.551)\end{array}$ & $\begin{array}{c}1.578^{* *} \\
(0.741)\end{array}$ & $\begin{array}{c}1.384 \\
(1.068)\end{array}$ & $\begin{array}{c}1.104 \\
(2.213)\end{array}$ & $\begin{array}{c}0.843 \\
(3.206)\end{array}$ & $\begin{array}{c}7.630 \\
(10.26)\end{array}$ \\
& & & & & & \\
Firstborn girl * Female * Post1 & $-2.242^{* * *}$ & -0.251 & -0.141 & 2.004 & -0.903 & -7.292 \\
& $(0.788)$ & $(0.782)$ & $(1.218)$ & $(2.617)$ & $(3.395)$ & $(11.94)$ \\
Firstborn girl * Female * Post2 & $-1.585^{* *}$ & -1.458 & -0.393 & -0.927 & -0.912 & -10.69 \\
& $(0.651)$ & $(0.994)$ & $(1.301)$ & $(2.759)$ & $(3.327)$ & $(10.35)$ \\
\hline N & 133,635 & 86,551 & 48,491 & 25,363 & 12,408 & 5,648 \\
Baseline mean & 6.97 & 7.10 & 7.97 & 9.43 & 9.15 & 13.00 \\
\hline
\end{tabular}

NOTES: Estimates corresponding to the specification in column (3) of Table 2 estimated separately for various birth orders. Each column is a separate regression. The outcome measureS mortality as $\%$ of births that do not survive. Standard errors in parentheses are clustered by state. ${ }^{* *} 1 \%,{ }^{* *} 5 \%,{ }^{*} 10 \%$. 
Table A.8: Post-neonatal child mortality: Estimates for first births

\begin{tabular}{lc}
\hline Dependent Variable: Post-neonatal child mortality \\
\hline Female & -0.404 \\
& $(0.855)$ \\
Female * Post1 & 0.0264 \\
& $(0.615)$ \\
Female * Post2 & -0.204 \\
& $(0.731)$ \\
\hline $\mathrm{N}$ & 158,194 \\
\hline
\end{tabular}

NOTES: This table reports the coefficients from a specification similar to (1). The sample is restricted to first births. Post 1 and Post 2 indicate that the second birth took place during early and later diffusion period, respectively. Standard errors in parentheses are clustered by state. ${ }^{* * *} 1 \%,{ }^{* *} 5 \%,{ }^{*} 10 \%$. 
Table A.9: Placebo test: Ideal household structure and gender gaps in school enrollment

\begin{tabular}{|c|c|c|c|c|}
\hline & $\begin{array}{c}\text { Neonatal } \\
(1)\end{array}$ & $\begin{array}{c}\text { Post-neo Child } \\
(2)\end{array}$ & $\begin{array}{c}\text { Neonatal } \\
(3)\end{array}$ & $\begin{array}{c}\text { Post-neo Child } \\
\text { (4) }\end{array}$ \\
\hline Firstborn girl $*$ Female & $\begin{array}{l}1.051^{*} \\
(0.560)\end{array}$ & $\begin{array}{c}0.521 \\
(0.926)\end{array}$ & $\begin{array}{l}1.261^{* *} \\
(0.455)\end{array}$ & $\begin{array}{c}1.926^{* * *} \\
(0.366)\end{array}$ \\
\hline Firstborn girl ${ }^{*}$ Female ${ }^{*}$ Post 1 & $\begin{array}{l}-0.193 \\
(0.397)\end{array}$ & $\begin{array}{l}-0.685 \\
(0.518)\end{array}$ & $\begin{array}{l}-0.516 \\
(0.521)\end{array}$ & $\begin{array}{l}-0.945^{*} \\
(0.493)\end{array}$ \\
\hline Firstborn girl $*$ Female $*$ Post2 & $\begin{array}{l}-0.474 \\
(0.336)\end{array}$ & $\begin{array}{c}-1.192^{* * *} \\
(0.426)\end{array}$ & $\begin{array}{l}-0.656 \\
(0.394)\end{array}$ & $\begin{array}{c}-1.643^{* * *} \\
(0.544)\end{array}$ \\
\hline Ideal number of children ${ }^{*}$ Female & $\begin{array}{c}-0.465^{* * *} \\
(0.095)\end{array}$ & $\begin{array}{c}-0.525^{* * *} \\
(0.151)\end{array}$ & & \\
\hline Ideal Sex Ratio * Female & $\begin{array}{c}1.222^{* * *} \\
(0.112)\end{array}$ & $\begin{array}{c}1.382^{* * *} \\
(0.267)\end{array}$ & & \\
\hline Ideal number of children ${ }^{*}$ Female ${ }^{*}$ Firstborn girl & $\begin{array}{c}0.084 \\
(0.186)\end{array}$ & $\begin{array}{c}0.410^{* *} \\
(0.190)\end{array}$ & & \\
\hline Ideal Sex Ratio ${ }^{*}$ Female $^{*}$ Firstborn girl & $\begin{array}{c}0.043 \\
(0.268)\end{array}$ & $\begin{array}{c}0.009 \\
(0.396)\end{array}$ & & \\
\hline Girl-boy enrollment rate $6-11 *$ Female & & & $\begin{array}{c}0.163^{* * *} \\
(0.0520)\end{array}$ & $\begin{array}{c}0.460^{* * * *} \\
(0.0734)\end{array}$ \\
\hline Girl-boy enrollment rate $14-17 *$ Female & & & $\begin{array}{c}3.285^{* * *} \\
(0.912)\end{array}$ & $\begin{array}{c}0.225 \\
(0.710)\end{array}$ \\
\hline $\mathrm{N}$ & 400,035 & 380,605 & 364,989 & 345,078 \\
\hline
\end{tabular}

NOTES: Estimates of specification (1) with additional controls for son preference. Standard errors in parentheses are clustered by state. ${ }^{* * *} 1 \%,{ }^{* *}$ $5 \%, * 10 \%$. 
Table A.10: Mother's fertility preference and son preference

\begin{tabular}{lcc}
\hline & $\begin{array}{c}\text { Ideal No. of Children } \\
(1)\end{array}$ & $\begin{array}{c}\text { Ideal Fraction of Sons } \\
(2)\end{array}$ \\
\hline Firstborn girl ${ }^{*}$ Female & -0.026 & $0.011^{* * *}$ \\
& $(0.017)$ & $(0.003)$ \\
Firstborn girl ${ }^{*}$ Female ${ }^{*}$ Post1 & 0.013 & -0.002 \\
& $(0.017)$ & $(0.002)$ \\
Firstborn girl ${ }^{*}$ Female ${ }^{*}$ Post2 & $0.028^{*}$ & 0.001 \\
\hline $\mathrm{N}$ & $(0.015)$ & $(0.003)$ \\
\hline
\end{tabular}

NOTES: Estimates of specification (1) with dependent variables changed to stated preferences. Ideal fraction of sons $=\frac{\text { ideal }_{\text {boys }}+\left(0.5 * \text { ideal }_{\text {either }}\right)}{\text { ideal }_{\text {kids }}}$ if ideal $_{\text {kids }}>0$, where ideal $_{\text {boys }}$ is the ideal number of boys, ideal $_{\text {either }}$ is the ideal number of children of either sex, and ideal $_{\text {kids }}$ is the ideal number of total children, as reported by a woman. Standard errors in parentheses are clustered by state. ${ }^{* * *} 1 \%,{ }^{* *} 5 \%,{ }^{*} 10 \%$.

Table A.11: Using variation in self-reported ultrasound use

\begin{tabular}{lccc}
\hline & $\begin{array}{c}\text { Neonatal } \\
(1)\end{array}$ & $\begin{array}{c}\text { Post-neonatal Infant } \\
(2)\end{array}$ & $\begin{array}{c}\text { Post-neo natal Child } \\
(3)\end{array}$ \\
\hline Female $^{*}$ Firstborn girl & $0.930^{* *}$ & $0.734^{* *}$ & $0.760^{*}$ \\
& $(0.335)$ & $(0.282)$ & $(0.376)$ \\
Female $^{*}$ Firstborn girl * Ultra $_{\text {st }}$ & -1.302 & -1.219 & -1.006 \\
& $(0.864)$ & $(0.855)$ & $(1.031)$ \\
\hline $\mathrm{N}$ & 113,170 & 108,837 & 108,837 \\
\hline
\end{tabular}

NOTES: Estimates of a specification similar to (1) for childhood mortality rates, except that Post $t_{t}^{1}$ and Post $_{t}^{2}$ have been replaced with Ultra $_{s t}$. So, rather than use the timing of imports and production of ultrasound scanners, we use self-reported use of ultrasound scans in the NFHS data. Each column is from a separate regression. The sample is restricted to years after $1995 .{ }^{* * *} 1 \%,{ }^{* *} 5 \%, * 10 \%$. 
Table A.12: Placebo test: Fake treatment years in the pre-ultrasound era

\begin{tabular}{lcccccc}
\hline \multicolumn{7}{c}{ Dependent variable: Post-neonatal Child Mortality } \\
\hline Treatment Year & $\begin{array}{c}1977 \\
(1)\end{array}$ & $\begin{array}{c}1978 \\
(2)\end{array}$ & $\begin{array}{c}1979 \\
(3)\end{array}$ & $\begin{array}{c}1980 \\
(4)\end{array}$ & $\begin{array}{c}1981 \\
(5)\end{array}$ & $\begin{array}{c}1982 \\
(6)\end{array}$ \\
\hline Firstborn girl * Female & $2.070^{* *}$ & $2.004^{* *}$ & $2.125^{* * *}$ & $2.334^{* * *}$ & $2.460^{* * *}$ & $2.087^{* * *}$ \\
& $(0.954)$ & $(0.836)$ & $(0.559)$ & $(0.504)$ & $(0.490)$ & $(0.405)$ \\
Firstborn girl * Female * Post & 0.016 & 0.094 & -0.053 & -0.357 & -0.642 & -0.007 \\
& $(0.967)$ & $(0.898)$ & $(0.659)$ & $(0.521)$ & $(0.587)$ & $(0.438)$ \\
\hline $\mathrm{N}$ & & \multicolumn{7}{c}{110,295} \\
\hline
\end{tabular}

NOTES: This table presents coefficients from a specification similar to (1), except that a single Post indicator is used. The treatment year used to define Post varies across columns. Each column represents a different regression. The sample is restricted to the 1973-1984 period (i.e., pre-Ultrasound period). Standard errors in parentheses are clustered by state. ${ }^{* * *} 1 \%,{ }^{* *} 5 \%,{ }^{*} 10 \%$.

Table A.13: Testing whether first births were subject to sex selective abortion

\begin{tabular}{lccc}
\hline & $\begin{array}{c}\text { Neonatal } \\
(1)\end{array}$ & $\begin{array}{c}\text { Post-neo Infant } \\
(2)\end{array}$ & $\begin{array}{c}\text { Post-neo Child } \\
(3)\end{array}$ \\
\hline Firstborn girl * Female & $\begin{array}{c}1.182^{* * *} \\
(0.381)\end{array}$ & $\begin{array}{c}0.730^{* *} \\
(0.301)\end{array}$ & $\begin{array}{c}1.790^{* * *} \\
(0.400)\end{array}$ \\
& & & -0.485 \\
Firstborn girl * Female * Post1 & $-0.969^{*}$ & 0.0238 & $(0.517)$ \\
& $(0.550)$ & $(0.350)$ & $-2.139^{*}$ \\
Firstborn girl * Female * Post2 & -1.270 & -1.338 & $(1.124)$ \\
\hline $\mathrm{N}$ & $(1.550)$ & $(0.942)$ & 185,894 \\
\hline
\end{tabular}

NOTES: This table reports the coefficients from specification (1) for the sample of women whose first child was born before 1985. The explanatory variables are the same as those in Column (3) of Table 2. Standard errors in parentheses are clustered by state. ${ }^{* * *} 1 \%,{ }^{* *} 5 \%, * 10 \%$. 
Table A.14: Parental health investments: Prenatal and postnatal

\begin{tabular}{lcccc}
\hline & $\begin{array}{c}\text { \# Antenatal Checks } \\
(1)\end{array}$ & $\begin{array}{c}\text { At least 1 vaccination } \\
(2)\end{array}$ & $\begin{array}{c}\text { Full immunization } \\
(3)\end{array}$ & $\begin{array}{c}\text { \# Months breastfed } \\
(4)\end{array}$ \\
\hline Firsborn girl ${ }^{*}$ Female & -0.041 & $-0.029^{* *}$ & $-0.032^{* * *}$ & $(0.011)$ \\
& $(0.056)$ & $(0.012)$ & $0.422^{* *}$ & $(0.155)$ \\
Firsborn girl * Female * Post2 & 0.002 & $0.025^{* *}$ & $(0.017$ & 0.129 \\
& $(0.060)$ & $(0.012)$ & 79,809 & $(0.258)$ \\
\hline $\mathrm{N}$ & 92,525 & 79,809 & 83,480 \\
\hline
\end{tabular}

NOTES: NFHS data. Investments are only queried for cohorts born in a few years before each survey so there are no pre-ultrasound cohorts. The comparison here is therefore across the two post-ultrasound periods. The estimates are from the following specification for child $i$ of birth order $b$ born to mother $j$ in year $t: I_{i b j t}=\alpha+\beta G_{j} * F_{i} * P_{o s t}^{2}+\gamma G_{j} * F_{i}+\omega_{t} G_{j}+\sigma_{t} F_{i}+\psi_{b} F_{i}+X_{i j t}^{\prime} \tau+\delta_{s} F_{i}+\rho_{b t}+\eta_{b s}+\phi_{s t}+\epsilon_{i b j t}$. Among children who were at least 12 months old at the time of survey, we define a child to be fully immunized if he or she had received the eight most common vaccines by that time. Standard errors in parentheses are clustered by state. *** $1 \%, * * 5 \%, * 10 \%$.

Table A.15: Parental investments: Estimates for first births

\begin{tabular}{lccccc}
\hline & $\begin{array}{c}\text { Allopathic treatment } \\
(1)\end{array}$ & $\begin{array}{c}\text { Exp on education } \\
(2)\end{array}$ & $\begin{array}{c}\text { Doctors' fees } \\
(4)\end{array}$ & $\begin{array}{c}\text { Medicine and special food } \\
(5)\end{array}$ & $\begin{array}{c}\text { Medical exp } \\
(3)\end{array}$ \\
\hline Female & $-0.122^{* *}$ & $-562.307^{*}$ & $-18.251^{* *}$ & $-50.795^{*}$ & $-69.045^{*}$ \\
& $(0.043)$ & $(319.263)$ & $(8.138)$ & $(26.306)$ & $(32.630)$ \\
Female * Post 1 & $0.140^{* * *}$ & 317.710 & $24.433^{* *}$ & $62.443^{* *}$ & $86.876^{* *}$ \\
& $(0.037)$ & $(329.164)$ & $(9.610)$ & $(26.887)$ & $(33.986)$ \\
Female * Post2 & $0.187^{* * *}$ & $615.970^{*}$ & 16.469 & $57.778^{* *}$ & $74.248^{*}$ \\
& $(0.057)$ & $(333.976)$ & $(10.737)$ & $(27.141)$ & $(35.897)$ \\
\hline $\mathrm{N}$ & 3,018 & 3,541 & 3,541 & 3,541 & 3,541 \\
\hline
\end{tabular}

NOTES: This table reports the coefficients from a specification similar to (1). The sample is restricted to first births. Post 1 and Post2 indicate that the second birth took place during early and later diffusion period, respectively. Standard errors in parentheses are clustered by state. The dependent variables are defined in Appendix A. *** 1\%,** 5\%, * $10 \%$. 
Table A.16: Fertility: Investigating the margin of response by number of children

\begin{tabular}{lcccc}
\hline & \multicolumn{4}{c}{ Number of children } \\
& $(1)$ & $(2)$ & $(3)$ & $(4)$ \\
\hline Firstborn girl & $0.012^{* *}$ & $-0.067^{* * *}$ & $-0.015^{*}$ & $0.069^{* * *}$ \\
& $(0.005)$ & $(0.006)$ & $(0.007)$ & $(0.006)$ \\
& & & & \\
Firstborn girl * post1 & -0.010 & $0.021^{* *}$ & $0.030^{* * *}$ & $-0.042^{* * *}$ \\
& $(0.007)$ & $(0.008)$ & $(0.009)$ & $(0.007)$ \\
Firstborn girl * post2 & $-0.017^{* *}$ & $0.040^{* * *}$ & $0.035^{* * *}$ & $-0.058^{* * *}$ \\
& $(0.007)$ & $(0.009)$ & $(0.010)$ & $(0.009)$ \\
\hline N & 118663 & 118663 & 118663 & 118663 \\
Baseline mean & 0.114 & 0.271 & 0.300 & 0.315 \\
\hline
\end{tabular}

NOTES: This table presents estimates from specification (3) using indicators for the mother having, respectively, 1, 2, 3, and $\geq 4$ children at the time of survey in columns (1)-(4). Standard errors in parentheses are clustered by state. ${ }^{* * *} 1 \%, * * 5 \%, * 10 \%$. 
Table A.17: Heterogeneity by socioeconomic status in effects on fertility, cross-sectional approach

\begin{tabular}{|c|c|c|c|c|c|c|}
\hline & \multicolumn{2}{|c|}{ Mother's Education } & \multicolumn{2}{|c|}{ Wealth } & \multicolumn{2}{|c|}{ Mother's Employment } \\
\hline & $\begin{array}{l}\text { Illiterate } \\
\quad(1)\end{array}$ & $\begin{array}{l}\text { Literate } \\
\qquad(2)\end{array}$ & $\begin{array}{c}\text { Bottom } 40 \% \\
(3)\end{array}$ & $\begin{array}{c}\text { Top } 20 \% \\
\quad(4)\end{array}$ & $\begin{array}{c}\text { Paid employment }=0 \\
(5)\end{array}$ & $\begin{array}{c}\text { Paid employment }=1 \\
(6)\end{array}$ \\
\hline Firstborn girl & $\begin{array}{c}0.113^{* * *} \\
(0.020)\end{array}$ & $\begin{array}{c}0.198^{* * *} \\
(0.018)\end{array}$ & $\begin{array}{c}0.126^{* * *} \\
(0.031)\end{array}$ & $\begin{array}{c}0.183^{* * *} \\
(0.019)\end{array}$ & $\begin{array}{c}0.172^{* * *} \\
(0.014)\end{array}$ & $\begin{array}{c}0.142^{* * *} \\
(0.021)\end{array}$ \\
\hline Firstborn girl * Post 1 & $\begin{array}{r}-0.063^{*} \\
(0.031)\end{array}$ & $\begin{array}{c}-0.110^{* * *} \\
(0.023)\end{array}$ & $\begin{array}{l}-0.060 \\
(0.042)\end{array}$ & $\begin{array}{c}-0.099 * * * \\
(0.029)\end{array}$ & $\begin{array}{c}-0.114^{* * *} \\
(0.018)\end{array}$ & $\begin{array}{l}-0.054^{*} \\
(0.030)\end{array}$ \\
\hline Firstborn girl $*$ Post2 & $\begin{array}{c}-0.059^{* *} \\
(0.028)\end{array}$ & $\begin{array}{c}-0.148^{* * *} \\
(0.024)\end{array}$ & $\begin{array}{l}-0.069^{*} \\
(0.036)\end{array}$ & $\begin{array}{c}-0.121^{* * *} \\
(0.027)\end{array}$ & $\begin{array}{c}-0.132^{* * *} \\
(0.021)\end{array}$ & $\begin{array}{c}-0.088^{* * *} \\
(0.029)\end{array}$ \\
\hline $\begin{array}{l}\mathrm{N} \\
\text { Baseline mean }\end{array}$ & $\begin{array}{c}46,597 \\
3.230\end{array}$ & $\begin{array}{c}72,066 \\
2.812\end{array}$ & $\begin{array}{c}36,831 \\
3.101\end{array}$ & $\begin{array}{c}36,352 \\
2.769\end{array}$ & $\begin{array}{c}78,717 \\
3.026\end{array}$ & $\begin{array}{c}39,840 \\
2.964\end{array}$ \\
\hline \multirow{2}{*}{ Baseline mean } & \multicolumn{2}{|r|}{ Caste } & \multicolumn{2}{|c|}{ Rurality } & & \\
\hline & $\begin{array}{l}\mathrm{SC} \\
(1)\end{array}$ & $\begin{array}{c}\text { General } / \mathrm{OBC} / \mathrm{ST} \\
(2)\end{array}$ & $\begin{array}{c}\text { Rural } \\
(3)\end{array}$ & $\begin{array}{l}\text { Urban } \\
(4)\end{array}$ & & \\
\hline Firstborn girl & $\begin{array}{c}0.146^{* * *} \\
(0.039)\end{array}$ & $\begin{array}{c}0.154^{* * * *} \\
(0.012)\end{array}$ & $\begin{array}{c}0.134^{* * *} \\
(0.017)\end{array}$ & $\begin{array}{c}0.190^{* * *} \\
(0.015)\end{array}$ & & \\
\hline Firstborn girl * Post1 & $\begin{array}{l}-0.014 \\
(0.056)\end{array}$ & $\begin{array}{c}-0.098^{* * *} \\
(0.016)\end{array}$ & $\begin{array}{c}-0.095^{* * *} \\
(0.023)\end{array}$ & $\begin{array}{c}-0.079 * * * \\
(0.023)\end{array}$ & & \\
\hline Firstborn girl * Post2 & $\begin{array}{c}-0.032 \\
(0.041)\end{array}$ & $\begin{array}{c}-0.124^{* * *} \\
(0.018)\end{array}$ & $\begin{array}{c}-0.108^{* * *} \\
(0.026)\end{array}$ & $\begin{array}{c}-0.122^{* * *} \\
(0.018)\end{array}$ & & \\
\hline $\mathrm{N}$ & 17,043 & 101,620 & 71,155 & 47,508 & & \\
\hline Baseline mean & 3.243 & 2.966 & 3.109 & 2.850 & & \\
\hline
\end{tabular}

NOTES: Estimates of specification (3). The dependent variable is the number of births at the time of interview. Standard errors in parentheses are clustered by state. Baseline mean refers to the mean fertility of mother at time of interview, with the specific socioeconomic status who had their first and last birth in the pre-ultrasound period $1972-1984$. *** $1 \%, * * 5 \%, * 10 \%$. 
Table A.18: Impacts of ultrasound availability on the sex ratio at birth

\begin{tabular}{lc}
\hline Dependent Variable: Child is female \\
\hline Firstborn girl & -0.002 \\
& $(0.004)$ \\
Firstborn girl * Post1 & $-0.008^{*}$ \\
& $(0.005)$ \\
Firstborn girl * Post2 & $-0.018^{* * *}$ \\
& $(0.006)$ \\
\hline $\mathrm{N}$ & 503,316 \\
\hline
\end{tabular}

NOTES: This table reports the coefficients from the following specification: $G_{i b j t}=\alpha+\beta_{1} F_{i}+\beta_{2} F_{i} * P_{o s t}^{1}+$ $\beta_{3} F_{i} *$ Post $_{t}^{2}+X_{i j t}^{\prime} \tau+\Pi^{\prime} \gamma+\epsilon_{i b j t}$, where $G_{i b j t}$ indicates that child $i$ of birth order $b$ born to mother $j$ in year $t$ is female; $F_{i}$ indicates that the firstborn is a girl; $X_{i}^{\prime} \tau$ is a vector of household characteristics and $\Pi^{\prime} \gamma$ is a vector of fixed effects that are analogous to equation (1), except that all interactions with $F_{i}$ are omitted. Standard errors in parentheses are clustered by state. ${ }^{* * *} 1 \%, * * 5 \%, * 10 \%$. 